ISSN 2770-5900 (Online)

Volume 2 | Issue 1 | February 2022

en Energy Materials
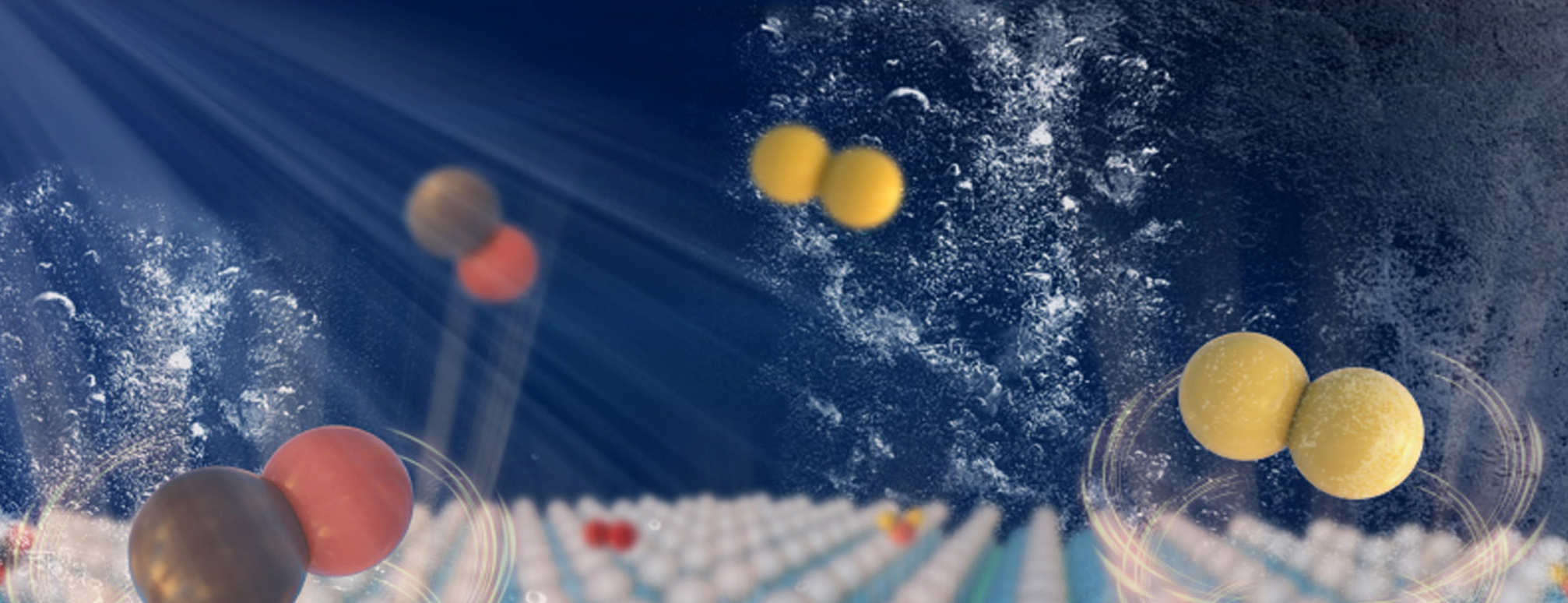

Q.

As

d)

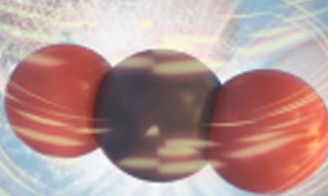

कर्ष
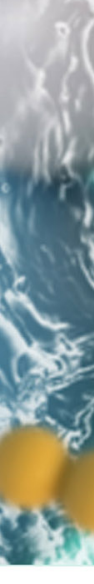

(

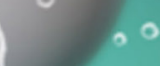

12

Non

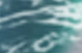

28

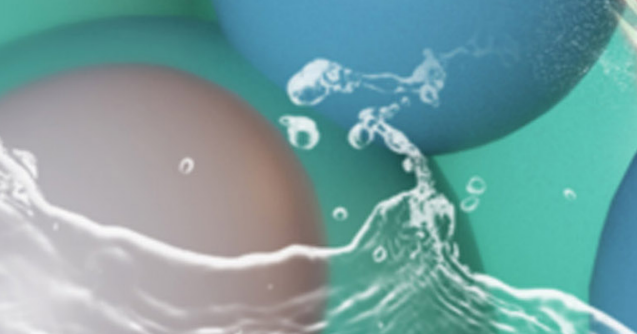

Open Access 


\title{
Recent advances in photocatalytic renewable energy production
}

\author{
Xiaolang Chen\#, Jingjing Zhao", Guisheng Li, Dieqing Zhang*, Hexing Li* \\ The Education Ministry Key Lab of Resource Chemistry, Shanghai Key Laboratory of Rare Earth Functional Materials, Shanghai \\ Frontiers Science Center of Biomimetic Catalysis, College of Chemistry and Materials Science, Shanghai Normal University, \\ Shanghai, 200234, China. \\ \#Authors contributed equally.

\begin{abstract}
*Correspondence to: Prof. Dieqing Zhang, the Education Ministry Key Lab of Resource Chemistry, Shanghai Key Laboratory of Rare Earth Functional Materials, Shanghai Frontiers Science Center of Biomimetic Catalysis, College of Chemistry and Materials Science, Shanghai Normal University, No. 100, Guilin Road, Xuhui District, Shanghai, 200234, China.

E-mail: happy2002zdq@126.com; Prof. Hexing Li, the Education Ministry Key Lab of Resource Chemistry, Shanghai Key Laboratory of Rare Earth Functional Materials, Shanghai Frontiers Science Center of Biomimetic Catalysis, College of Chemistry and Materials Science, Shanghai Normal University, No. 100, Guilin Road, Xuhui District, Shanghai, 200234, China.

E-mail: hexing-li@shnu.edu.cn
\end{abstract}

How to cite this article: Chen X, Zhao J, Li G, Zhang D, Li H. Recent advances in photocatalytic renewable energy production. Energy Mater 2022;2:200001. https://dx.doi.org/10.20517/energymater.2021.24

Received: 26 Nov 2021 First Decision: 29 Dec 2021 Revised: 11 Jan 2022 Accepted: 19 Jan 2022 Published: 29 Jan 2022

Academic Editors: Yuping Wu, Yuhui Chen Copy Editor: Xi-Jun Chen Production Editor: Xi-Jun Chen

\begin{abstract}
The development of green and renewable energy is becoming increasingly more important in reducing environmental pollution and controlling $\mathrm{CO}_{2}$ discharge. Photocatalysis can be utilized to directly convert solar energy into chemical energy to achieve both the conversion and storage of solar energy. On this basis, photocatalysis is considered to be a prospective technology to resolve the current issues of energy supply and environmental pollution. Recently, several significant achievements in semiconductor-based photocatalytic renewable energy production have been reported. This review presents the recent advances in photocatalytic renewable energy production over the last three years by summarizing the typical and significant semiconductorbased and semiconductor-like photocatalysts for $\mathrm{H}_{2}$ production, $\mathrm{CO}_{2}$ conversion and $\mathrm{H}_{2} \mathrm{O}_{2}$ production. These reactions demonstrate how the basic principles of photocatalysis can be exploited for renewable energy production. Finally, we conclude our review of photocatalytic renewable energy production and provide an outlook for future related research.
\end{abstract}


Keywords: Photocatalysis, solar energy conversion, renewable energy, semiconductors

\section{INTRODUCTION}

The overconsumption of fossil fuels has depleted traditional energy resources and contributed to environmental pollution in water, soil and air environment ${ }^{[1]}$. It is highly expected that renewable and green energy can be exploited to resolve the energy crisis and environmental pollution. Solar energy is an extremely attractive natural energy source. The amount of solar energy that hits the Earth's surface each year $\left(1.3 \times 10^{5} \mathrm{TW}\right)$ is much greater than that consumed by humans $\left(1.6 \times 10^{1} \mathrm{TW} \text { in } 2010\right)^{[2,3]}$. The conversion of solar energy to chemical energy via chemical reactions is a prospective method of producing renewable energy. Inspired by the natural photosynthesis of green plants and some other microorganisms, which convert solar energy to chemical energy in the form of carbohydrates or hydrogen, artificial photosynthesis (photocatalysis) is considered a prospective technology for the conversion of solar energy to chemical energy ${ }^{[4-6]}$. Since Fujishima and Honda discovered water photolysis on $\mathrm{TiO}_{2}$ electrodes in 1972 , photocatalysis has received tremendous attention and developed rapidly in recent decades due to its promising applications in renewable energy production ${ }^{[7,8]}$.

The basic principles of semiconductor-based photocatalysis are presented in Figure $1^{[9]}$. In general, a complete photocatalytic process on a semiconductor involves three steps. The first step is light absorption, where photons are absorbed by the semiconductor photocatalyst. If the energy $(h v)$ of the photons is larger than the bandgap energy of the semiconductor, the electrons (e) are excited and transmitted to the conduction band (CB) from the valence band (VB), leaving holes $\left(\mathrm{h}^{+}\right)$in the VB. Pairs of negatively charged electrons and positively charged holes ( $\mathrm{e}^{-} \mathrm{h}^{+}$pairs) are generated in this step. The second step is charge separation and transfer. The photogenerated $\mathrm{e}^{-}-\mathrm{h}^{+}$pairs are separated and transferred to the surface of the semiconductor, while some photogenerated $\mathrm{e}^{-}$and $\mathrm{h}^{+}$recombine in the bulk of the photocatalyst (volume recombination). The final step is surface reduction and oxidation reactions. The photogenerated charges on the surface of the semiconductor react with chemical species ${ }^{[9,10]}$. Meanwhile, some photogenerated $\mathrm{e}^{-}$and $\mathrm{h}^{+}$ recombine without taking part in any chemical reaction (surface recombination).

Realizing the efficient conversion of solar energy to chemical energy for the production of renewable energy relies on semiconductor photocatalysts ${ }^{[11]}$. One of the major issues associated with semiconductor photocatalysts is the insufficient rate of light utilization. The positions of the band edge (CB and VB) in a semiconductor should meet the required potentials of redox reactions. However, this means that light with a lower energy than the absorption onset [visible or even near-infrared (NIR) light] cannot be used. In addition, semiconductor photocatalysts suffer from the inefficient separation of photogenerated charge carriers, resulting in poor photoactivity and quantum efficiency ${ }^{[11]}$. There are two effective strategies for overcoming these issues. The first is the development of semiconductor photocatalysts with excellent light absorption ability to improve the light utilization rate. The second is the construction of a scheme or system (including cocatalysts) to effectively facilitate the separation of photogenerated $\mathrm{e}^{-}-\mathrm{h}^{+}$pairs. Current state-ofthe-art semiconductor-based nanocomposite systems (e.g., materials with element doping/single atom modification, the construction of heterostructures and the development of cocatalysts) offer intense and wide absorption of light from across the solar spectrum, as well as highly efficient charge separation. These achievements have contributed greatly to the field of renewable energy production.

Herein, we introduce the advances in photocatalytic renewable energy production made in the last three years. We demonstrate how the basic principles of photocatalysis are used in certain reactions for renewable energy production, such as photocatalytic $\mathrm{H}_{2}$ production, $\mathrm{CO}_{2}$ conversion and $\mathrm{H}_{2} \mathrm{O}_{2}$ production, and 


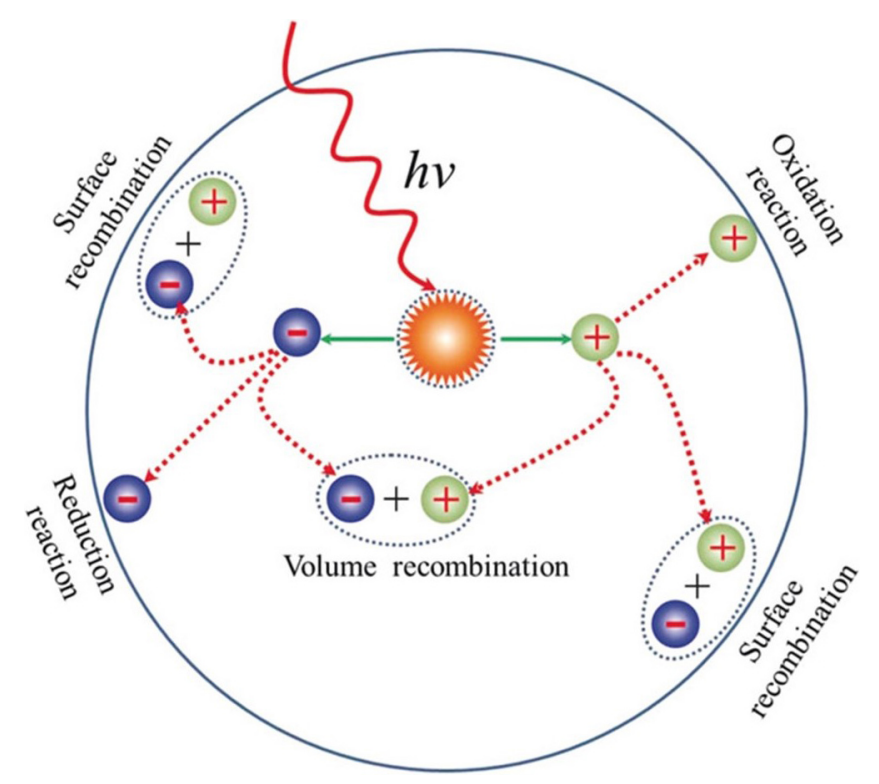

Figure 1. Basic principles of semiconductor-driven photocatalysis. Reproduced from Ref. ${ }^{[9]}$ with permission from Wiley.

introduce some of the typical heterogeneous photocatalysts used in these reactions, such as inorganic semiconductors and organic semiconductor-like materials (e.g., metal- and covalent-organic frameworks). Finally, we conclude with the progression made in photocatalytic renewable energy production and provide an outlook for future related research.

\section{PHOTOCATALYTIC RENEWABLE ENERGY PRODUCTION}

\section{Photocatalytic $\mathrm{H}_{2}$ production}

Basic principles of photocatalytic $\mathrm{H}_{2}$ production

$\mathrm{H}_{2}$ is a promising clean energy source that does not produce secondary pollution ${ }^{[12]}$. After light harvesting and the separation and transfer of the photogenerated $\mathrm{e}^{-} \mathrm{h}^{+}$pairs in the aforementioned principle of photocatalysis, the photogenerated $\mathrm{e}^{-}$in the $\mathrm{CB}$ reduce adsorbed $\mathrm{H}^{+}$to $\mathrm{H}_{2}$ [Figure 2] and the photogenerated $\mathrm{h}^{+}$in the $\mathrm{VB}$ oxidize a sacrificial agent (S), such as alcohols (e.g., $\mathrm{CH}_{3} \mathrm{OH}, \mathrm{CH}_{3} \mathrm{CH}_{2} \mathrm{OH}$ and $\mathrm{CH}_{3} \mathrm{CH}_{2} \mathrm{CH}_{2} \mathrm{OH}$ ), triethanolamine (TEOA) or triethylamine (TEA) into an oxidative product $\left(\mathrm{S}^{+}\right)$or water into oxygen $\left(\mathrm{O}_{2}\right)^{[13-15]}$. Nonetheless, the energy level of $\mathrm{CB}$ for the $\mathrm{H}_{2}$ evolution reaction should be lower than $0 \mathrm{~V}$ vs. the normal hydrogen electrode (NHE) at $\mathrm{pH}$ 7. Additionally, the energy level of the $\mathrm{VB}$ for the $\mathrm{H}_{2} \mathrm{O}$ oxidation reaction should be higher than $1.23 \mathrm{~V}$ vs. NHE, as the following redox reactions show:

Reduction reaction:

$2 \mathrm{H}^{+}+2 \mathrm{e}^{-} \rightarrow \mathrm{H}_{2} E=0.00 \mathrm{eV}(1)$

Oxidation reaction:

Sacrificial agent $(\mathrm{S})+\mathrm{h}^{+} \rightarrow \mathrm{S}^{+} E>1.23 \mathrm{eV}(2)$

or

$\mathrm{H}_{2} \mathrm{O}+2 \mathrm{~h}^{+} \rightarrow 1 / 2 \mathrm{O}_{2}+2 \mathrm{H}^{+} E=1.23 \mathrm{eV}(3)$

Overall water splitting:

$2 \mathrm{H}_{2} \mathrm{O} \rightarrow \mathrm{O}_{2}+2 \mathrm{H}_{2} E=-1.23 \mathrm{eV}(4)$ 


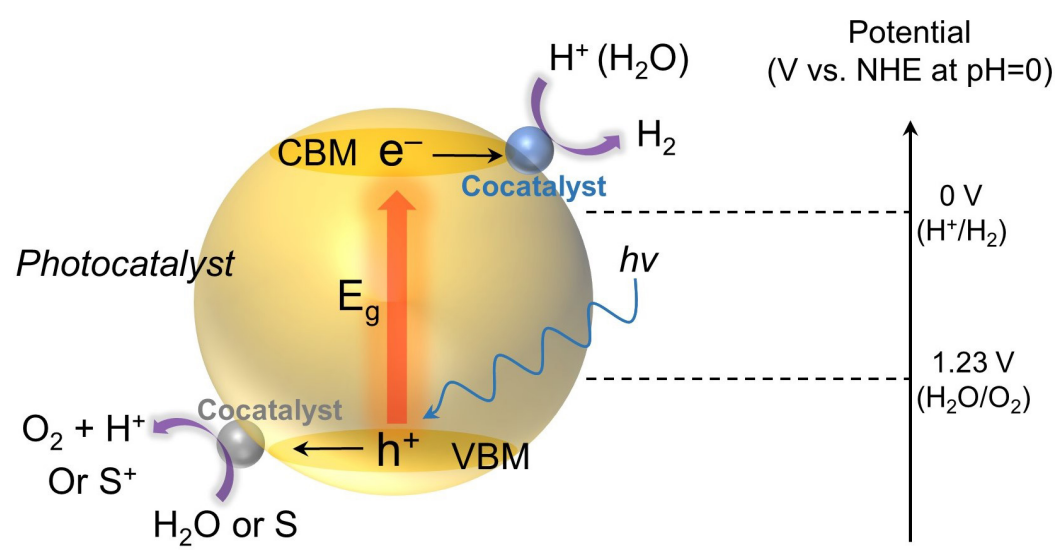

Figure 2. Schematic energy diagram of photocatalytic $\mathrm{H}_{2}$ production from water-splitting on a semiconductor photocatalyst. CBM: Conduction band minimum; VBM: valence band maximum; $E_{g}$ : bandgap energy.

Recent advances in photocatalytic $\mathrm{H}_{2}$ production

$\mathrm{H}_{2}$ production from water with sacrificial agents

I. Metal oxide-based photocatalysts

Metal oxides have the advantages of low cost, good structural stability and low toxicity. In addition, they are easy to prepare and can be modified via various strategies, which can impart them with improved performances. Moreover, the proper band positions confer metal oxides with good redox capability in the photocatalytic $\mathrm{H}_{2}$ production reaction ${ }^{[16]}$.

Titanium dioxide $\left(\mathrm{TiO}_{2}\right)$ is the most frequently investigated semiconductor material for photocatalytic $\mathrm{H}_{2}$ production. Hejazi et al ${ }^{[17]}$ described an atomic-scale defect engineering method to form and control traps for Pt single atom (SA) sites upon thin sputtered $\mathrm{TiO}_{2}$ layers for photocatalytic $\mathrm{H}_{2}$ production. The density of defect centers can be precisely regulated, resulting in the controlled density of Pt SA sites on $\mathrm{TiO}_{2}$. These decorated Pt SA sites improved the photoactivity of $\mathrm{TiO}_{2}$ by 150 times compared to that on conventional $\mathrm{Pt}$ nanoparticle-modified $\mathrm{TiO}_{2}$. Cho et al. ${ }^{[18]}$ reported that a pre-reduced $\mathrm{TiO}_{2}$ support, which can reverse the interaction with $\mathrm{Pt}$ nanoparticles and reinforce the metallic state of $\mathrm{Pt}$, resulting in a three-fold increase in $\mathrm{H}_{2}$ production rate compared to that on traditional $\mathrm{Pt} / \mathrm{TiO}_{2}$. $\mathrm{Pt} / \mathrm{TiO}_{2} / \mathrm{H}_{2} \mathrm{O}$ triple junctions are the active catalytic sites for $\mathrm{H}_{2}$ production in the presence of $\mathrm{CH}_{3} \mathrm{OH}$. Méndez-Medrano et al. ${ }^{[19]}$ constructed a heterojunction between small $\mathrm{CuO}$ nanoclusters and $\mathrm{TiO}_{2}(\mathrm{P} 25)$, which induces a photocatalytic activity of $\mathrm{H}_{2}$ production by using $\mathrm{CH}_{3} \mathrm{OH}$ as a sacrificial agent under visible-light irradiation because of the narrow bandgap $(1.7 \mathrm{eV})$ of $\mathrm{CuO}$. The photogenerated $\mathrm{e}^{-}$was injected from $\mathrm{CuO}$ nanoclusters to the $\mathrm{CB}$ of $\mathrm{TiO}_{2}$ (P25), resulting in high photoactivity. Osuagwu et al. ${ }^{[20]}$ presented anatase $\mathrm{TiO}_{2}$ nanosheet (NS) layers grown on a $\mathrm{Ta}_{2} \mathrm{O}_{5}$ substrate and this $\mathrm{TiO}_{2} \mathrm{NSs} / \mathrm{Ta}_{2} \mathrm{O}_{5}$ displayed a 170 -fold increase in photocatalytic $\mathrm{H}_{2}$ production rate compared to that on $\mathrm{TiO}_{2}$ NSs on a fluorine-doped tin oxide (FTO) substrate with $\mathrm{CH}_{3} \mathrm{OH}$ as a sacrificial agent. Such drastically enhanced photoactivity can be ascribed to the blocking effect of $\mathrm{Ta}_{2} \mathrm{O}_{5}$ for the photogenerated $\mathrm{e}^{-}$in $\mathrm{TiO}_{2} \mathrm{NSs}$.

Sun et al. ${ }^{[21]}$ synthesized a dodecahedral N-doped C-coated CuO- $\operatorname{In}_{2} \mathrm{O}_{3}$ p-n heterojunction photocatalyst, which showed a photocatalytic $\mathrm{H}_{2}$ production rate of $600 \mu \mathrm{mol} \cdot \mathrm{g}^{-1} \cdot \mathrm{h}^{-1}$ and good long-term stability of $50 \mathrm{~h}$ in a TEOA aqueous solution. Such a photocatalytic $\mathrm{H}_{2}$ production rate can be attributed to the efficient separation of photogenerated $\mathrm{e}^{-}-\mathrm{h}^{+}$pairs and the mediated adsorption behavior $\left(\left|\Delta \mathrm{G}_{\mathrm{H}^{+}}\right| \rightarrow 0\right)$ by coupling the $\mathrm{N}$-doped $\mathrm{C}$ layer with the $\mathrm{CuO}-\mathrm{In}_{2} \mathrm{O}_{3} \mathrm{p}$-n heterojunction. The improved stability may originate from the mitigation of electron deficiency in $\mathrm{CuO}$ by the formation of the $\mathrm{p}-\mathrm{n}$ heterojunction and protection with the 
$\mathrm{N}$-doped C layer. In 2021, Han et al. ${ }^{[22]}$ proposed a rhombohedral corundum/cubic $\operatorname{In}_{2} \mathrm{O}_{3}\left(\mathrm{rh} / \mathrm{c}-\mathrm{In}_{2} \mathrm{O}_{3}\right)$ phase-junction photocatalyst, which could effectively promote the separation and transfer of photogenerated charges between rh- $\operatorname{In}_{2} \mathrm{O}_{3}$ and $c-\operatorname{In}_{2} \mathrm{O}_{3}$ with a Z-scheme mechanism. This $\operatorname{In}_{2} \mathrm{O}_{3}$ phasejunction photocatalyst showed a $\mathrm{H}_{2}$ production rate of $2244 \mu \mathrm{mol} \cdot \mathrm{g}^{-1} \cdot \mathrm{h}^{-1}$ in a TEOA aqueous solution. A relevant apparent quantum efficiency (AQE) of $35 \%$ was achieved at $400 \mathrm{~nm}$, which is $\sim 12$ times that on bare c- $\operatorname{In}_{2} \mathrm{O}_{3}$.

II. Sulfide-based photocatalysts

Sulfides, such as molybdenum disulfide $\left(\mathrm{MoS}_{2}\right)$, zinc sulfide $(\mathrm{ZnS})$, cadmium sulfide (CdS) and tungsten sulfide $\left(\mathrm{WS}_{2}\right)$, have been developed for photocatalytic $\mathrm{H}_{2}$ production.

In 2018, Guo et al. ${ }^{[23]}$ reported a $\mathrm{MoS}_{2} @ \mathrm{TiO}_{2}$ catalyst for photocatalytic $\mathrm{H}_{2}$ production. The catalyst realized a $\mathrm{H}_{2}$ production rate of $580 \mathrm{mmol} \cdot \mathrm{g}_{\mathrm{Mos}} \square^{-1} \cdot \mathrm{h}^{-1}$ under simulated solar light irradiation, while methanol was used as a sacrificial hole scavenger. The heterostructure between plasmonic $\mathrm{MoS}_{2}$ and $\mathrm{TiO}_{2}$ regulated the charge transfer pathways, which were responsible for light harvesting and photocatalytic $\mathrm{H}_{2}$ production. Wang et al. ${ }^{[2]}$ embedded edge-enriched ultrathin $\mathrm{MoS}_{2}$ flake cocatalysts into a yolk-shell $\mathrm{TiO}_{2}$ bulk to boost photogenerated e transfer from the bulk to the $\mathrm{TiO}_{2}$ surface. The as-prepared $\mathrm{MoS}_{2} / \mathrm{TiO}_{2}$ hybrid showed a $\mathrm{H}_{2}$ production rate of $2443 \mu \mathrm{mol} \cdot \mathrm{g}^{-1} \cdot \mathrm{h}^{-1}$, which is $\sim 10$ - and $\sim 4.7$-fold greater than that of pure $\mathrm{TiO}_{2}$ $\left(247 \mu \mathrm{mol} \cdot \mathrm{g}^{-1} \cdot \mathrm{h}^{-1}\right)$ and bulk $\mathrm{MoS}_{2}$-modified $\mathrm{TiO}_{2}\left(513 \mu \mathrm{mol} \cdot \mathrm{g}^{-1} \cdot \mathrm{h}^{-1}\right)$, respectively. This improved activity was ascribed to the exposed catalytic edges of the ultra-thin $\mathrm{MoS}_{2}$ cocatalysts with strong Ti-S bonds, offering a fast charge-transfer pathway between $\mathrm{TiO}_{2}$ and $\mathrm{MoS}_{2}$. Furthermore, $\mathrm{WS}_{2}-\mathrm{MoS}_{2}$ in-plane few-layer heterostructures that function as efficient photocatalysts have been developed recently ${ }^{[25]}$. The built-in potential at the epitaxially-grown $\mathrm{WS}_{2}-\mathrm{MoS}_{2}$ interface facilitated fast separation of the photogenerated $\mathrm{e}^{-}-\mathrm{h}^{+}$ pairs, resulting in a $\mathrm{H}_{2}$ production rate of $9.83 \mathrm{mmol} \cdot \mathrm{g}^{-1} \cdot \mathrm{h}^{-1}$.

Xiao et al ${ }^{[26]}$ fabricated a copper nanowire $(\mathrm{CuNW}) / \mathrm{ZnS}$ hybrid with a core-shell structure by a microwaveassisted hydrothermal route [Figure $3 \mathrm{~A}$ ]. The obtained $\mathrm{ZnS}$ with a narrowed bandgap could form a strong coupled interface with the CuNWs. As a result, this catalyst exhibited improved activity and stability for photocatalytic $\mathrm{H}_{2}$ production under the illumination of visible light [Figure $3 \mathrm{~B}$ and C]. The corresponding $\mathrm{H}_{2}$ production rate reached $10,722 \mu \mathrm{mol} \cdot \mathrm{g}^{-1} \cdot \mathrm{h}^{-1}$ with an AQE of $69 \%$ under LED illumination with a wavelength $(\lambda)$ of $420 \mathrm{~nm}$. $\mathrm{Cu}^{+}$ions from the CuNWs doped the $\mathrm{ZnS}$ shell, lowering the Schottky barrier and enabling photogenerated $\mathrm{e}^{-}$to be injected from $\mathrm{Cu}^{+} / \mathrm{ZnS}$ to the CuNWs, resulting in efficient charge separation. The core-shell NW structure benefited reactant absorption, charge separation and active site protection. Specifically, the CuNW cores acted as active sites to accept $\mathrm{e}^{-}$for the efficient reduction of $\mathrm{H}^{+}$to $\mathrm{H}_{2}$ [Figure 3D and E].

Wang et al. ${ }^{[27]}$ prepared a zinc oxide/CdS hierarchical composite. The CdS moiety plays a key role in light harvesting. A photocatalytic $\mathrm{H}_{2}$ production rate of $4134 \mu \mathrm{mol} \cdot \mathrm{g}^{-1} \cdot \mathrm{h}^{-1}$ was obtained with $\mathrm{Na}_{2} \mathrm{~S}$ and $\mathrm{Na}_{2} \mathrm{SO}_{3}$ as electron donors. The $\mathrm{Z}$-scheme charge migration scheme bestowed the photocatalyst with a strong ability for $\mathrm{H}_{2}$ production and improved the photoactivity. Dai et al. ${ }^{[28]}$ constructed a system composed of a unique pyroelectric substrate, poly(vinylidene fluoride-co-hexafluoropropylene), carbon nanotubes and a CdS photocatalyst for infrared (IR)-light-driven $\mathrm{H}_{2}$ production in the presence of TEA. The photocatalytic $\mathrm{H}_{2}$ production efficiency was improved by more than five times with an AQE of $16.9 \%$. Zhang et al. ${ }^{[29]}$ first converted Cd-based Prussian blue analog cubes into a CdS cage, which were then further transformed into a $\mathrm{CdS}$ frame-in-cage. Owing to the novel frame-in-cage structure, a visible-light-driven $\mathrm{H}_{2}$ production rate of $13.6 \mathrm{mmol} \cdot \mathrm{g}^{-1} \cdot \mathrm{h}^{-1}$ was achieved while $\mathrm{Na}_{2} \mathrm{~S}$ and $\mathrm{Na}_{2} \mathrm{SO}_{3}$ were used as sacrificial hole scavengers, which was much higher compared to that of the CdS cubes and cages. 
A

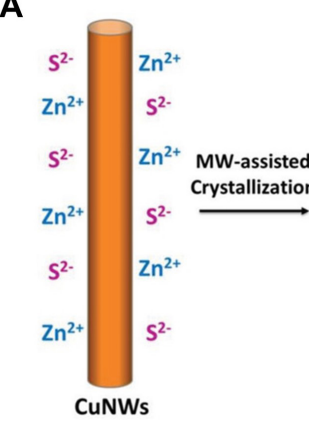

B

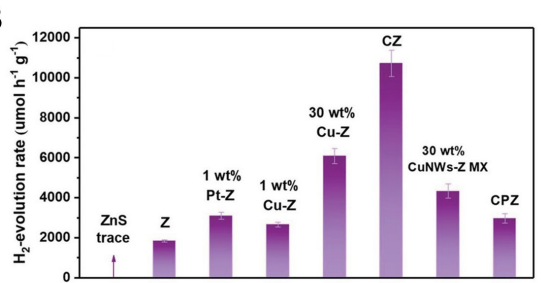

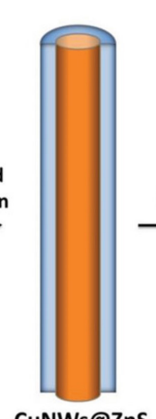

CuNWs@ZnS
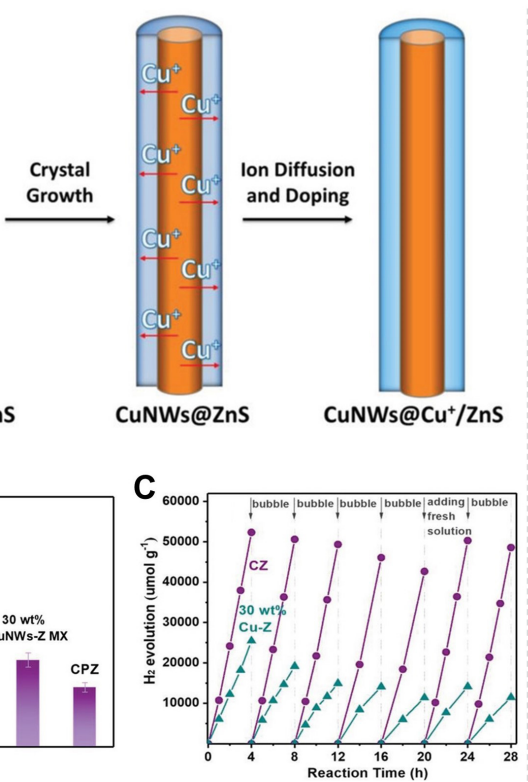

D

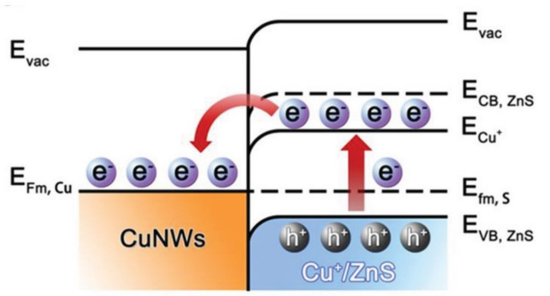

$E$

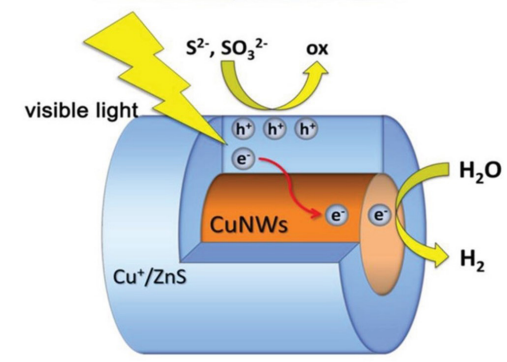

Figure 3. (A) Schematic illustration of CuNW/ZnS core-shell hybrids formed by a microwave-assisted hydrothermal route. (B) Photocatalytic $\mathrm{H}_{2}$ production rate of different samples under LED light irradiation $(\lambda=420 \mathrm{~nm}$ ). (C) Cycling activity of $\mathrm{CZ}$ and 30 wt. $\%$ $\mathrm{Cu}-Z$. (D) Schottky contact, band structure and schematic illustration of the $\mathrm{e}^{-} \mathrm{h}^{+}$separation process under visible-light irradiation. (E) Schematic diagram of the core-shell structure and the proposed photocatalytic mechanism. Reproduced from Ref. ${ }^{[26]}$ with permission from Wiley.

III. Carbon nitride-based photocatalysts

Carbon nitride $\left(\mathrm{C}_{3} \mathrm{~N}_{4}\right)$ comprises only earth-abundant $\mathrm{C}$ and $\mathrm{N}$ elements and has high thermal and chemical stability because of the robust covalent bonds between the $\mathrm{C}$ and $\mathrm{N}$ atoms in the layered structure [Figure 4$]^{[30,31]}$. Its bandgap energy is $\sim 2.7 \mathrm{eV}$, meaning that it can absorb visible light. In addition, the $\mathrm{CB}$ and $\mathrm{VB}$ edge positions of $\mathrm{C}_{3} \mathrm{~N}_{4}$ are suitable for water reduction and oxidation, respectively ${ }^{[32-34]}$. Therefore, $\mathrm{C}_{3} \mathrm{~N}_{4}$ is a promising photocatalyst.

In 2019, Mo et al ${ }^{[35]}$ proposed a Z-scheme system containing two-dimensional (2D) $\mathrm{MnO}_{2} /$ monolayer graphitic carbon nitride with defective $\mathrm{Mn}^{3+}$ active sites for $\mathrm{H}_{2}$ production, while TEOA was used as a sacrificial agent. After $\mathrm{Mn}^{3+} / \mathrm{Mn}^{4+}$ redox couples were introduced, these defective $\mathrm{Mn}^{3+}$ active sites could promote $\mathrm{H}_{2} \mathrm{O}$ adsorption and boost the charge separation and transfer at the interface, resulting in a $\mathrm{H}_{2}$ production rate of $28.0 \mathrm{mmol} \cdot \mathrm{g}^{-1} \cdot \mathrm{h}^{-1}$ and an AQE of $23.33 \%$ at $\lambda=420 \mathrm{~nm}$. Wang et al ${ }^{[36]}$ prepared Se-doped carbon nitride $\left(\mathrm{Se}-\mathrm{C}_{3} \mathrm{~N}_{4}\right)$ by fluorination, followed by thermal defluorination in Se vapor to realize $2 \mathrm{D} \mathrm{C}_{3} \mathrm{~N}_{4}$ with a strong visible-light absorption band. The formation of cyano groups accompanied by Se doping expanded the absorption edge of the $\mathrm{C}_{3} \mathrm{~N}_{4}$ from 416 to $584 \mathrm{~nm}$. In addition, a downward electron spin polarization in the $\mathrm{C}_{3} \mathrm{~N}_{4}$ structure facilitated charge separation and surface catalysis reactions. The visiblelight-driven $\mathrm{H}_{2}$ production rate reached $5411.2 \mu \mathrm{mol} \cdot \mathrm{g}^{-1} \cdot \mathrm{h}^{-1}$ using Se- $\mathrm{C}_{3} \mathrm{~N}_{4}$ with $3 \mathrm{wt} . \% \mathrm{Pt}$ as a cocatalyst, which was 176.5 times that of the pure $\mathrm{C}_{3} \mathrm{~N}_{4}$ in the presence of TEOA.

In 2021, Xu et al. ${ }^{[37]}$ prepared a NIR-active C/K-doped red polymeric carbon nitride (RPCN). The homogeneous and high incorporation of $\mathrm{C}$ and $\mathrm{K}$ narrowed the bandgap of $\mathrm{C}_{3} \mathrm{~N}_{4}(1.7 \mathrm{eV})$, thus extending the light absorption edge to the NIR region [Figure 5A]. RPCN displayed a NIR-driven $\mathrm{H}_{2}$ production rate of $140 \mu \mathrm{mol} \cdot \mathrm{g}^{-1} \cdot \mathrm{h}^{-1}$ from water [Figure 5B and C]. The AQE was $0.84 \%$ at $700 \pm 10 \mathrm{~nm}$ and $13 \%$ at $500 \pm 10 \mathrm{~nm}$ [Figure 5D]. 
A

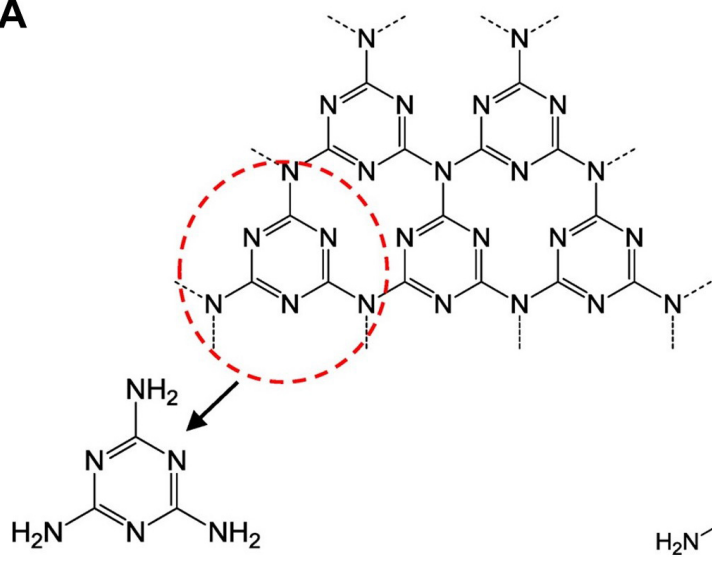

B

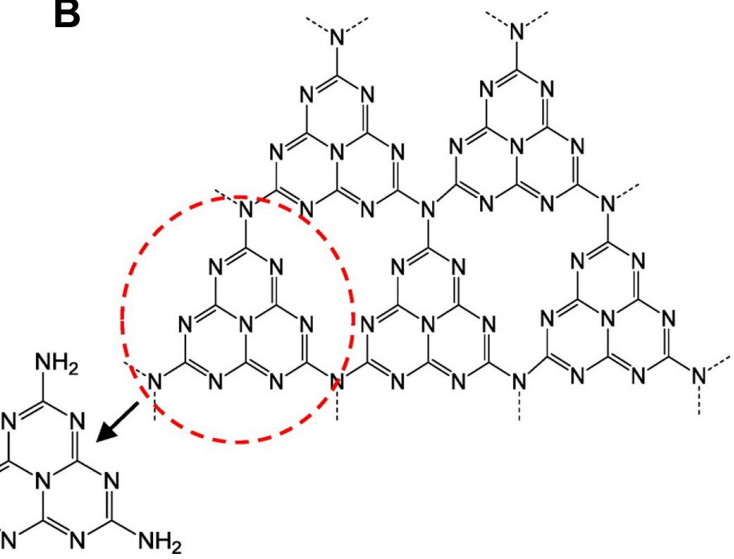

Figure 4. (A) Triazine and (B) tri-s-triazine (heptazine) structures of graphitic carbon nitride $\left(\mathrm{g}-\mathrm{C}_{3} \mathrm{~N}_{4}\right)$. Reproduced from Ref. ${ }^{[30]}$ with permission from the American Chemical Society.

A

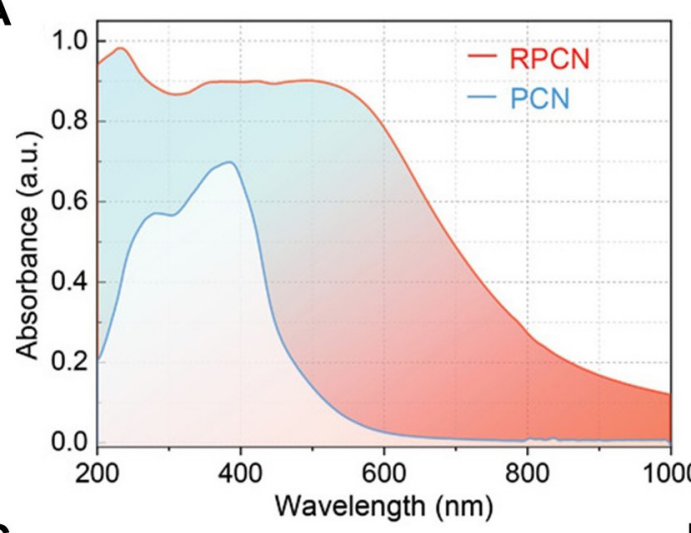

C

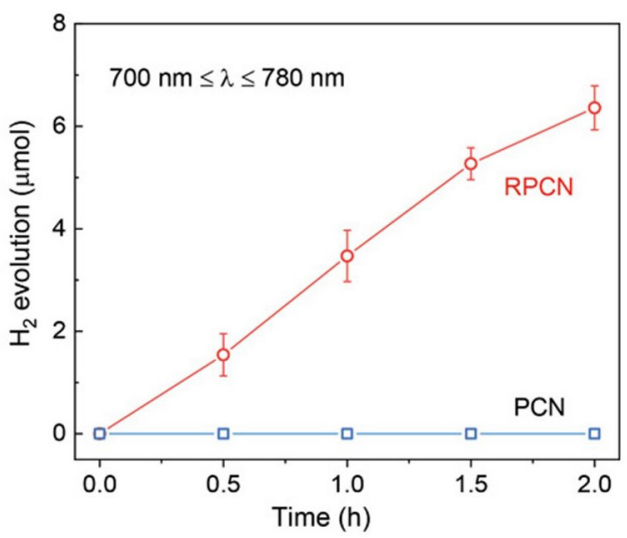

B

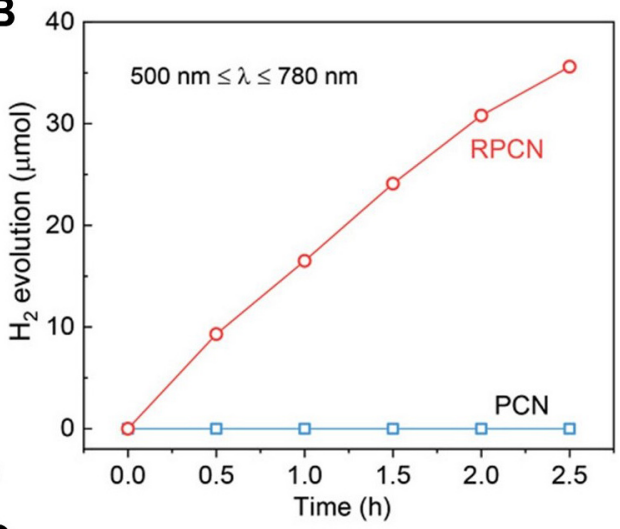

D

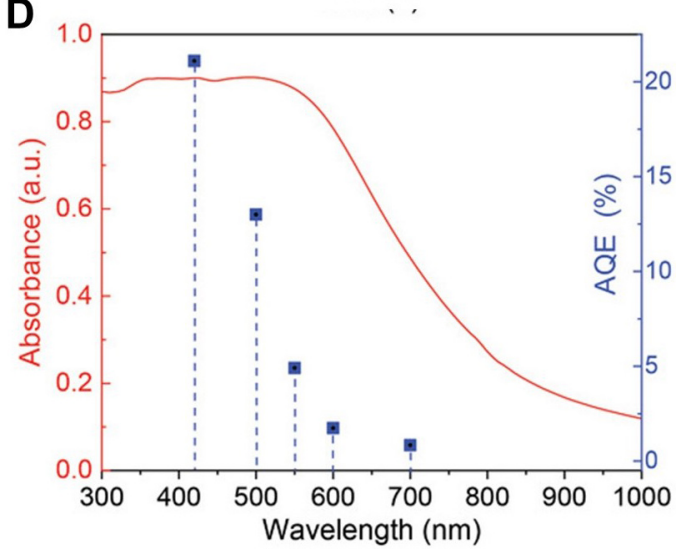

Figure 5. (A) Ultraviolet-Visible-Near Infrared (UV-Vis-NIR) diffuse reflection spectra. Activity of $\mathrm{H}_{2}$ production from water with RPCN under irradiation within different light ranges of (B) $500 \leq \lambda \leq 780 \mathrm{~nm}$ and (C) $700 \leq \lambda \leq 780 \mathrm{~nm}$, using 3 wt.\% Pt as the cocatalyst and 10 vol.\% TEOA as the sacrificial agent. (D) AQE at various monochromatic wavelengths. Reproduced from Ref. ${ }^{[37]}$ with permission from Wiley. RPCN: Polymeric carbon nitride; TEOA: triethanolamine; AQE: apparent quantum efficiency.

IV. Metal-organic framework-based photocatalysts

Metal-organic frameworks (MOFs) are porous materials self-assembled from inorganic metal oxide clusters and organic linkers ${ }^{[38-40]}$. Owing to their unique properties that include high surface areas, well-defined metal 
nodes, adjustable chemical composition and enriched functionality, they have been extensively applied in various fields, such as gas separation and storage, sensors, environmental purification and catalysis ${ }^{[3,38,41,42]}$.

In 2018, Xiao et al. ${ }^{[43]}$ combined surface plasmonic Au with a Pt-MOF Schottky junction to synthesize a Pt@MIL-125/Au catalyst [MIL-125 is a Ti-based MOF consisting of $\mathrm{Ti}_{8} \mathrm{O}_{8}(\mathrm{OH})_{4}$ clusters and terephthalate acid linkers]. The spatial separation of the Pt and Au particles steered the formation of electron flow and expedited electron transport. Therefore, Pt@MIL-125/Au showed a much higher photocatalytic $\mathrm{H}_{2}$ production rate compared to catalysts with $\mathrm{Pt}$ or $\mathrm{Au}$ from water under the illumination of visible light with TEOA as electron donors.

Chen et al. ${ }^{[39]}$ bestowed the organic linkers (2-aminoterephthalate acid) of $\mathrm{NH}_{2}$-MIL-125(Ti) with mixedvalent copper $\left(\mathrm{Cu}^{2+} / \mathrm{Cu}^{+}\right)$centers $(\mathrm{Cu}-\mathrm{NM})$, which enabled effective electron transfer to the mixed-valent $\mathrm{Cu}^{2+} / \mathrm{Cu}^{+}$centers from the 2-aminoterephthalate acid linkers [Figure $6 \mathrm{~A}$ and $\mathrm{B}$ ]. This resulted in increases in the carrier density and lifetime of the photogenerated charges by 7000 and 27 times, respectively. As a result, a much higher rate of $\mathrm{H}_{2}$ production compared to that of MOFs with $\mathrm{Pt}$ as a cocatalyst (Pt-NM) was obtained under the illumination of visible light from water when TEA was used as a sacrificial hole scavenger [Figure 6C].

Dong et al. ${ }^{[44]}$ fabricated a CdS-based MOF, DLNU-M-CdS( $\left.\mathrm{H}_{2} \mathrm{TD}\right)\left(\mathrm{H}_{2} \mathrm{TD}=1,3,4\right.$-thiadiazole-2,5-dithiol), for photocatalytic $\mathrm{H}_{2}$ production in the presence of TEOA without the assistance of cocatalysts. During the photocatalytic reaction, the electron-donating process from TEOA to $\mathrm{H}_{2} \mathrm{TD}$ evoked fast electron transfer in the path of TEOA $\rightarrow \mathrm{H}_{2} \mathrm{TD} \rightarrow \mathrm{Cd} \rightarrow \mathrm{H}^{+}$to separate photogenerated $\mathrm{e}^{-} \mathrm{h}^{+}$pairs in DLNU-M-Cd( $\left.\mathrm{H}_{2} \mathrm{TD}\right)$, resulting in a $\mathrm{H}_{2}$ production rate of $26.1 \mathrm{mmol} \cdot \mathrm{g}^{-1} \cdot \mathrm{h}^{-1}$ under the irradiation of $\mathrm{UV}$-visible-light.

Sun et al. ${ }^{[45]}$ incorporated noble-metal-free $\mathrm{Ni}_{2} \mathrm{P}$ and $\mathrm{Ni}_{12} \mathrm{P}_{5}$ into $\mathrm{UiO}-66-\mathrm{NH}_{2}$ [a MOF consisting of $\mathrm{Zr}_{6} \mathrm{O}_{6}(\mathrm{OH})_{4}$ clusters and 2-aminoterephthalate acid linkers] to form $\mathrm{Ni}_{2} \mathrm{P} @ \mathrm{MOF}$ and $\mathrm{Ni}_{12} \mathrm{P}_{5} @ \mathrm{MOF}$ photocatalysts, respectively, for photocatalytic $\mathrm{H}_{2}$ production with TEA as a hole sacrificial agent. Both $\mathrm{Ni}_{2} \mathrm{P} @ \mathrm{MOF}$ and $\mathrm{Ni}_{12} \mathrm{P}_{5} @ \mathrm{MOF}$ showed enhanced $\mathrm{H}_{2}$ production rates in comparison with the pristine MOF and their physical mixtures. $\mathrm{Ni}_{2} \mathrm{P}$ and $\mathrm{Ni}_{12} \mathrm{P}_{5}$ exhibit a similar capability to $\mathrm{Pt}$ in promoting the charge transfer from linkers to clusters and lowering the activation energy of the $\mathrm{H}_{2}$ production reaction. $\mathrm{Pt}$ is thermodynamically favorable, while $\mathrm{Ni}_{2} \mathrm{P}$ is kinetically more suitable for $\mathrm{H}_{2}$ production, resulting in higher activity over $\mathrm{Ni}_{2} \mathrm{P} @ \mathrm{MOF}$ than over Pt@MOF.

Meng et al.$^{[46]}$ immobilized CdS quantum dots and carbon nanodots (CDs) in the cages of MIL-101 (a Crbased MOF consisting of Cr clusters and terephthalic acid linkers) to form CD/CdS@MIL-101 composites. The $\mathrm{H}_{2}$ production rate on CD/CdS@MIL-101 with a CD content of $5.2 \mathrm{wt} . \%$ was $14.66 \mu \mathrm{mol} \cdot \mathrm{h}^{-1}$ when using lactic acid as a sacrificial agent under the illumination of visible light, which was 8.5 and 18.6 times that on CdS@MIL-101 and pure CdS, respectively. The enhanced photoactivity can be ascribed to the role of electron collection of the CDs, which prolongs the lifetime of the photogenerated charge carriers in the CdS@MIL-101 heterostructure photocatalyst.

Lin et al. ${ }^{[47]}$ demonstrated porphyrin-based zirconium MOFs $\left(\mathrm{PCN}-\mathrm{H}_{2} / \mathrm{Pt}_{\mathrm{x}: \mathrm{y}} \mathrm{x}: \mathrm{y}=4: 1,3: 2,2: 3\right.$ and $\left.0: 1\right)$ with different ratios of $\mathrm{H}_{2}$ TCPP and $\mathrm{Pt}{ }^{\mathrm{II}} \mathrm{TCPP}$ [TCPP = tetrakis(4-carboxyphenyl)porphyrinate] linkers. $\mathrm{PCN}-\mathrm{H}_{2} / \mathrm{Pt}_{0: 1}$ displayed the highest $\mathrm{H}_{2}$ production reaction rate $\left(351.08 \mu \mathrm{mol} \cdot \mathrm{h}^{-1} \cdot \mathrm{g}^{-1}\right)$ with TEOA as a sacrificial agent under visible-light irradiation. Such photoactivity can be ascribed to the uniformly dispersed $\mathrm{Pt}^{2+}$ ions in $\mathrm{PCN}-\mathrm{H}_{2} / \mathrm{Pt}_{0: 1}$, which boost the transfer of charges from porphyrins (photosensitizers) to $\mathrm{Pt}^{\mathrm{II}}$ ions (catalytic centers). 

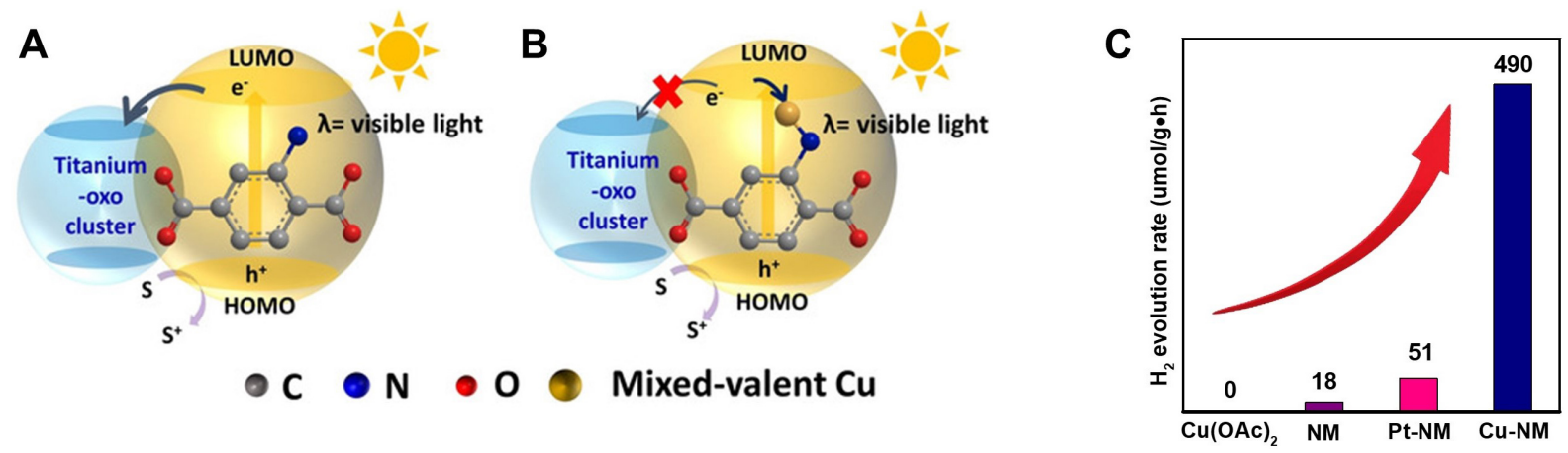

Figure 6. $(\mathrm{A})$ and $(\mathrm{B})$ Schematic of electron-transfer pathways from an organic linker to a titanium-oxo cluster in $\mathrm{NH}_{2}-\mathrm{MIL}^{-125}(\mathrm{Ti})$ and to a mixed-valent $\mathrm{Cu}$ center, respectively. S represents a sacrificial agent. (C) Activity of NM, Pt-NM and Cu-NM in photocatalytic $\mathrm{H}_{2}$ production under visible-light irradiation. Reproduced from Ref. ${ }^{[39]}$ with permission from Wiley.

V. Covalent-organic framework-based photocatalysts

Covalent-organic frameworks (COFs) are another type of porous crystalline polymers that can precisely integrate molecular building blocks into extended $2 \mathrm{D}$ or three-dimensional (3D) structures via covalent bonds ${ }^{[48-50]}$. Because of their characteristics, which include low density, high porosity, structural periodicity and modular functionality, COFs have been extensively studied for gas adsorption and separation ${ }^{[51,52]}$, catalysis $^{[3,54]}$, sensors ${ }^{[55-57]}$, optoelectronics ${ }^{[5,59]}$ and energy storage systems ${ }^{[60-62]}$.

In 2018, Xie et al ${ }^{[63]}$ reported a highly ordered COF, CTF-1 $\left(\mathrm{C}_{8} \mathrm{~N}_{2} \mathrm{H}_{4}\right)$, which can efficiently produce $\mathrm{H}_{2}$ from water. A high AQE for $\mathrm{H}_{2}$ production of $6 \%$ at $\lambda=420 \mathrm{~nm}$ was obtained, which was ascribed to the welldefined and ordered structure of CTF-1, as well as low carbonization and superior band positions. In 2021, Chen et al. ${ }^{[64]}$ reported the synthesis of four isostructural porphyrinic 2D COFs (MPor-DETH-COF, $M=\mathrm{H}_{2}$, Co, $\mathrm{Ni}, \mathrm{Zn}$; DETH = 2,5-diethoxyterephthalohydrazide) and their application in photocatalytic $\mathrm{H}_{2}$ production [Figure 7]. All four COFs have AA stacking structures with high crystallinity and large surface areas. The introduction of different transition metals into the porphyrin rings regulated the photocatalytic $\mathrm{H}_{2}$ production rate of these COFs in the following order: CoPor-DETH-COF $<\mathrm{H}_{2}$ Por-DETH-COF $<$ NiPor-DETH-COF $<$ ZnPor-DETH-COF. In the same year, COFs with an ordered arrangement of layered structures were reported for visible-light-driven $\mathrm{H}_{2}$ production with ascorbic acid as a sacrificial agent ${ }^{[65]}$. The mesoporous channels of a $\beta$-ketoenamine-linked COF, including a benzothiadiazole moiety, were filled with polyethylene glycol, which inhibited the dislocation of neighboring layers while retaining the columnar $\pi$-orbital arrays to boost free charge transfer. Thus, the $\mathrm{H}_{2}$ production rate was enhanced compared to that of the pure COFs. Yang et al. ${ }^{[6]]}$ demonstrated that donor-acceptor-type imine-linked COFs could catalyze $\mathrm{H}_{2}$ production with a rate of $20.7 \mathrm{mmol} \cdot \mathrm{g}^{-1} \cdot \mathrm{h}^{-1}$ under the illumination of visible light with ascorbic acids as hole scavengers. The improved photoactivity was ascribed to the extended light harvesting range, enhanced charge separation efficiency and increased hydrophilicity.

VI. Nitride-based photocatalysts

Nitrides, particularly transition metal nitrides with narrow energy bandgaps and excellent physicochemical properties, can effectively regulate the structures of semiconductor photocatalysts and their photocatalytic performance ${ }^{[67]}$.

In 2021, Xiao et al. ${ }^{[68]}$ fabricated Mg-Zr-codoped single-crystalline $\mathrm{Ta}_{3} \mathrm{~N}_{5}\left(\mathrm{Ta}_{3} \mathrm{~N}_{5}: \mathrm{Mg}+\mathrm{Zr}\right)$ nanoparticles for $\mathrm{H}_{2}$ production from $\mathrm{H}_{2} \mathrm{O}$. The photoactivity was 45 times that of pristine $\mathrm{Ta}_{3} \mathrm{~N}_{5}$. Simultaneous defect tuning and surface property optimization generated high concentrations of long-lived electrons and facilitated 

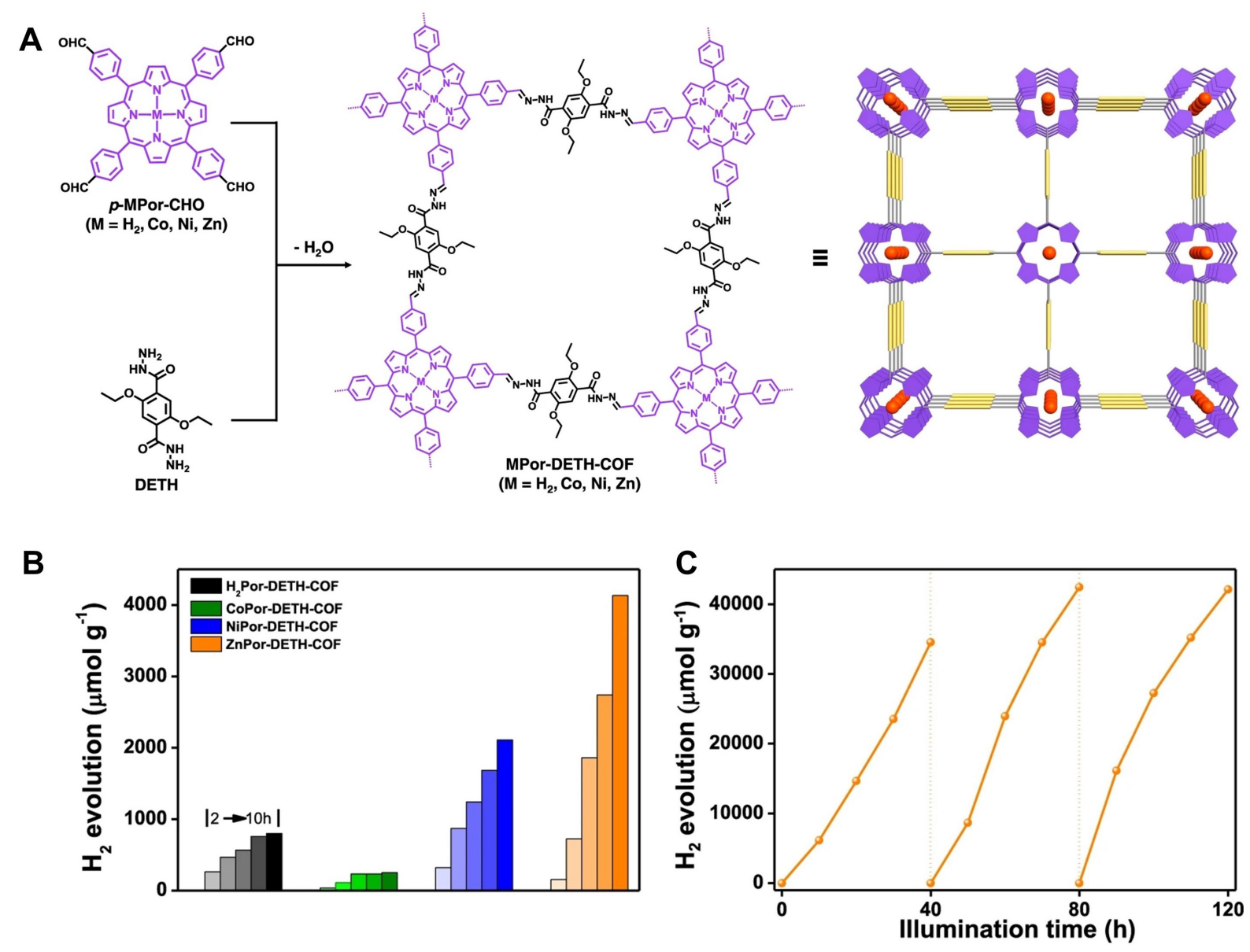

Figure 7. (A) Schematic illustration of the synthesis of MPor-DETH-COFs. (B) Activity of $\mathrm{H}_{2}$ production under visible-light irradiation using $\mathrm{H}_{2}$ Por-DETH-COF, CoPor-DETH-COF, NiPor-DETH-COF and ZnPor-DETH-COF. (C) Cycling results of $\mathrm{H}_{2}$ production under visible-light irradiation using ZnPor-DETH-COF. Reproduced from Ref. ${ }^{[64]}$ with permission from Springer Nature.

electron migration to the Pt sites on the surface of the photocatalyst, thus enhancing the photoactivity under the illumination of visible light. In the same year, Wang et al. ${ }^{[60]}$ reported the efficient utilization of photogenerated electrons in a single-crystal $\mathrm{BaTaO}_{2} \mathrm{~N}$ photocatalyst for $\mathrm{H}_{2}$ production via the sequential decoration of a Pt cocatalyst. The $\mathrm{H}_{2}$ production rate in a methanol aqueous solution was improved 100fold compared to that of $\mathrm{BaTaO}_{2} \mathrm{~N}$. Its AQE was $6.8 \%$ at $\lambda=420 \mathrm{~nm}$.

$\mathrm{H}_{2}$ production from overall water splitting

Photocatalytic $\mathrm{H}_{2}$ production from overall water splitting can effectively avoid the secondary pollution caused by the use of sacrificial hole scavengers, while $\mathrm{O}_{2}$ is produced from water oxidation.

I. Selenide- and sulfide-based photocatalysts

Wang et al. ${ }^{[70]}$ developed uniform hollow $\mathrm{MoSe}_{2} / \mathrm{CdSe}$ nanospheres without any template/surfactant assistance. Owing to the Z-scheme mechanism for charge transfer in the heterostructure, it displayed a $\mathrm{H}_{2}$ production rate of $7120.0 \mu \mathrm{mol} \cdot \mathrm{g}^{-1} \cdot \mathrm{h}^{-1}$ from water splitting under the irradiation of simulated sunlight and the AQE reached $27.2 \%$ at $\lambda=670 \mathrm{~nm}$. 
$\mathrm{S} 3 \mathrm{p}$ and $\mathrm{O} 2 \mathrm{p}$ orbitals were hybridized by Zhang et al ${ }^{[71]}$ to generate oxysulfides with stabilization of $\mathrm{S}^{2-}$ in a sulfide-based photocatalyst. Additional surface modification of the oxysulfides with dual cocatalysts promoted the separation and transfer of photogenerated charges, thereby reducing charge accumulation and inhibiting photocorrosion. The results demonstrated that the $\mathrm{pH}$ value played an important role in realizing the efficient production of stoichiometric $\mathrm{H}_{2}$ and $\mathrm{O}_{2}$. Pan et al. ${ }^{[72]}$ reported that Ag dopant and nanohole dual defects in $\mathrm{ZnIn}_{2} \mathrm{~S}_{4}$ monolayers promoted stoichiometric $\mathrm{H}_{2}$ and $\mathrm{O}_{2}$ production from water under the illumination of visible light. The Ag dopant and nanohole dual defects optimized the light harvesting and carrier dynamics and served as active sites for the oxidation and reduction of water, respectively, thereby resulting in stable activity for photocatalytic water splitting.

\section{II. $\mathrm{C}_{3} \mathrm{~N}_{4}$-based photocatalysts}

Chen et al. ${ }^{[73]}$ constructed $3 \mathrm{D}$ porous $\mathrm{g}_{-} \mathrm{C}_{3} \mathrm{~N}_{4}$ assembled using highly crystalline and ultrathin NSs. The $3 \mathrm{D}$ g- $\mathrm{C}_{3} \mathrm{~N}_{4}$ NSs could produce $\mathrm{H}_{2}$ and $\mathrm{O}_{2}$ from water splitting with production rates of 101.4 and $49.1 \mu \mathrm{mol} \cdot \mathrm{g}^{-1} \cdot \mathrm{h}^{-1}$, respectively, under the illumination of visible light. These rates are $\sim 11.8$ and $\sim 5.1$ times that of bulk g- $\mathrm{C}_{3} \mathrm{~N}_{4}$ and g- $\mathrm{C}_{3} \mathrm{~N}_{4} \mathrm{NSs}$, respectively. Furthermore, the $3 \mathrm{D}$ g- $\mathrm{C}_{3} \mathrm{~N}_{4} \mathrm{NSs}$ showed an AQE of $1.4 \%$ under light radiation at $\lambda=420 \mathrm{~nm}$ and maintained good stability for $100 \mathrm{~h}$. Lin et al. ${ }^{[74]}$ demonstrated a onephoton excitation route by coupling a polymeric carbon nitride (PCN) with $\mathrm{LaOCl}$ to realize overall water splitting. The modification of $\mathrm{LaOCl}$ formed an interfacial electric field that boosted the rapid separation and transfer of photogenerated $\mathrm{e}^{-}-\mathrm{h}^{+}$pairs in the catalyst. The water reduction half-reaction occurred on $\mathrm{LaOCl}$ and its oxidation half-reaction appeared on the PCN. As a result, this "artificial photosynthesis" catalyst showed $\mathrm{H}_{2}$ and $\mathrm{O}_{2}$ production rates of 22.3 and $10.7 \mu \mathrm{mol} \cdot \mathrm{h}^{-1}$, respectively, from overall water splitting.

Chen et al. ${ }^{[75]}$ synthesized a g- $\mathrm{C}_{3} \mathrm{~N}_{4} /$ reduced graphene oxide (rGO)/perylene diimide polymer (PDIP) photocatalyst with a Z-scheme heterostructure to achieve excellent photocatalytic overall water splitting [Figure 8A]. A significant internal electric field was built in the Z-scheme heterostructure [Figure 8B], thereby promoting the high-flux charge transfer and improving the charge separation efficiency by a factor of 8.5. The g- $\mathrm{C}_{3} \mathrm{~N}_{4} / \mathrm{rGO} / \mathrm{PDIP}$ photocatalyst presented $\mathrm{H}_{2}$ and $\mathrm{O}_{2}$ production rates of 15.80 and $7.80 \mu \mathrm{mol} \cdot \mathrm{h}^{-1}$, respectively, which are $\sim 12.1$ times that of pure $\mathrm{g}-\mathrm{C}_{3} \mathrm{~N}_{4}$. An AQE of $4.94 \%$ at $\lambda=420 \mathrm{~nm}$ and a conversion efficiency of solar energy to hydrogen energy of $0.3 \%$ were realized [Figure $8 \mathrm{C}$ and D]. Besides, it showed a very good stability within $120 \mathrm{~h}$ of photocatalytic reaction [Figure $8 \mathrm{E}$ ].

Wu et al.$^{[76]}$ prepared g- $\mathrm{C}_{3} \mathrm{~N}_{4}$ NSs exfoliated by a femtosecond pulsed laser, which achieved $\mathrm{H}_{2}$ and $\mathrm{O}_{2}$ production rates of 42.6 and $18.7 \mu \mathrm{mol} \cdot \mathrm{g}^{-1} \cdot \mathrm{h}^{-1}$, respectively, toward overall water splitting when Pt was used as a cocatalyst. The laser pulses created cyano $(-\mathrm{C} \equiv \mathrm{N})$ defects that favored the anchoring of divalent atomic Pt cocatalysts, which are different from Pt metal nanoparticles. This provided more active sites for the surface reaction and suppressed the reverse reaction of water splitting. In addition, the $-\mathrm{C} \equiv \mathrm{N}$ defects reduced the position of the band edge to improve the oxidation ability of $\mathrm{h}^{+}$.

Using an electrostatic self-assembly method, Zhao et al. ${ }^{[77]}$ coupled B-doped N-deficient $2 \mathrm{D} \mathrm{C}_{3} \mathrm{~N}_{4} \mathrm{NSs}$ to obtain a $2 \mathrm{D} / 2 \mathrm{D}$ polymeric $\mathrm{Z}$-scheme heterostructure. The combination of ultrathin nanostructures, the robust interfacial interaction and the staggered band arrangement in the Z-scheme system boosted the separation and transfer of photogenerated $\mathrm{e}^{-}-\mathrm{h}^{+}$pairs, thus realizing stoichiometric $\mathrm{H}_{2}$ and $\mathrm{O}_{2}$ production from photocatalytic overall water splitting with $\mathrm{Pt}$ and $\mathrm{Co}(\mathrm{OH})_{2}$ cocatalysts.

III. MOF-based photocatalysts

In 2020, a Pt@UiO-66- $\mathrm{NH}_{2} @ \mathrm{MnO}_{\mathrm{x}}$ photocatalyst with Pt and $\mathrm{MnO}_{\mathrm{x}}$ cocatalysts was designed by 

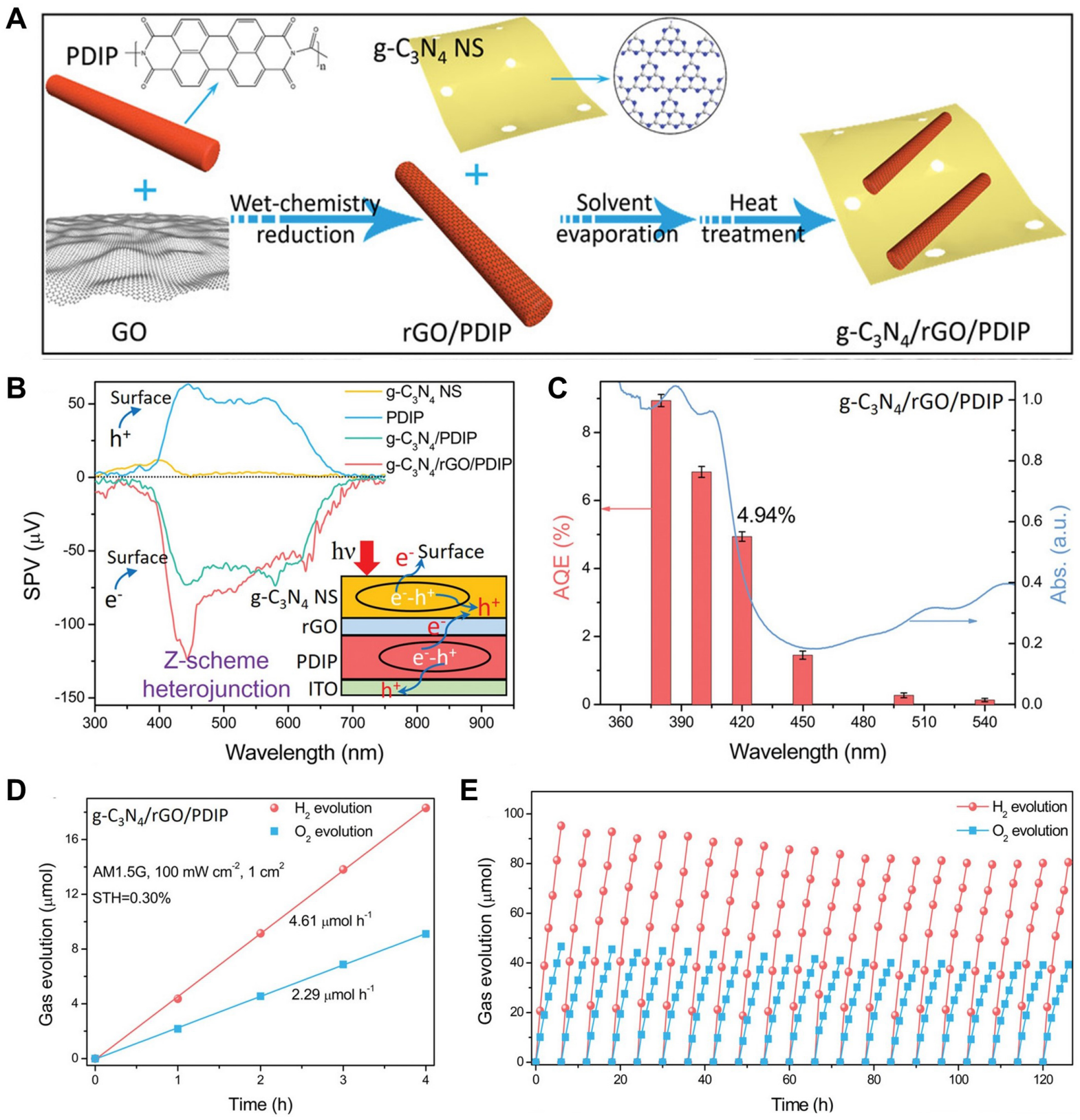

Figure 8. (A) Schematic illustration of $g-C_{3} N_{4} / r G O / P D I P$ fabrication. (B) Surface photovoltage (SPV) spectra. (C) Wavelength dependency of $A Q E$ for photocatalytic overall water splitting. (D) Photocatalytic activity of overall water splitting under AM 1.5G simulated sunlight irradiation using $g-\mathrm{C}_{3} \mathrm{~N}_{4} / \mathrm{rGO} / \mathrm{PDIP}$. (E) Cycling results of photocatalytic overall water splitting. Reproduced from Ref. ${ }^{[75]}$ with permission from Wiley. rGO: Reduced graphene oxide; PDIP: perylene diimide polymer.

Zhang et al. ${ }^{[78]}$ for the complete spatial separation of photogenerated $\mathrm{e}^{-}-\mathrm{h}^{+}$pairs in $\mathrm{UiO}-66-\mathrm{NH}_{2}$, thereby realizing $\mathrm{H}_{2}$ and $\mathrm{O}_{2}$ production from water. Compared with UiO-66- $\mathrm{NH}_{2}, \mathrm{Pt} @ \mathrm{UiO}-66-\mathrm{NH}_{2}$ and UiO-66$\mathrm{NH}_{2} @ \mathrm{MnO}_{\mathrm{x}}$ photocatalysts, Pt@UiO-66- $\mathrm{NH}_{2} @ \mathrm{MnO}_{\mathrm{x}}$ exhibited the highest photoactivity for overall water splitting. As cocatalysts, $\mathrm{Pt}$ favored the trapping of photogenerated $\mathrm{e}$, while $\mathrm{MnO}_{\mathrm{x}}$ particles tended to collect photogenerated $\mathrm{h}^{+}$. The photogenerated $\mathrm{e}^{-}$and $\mathrm{h}^{+}$flowed to the inside and outside of the MOF, respectively, accumulating on the respective cocatalysts and further inducing redox reactions. 
Significantly, $\mathrm{Hu}$ et al. ${ }^{[79]}$ integrated $\mathrm{H}_{2}$ evolution reaction (HER)-MOF and a water oxidation reaction (WOR)-MOF into liposomal structures for the spatial separation of photogenerated $\mathrm{e}^{-}-\mathrm{h}^{+}$pairs. The HERMOF consisted of a light-harvesting Zn-porphyrin and a catalytic Pt-porphyrin and was modified with pentafluoropropionic acid, making the HER-MOF hydrophobic and thus promoting its binding to the hydrophobic lipid bilayer of the liposome. The WOR-MOF was composed of a $\left[\mathrm{Ru}\left(2,2^{\prime} \text {-bipyridine }\right)_{3}\right]^{2+}$ based photosensitizer and an Ir-bipyridine catalytic center and was localized in the hydrophilic interior of the liposome. Owing to the rapid electron transfer from the $\mathrm{Zn}$-porphyrin and $\left[\mathrm{Ru}\left(2,2^{\prime} \text {-bipyridine }\right)_{3}\right]^{2+}$ antennae to the Pt-porphyrin and Ir-bipyridine reaction centers and the efficient charge separation in the lipid bilayers, this liposome-MOF achieved $\mathrm{H}_{2}$ and $\mathrm{O}_{2}$ production in a $\sim 2: 1$ ratio with an $\mathrm{AQE}$ of $\sim 1.5 \%$.

IV. Other photocatalysts

Wang et al. ${ }^{[80]}$ reported quadruple-band InGaN NW arrays, which are composed of $\operatorname{In}_{0.35} \mathrm{Ga}_{0.65} \mathrm{~N}, \operatorname{In}_{0.27} \mathrm{Ga}_{0.73} \mathrm{~N}$, $\mathrm{In}_{0.20} \mathrm{Ga}_{0.80} \mathrm{~N}$ and $\mathrm{GaN}$ sections, with energy bandgaps of $2.1,2.4,2.6$, and $3.4 \mathrm{eV}$, respectively. These multiband InGaN NW arrays were modified upon a nonplanar wafer to improve the light absorption. The doping gradient was introduced along the NWs to form a built-in electric field, which separated and extracted photogenerated charge carriers for water redox reactions. This InGaN photocatalyst exhibited a solar-to-hydrogen efficiency of $\sim 5.2 \%$.

Pan et al. ${ }^{[81]}$ used rGO NSs to promote the transfer of photogenerated charge carriers between $\mathrm{H}_{2}$ producing photocatalysts (e.g., carbon nitride and $\mathrm{BiVO}_{4}$ ) and $\mathrm{O}_{2}$ evolution photocatalysts (e.g., $\mathrm{Fe}_{2} \mathrm{O}_{3}$ and $\mathrm{WO}_{3}$ ), thereby realizing efficient overall water splitting. Furthermore, Oshima et al. ${ }^{[82]}$ presented $\mathrm{HCa}_{2} \mathrm{Nb}_{3} \mathrm{O}_{10} \mathrm{NSs}$ sensitized by a $\mathrm{Ru}(\mathrm{II})$ tris-diimine photosensitizer for overall water splitting under visible-light irradiation, combined with a $\mathrm{WO}_{3}$-based water oxidation photocatalyst and $\mathrm{I}_{3}^{-} / \mathrm{I}^{-}$redox couple. The Pt-intercalated $\mathrm{HCa}_{2} \mathrm{Nb}_{3} \mathrm{O}_{10}$ NSs, which were further modified with amorphous $\mathrm{Al}_{2} \mathrm{O}_{3}$ clusters as $\mathrm{H}_{2}$ production components, realized a dye-based turnover number and frequency of 4580 and $1960 \mathrm{~h}^{-1}$, respectively. Its $\mathrm{AQE}$ at $420 \mathrm{~nm}$ was $2.4 \%$.

Zhao et al.$^{[83]}$ presented a practically feasible strategy that mimicked natural photosynthesis known as the hydrogen farm project (HFP). The proposed system comprised solar energy harvesting and $\mathrm{H}_{2}$ production subsystems integrated by a $\mathrm{Fe}^{3+} / \mathrm{Fe}^{2+}$ redox ion pair [Figure 9]. The $\mathrm{BiVO}_{4}$ crystals with accurately tuned $\{110\} /\{010\}$ facets were used as photocatalysts for this project. The AQE of photocatalytic water oxidation and the complete forward reaction is $71 \%$ and there is almost no reverse reaction. A solar-to-chemical conversion efficiency of $>1.9 \%$ was also achieved.

In 2020, Takata et al ${ }^{[84]}$ used an aluminum-doped strontium titanate $\left(\mathrm{SrTiO}_{3}: \mathrm{Al}\right)$ photocatalyst to realize an $\mathrm{AQE}$ of $96 \%$ for overall water splitting at wavelengths of $350-360 \mathrm{~nm}$, which was equivalent to an almost uniform internal quantum efficient. The selective photodeposition of $\mathrm{Rh} / \mathrm{Cr}_{2} \mathrm{O}_{3}$ and $\mathrm{CoOOH}$ cocatalysts upon different crystal facets of the photocatalyst for the $\mathrm{H}_{2}$ and $\mathrm{O}_{2}$ production reactions, respectively, boosted the $\mathrm{H}_{2}$ and $\mathrm{O}_{2}$ production reactions separately. Thus, multiple consecutive forward charge transfers without reverse charge transfer were realized, thereby attaining the maximum AQE for overall water splitting.

Photocatalytic $\mathrm{H}_{2}$ production from hydrogen storage materials

Achieving the efficient storage and transportation of gaseous $\mathrm{H}_{2}$ is a significant challenge. Storing $\mathrm{H}_{2}$ in a liquid or solid material that holds $\mathrm{H}_{2}$ under ambient conditions and releases it as the conditions change is a safe and efficient method ${ }^{[3]}$. In particular, many efforts have been made to achieve the release of $\mathrm{H}_{2}$ from $\mathrm{H}_{2}$ storage materials, such as ammonia borane $(\mathrm{AB})$ and formic acid $(\mathrm{FA})$. 

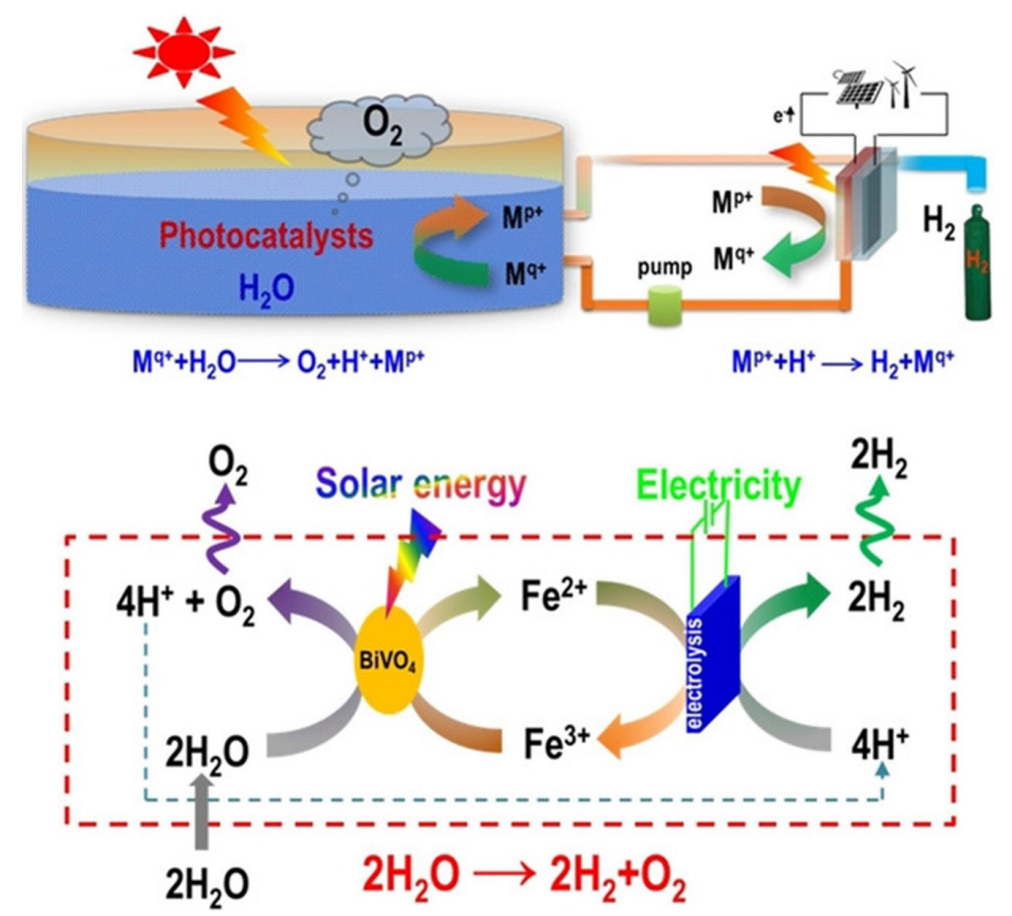

Figure 9. (A) Schematic of hydrogen farm project (HFP) for scalable solar $\mathrm{H}_{2}$ production using particulate photocatalysts for water oxidation and a shuttle ion loop for energy storage. (B) Practical realization for $\mathrm{HFP}_{\text {using }} \mathrm{BiVO}_{4}$ as a water oxidation photocatalyst, $\mathrm{Fe}^{3+} / \mathrm{Fe}^{2+}$ as shuttle ions for energy storage and an electrolysis cell for $\mathrm{H}_{2}$ production. Reproduced from Ref. ${ }^{[83]}$ with permission from Wiley.

In 2018, Zhang et al. ${ }^{[85]}$ demonstrated the NIR-plasmonic energy up-conversion process in $\mathrm{Yb}^{3+} / \mathrm{Er}^{3+}$-doped $\mathrm{NaYF}_{4}$ nanoparticle $\left(\mathrm{NaYF}_{4}: \mathrm{Yb}-\mathrm{Er} \mathrm{NP}\right) @ \mathrm{~W}_{18} \mathrm{O}_{49} \mathrm{NW}$ heterostructures. The improvement of the upconversion luminescence of the $\mathrm{NaYF}_{4}: \mathrm{Yb}$-Er NPs was attributed to the NIR-excited localized surface plasmon resonance (LSPR) of the $\mathrm{W}_{18} \mathrm{O}_{49}$ NWs. Simultaneously, this plasmon-enhanced up-conversion luminescence was partly absorbed by the $\mathrm{W}_{18} \mathrm{O}_{49}$ NWs, re-exciting its higher energy LSPR [Figure 10A]. Based on this plasmonic energy transfer process, the $\mathrm{NaYF}_{4}: \mathrm{Yb}-\mathrm{Er} \mathrm{NP@W}{ }_{18} \mathrm{O}_{49} \mathrm{NW}$ heterostructures exhibited an $\sim 35$-fold increase in catalytic $\mathrm{H}_{2}$ production from $\mathrm{AB}$ [Figure $10 \mathrm{~B}$ and $\mathrm{C}$ ].

Very recently, Zhang et al. ${ }^{[86]}$ reported a Pd-decorated Ti-MOF@TpTt composite (Pd@Ti-MOF@TpTt) coated with an ultrathin COF nanobelt [Figure 11A]. This catalyst presented much higher photoactivity for $\mathrm{H}_{2}$ production from $A B$ hydrolysis than that of the other counterparts with fibrillar-like COF shells [Figure 11B]. This improved activity could be ascribed to its high surface area, core-shell structure and type II heterojunction [Figure $11 \mathrm{C}$ ], which provided more active sites and promoted the separation of photogenerated $\mathrm{e}^{-} \mathrm{h}^{+}$pairs. Finally, Pd@Ti-MOF@TpTt displayed excellent stability for $\mathrm{H}_{2}$ production [Figure 11D].

Cao et al. ${ }^{[87]}$ synthesized a CdS/CoP@rGO hybrid for photocatalytic $\mathrm{H}_{2}$ production from FA using ultrasmall $\mathrm{CoP}$ nanoparticles as a cocatalyst for the first time. The visible-light-driven $\mathrm{H}_{2}$ production rate using the CdS/CoP@rGO hybrid reached $182 \pm 12.5 \mu \mathrm{mol} \cdot \mathrm{mg}^{-1} \cdot \mathrm{h}^{-1}$ without any additives, which was 30 times that of the bare CdS. The system could be sustained for more than seven days. 

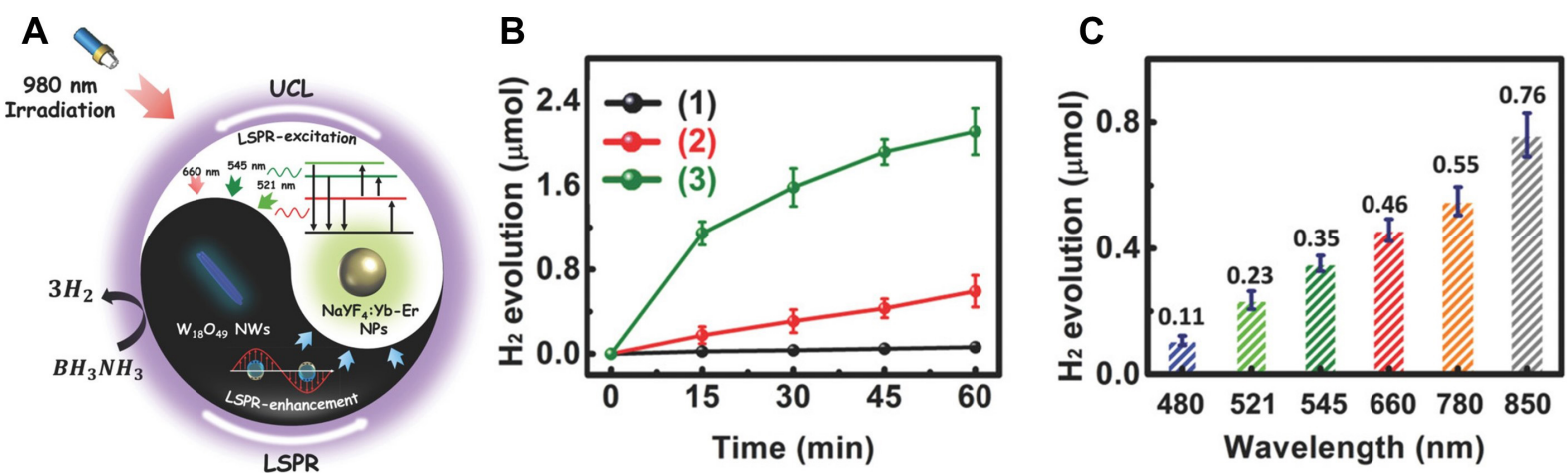

Figure 10. (A) Schematic diagram of plasmonic energy upconversion in the $\mathrm{NaYF}_{4}: \mathrm{Yb}$-Er NP/W ${ }_{18} \mathrm{O}_{49} \mathrm{NW}$ heterostructure system upon irradiation at $\lambda=980 \mathrm{~nm}$. (B) Amount of $\mathrm{H}_{2}$ production from $A B$ aqueous solution under irradiation at $\lambda=980 \mathrm{~nm}$ : (1) no catalyst; (2) $\mathrm{W}_{18} \mathrm{O}_{49} \mathrm{NWs}$; and (3) $\mathrm{NaYF}_{4}: \mathrm{Yb}-\mathrm{Er} \mathrm{NW} @ \mathrm{~W}_{18} \mathrm{O}_{49} \mathrm{NP}$ heterostructures. (C) Amount of $\mathrm{H}_{2}$ production of $\mathrm{W}_{18} \mathrm{O}_{49} \mathrm{NWs}$ in $1 \mathrm{~h}$ under irradiation at different incident light wavelengths. Reproduced from Ref. ${ }^{[85]}$ with permission from Wiley.

A

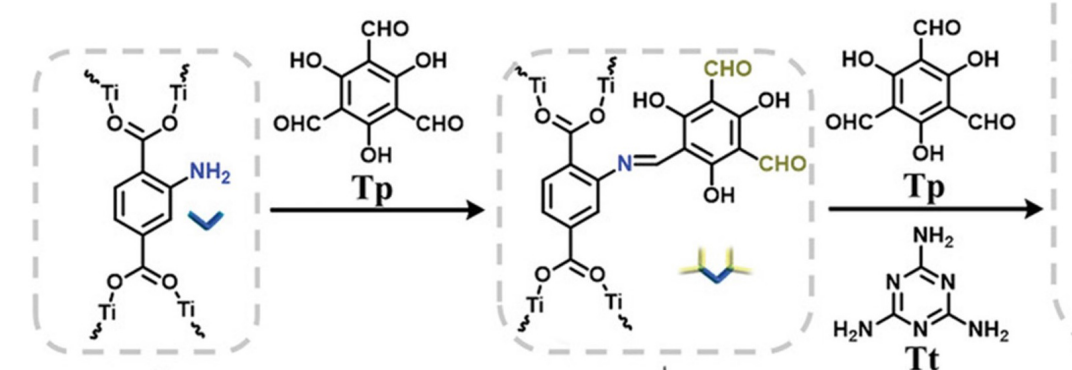

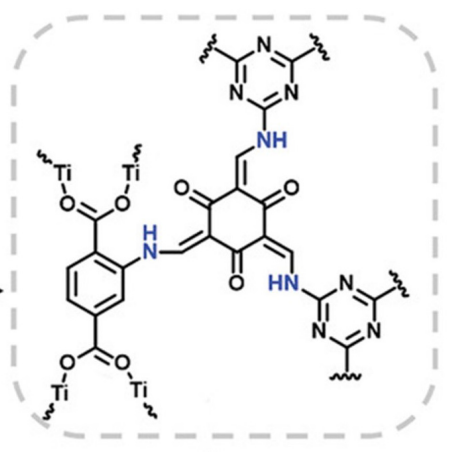
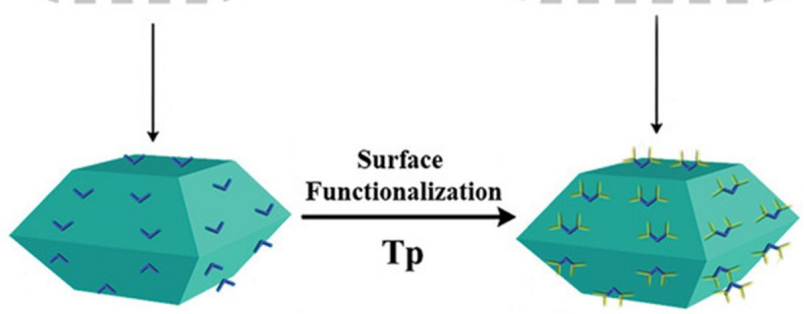

Tt

Ti-MOF

B

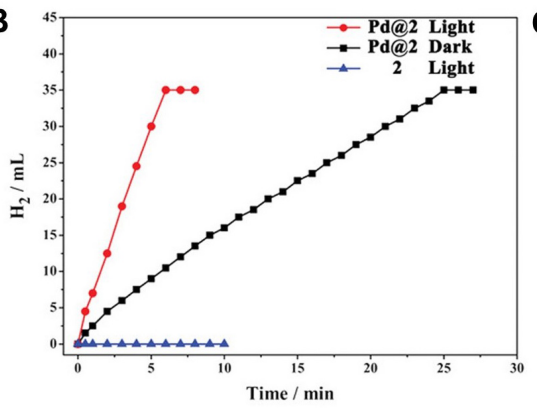

Ti-MOF-CHO

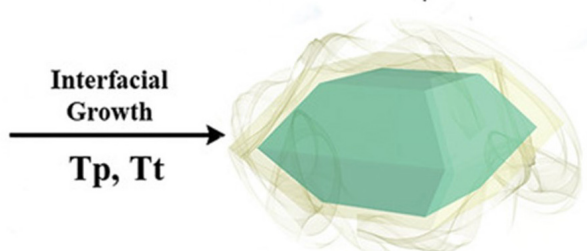

Ti-MOF@TpTt
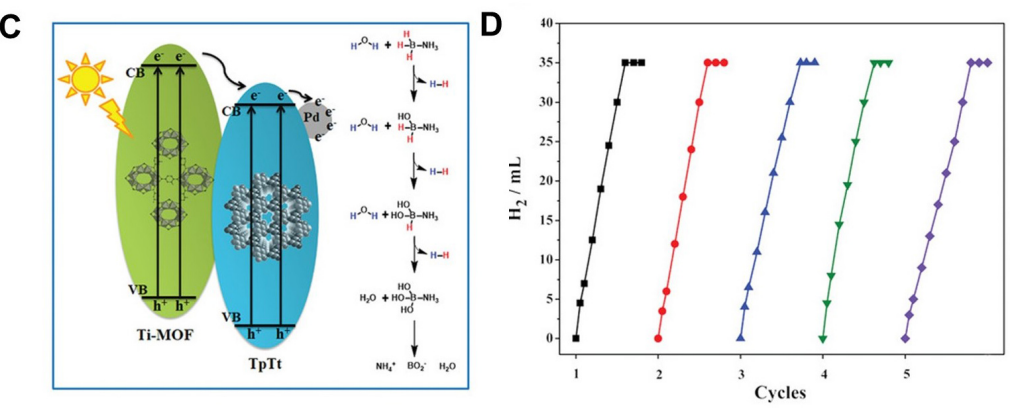

Figure 11. (A) Schematic illustration of the synthesis of Pd-decorated Ti-MOF@TpTt hybrids. (B) Activity of $\mathrm{H}_{2}$ production from AB aqueous solution overPd@Ti-MOF@TpTt and Ti-MOF@TpTt under different conditions. (C) Proposed mechanism for AB hydrolysis catalyzed by Pd@Ti-MOF@TpTt. (D) Cycling results of AB hydrolysis under light irradiation using Pd@Ti-MOF@TpTt. Reproduced from Ref. $^{[86]}$ with permission from Wiley. 
Zhang et al. ${ }^{[88]}$ loaded AuPd nanoparticles upon super-small carbon nitride nanospheres (AuPd/CNS) to construct a Mott-Schottky photocatalyst and used it to catalyze $\mathrm{H}_{2}$ production from FA. It showed a turnover frequency of $1017.8 \mathrm{~h}^{-1}$ under visible-light illumination $(\lambda>420 \mathrm{~nm})$. The alloying, plasmonic and Mott-Schottky effects optimized the electronic structure of Pd in the AuPd/CNS composite, which accelerated the electrons transferred from the carbon nitride and Au to the active Pd sites, thus resulting in improved photoactivity.

\section{Photocatalytic $\mathrm{CO}_{2}$ conversion}

Basic principles of photocatalytic $\mathrm{CO}_{2}$ conversion

The overuse of fossil resources has led to excessive $\mathrm{CO}_{2}$ emissions, which have contributed to the greenhouse effect. There are already many technologies for collecting and sequestering $\mathrm{CO}_{2}$, such as scrubbing, mineral carbonation, geological injection and oceanic injection ${ }^{[8]}$. Nevertheless, these technologies are expensive and may cause the leakage of $\mathrm{CO}_{2}{ }^{[89,90]}$. Alternatively, $\mathrm{CO}_{2}$ can be considered as a low-cost, safe and abundant carbon source that can be converted into valuable energy fuels. This strategy could not only reduce $\mathrm{CO}_{2}$ emissions and alleviate the greenhouse effect, but also mitigate the energy crisis.

$\mathrm{CO}_{2}$ is highly thermodynamically stable and its $\mathrm{C}=\mathrm{O}$ bond energy $\left(750 \mathrm{~kJ} \cdot \mathrm{mol}^{-1}\right)$ is much larger than that of $\mathrm{C}-\mathrm{H}\left(411 \mathrm{~kJ} \cdot \mathrm{mol}^{-1}\right), \mathrm{C}-\mathrm{O}\left(327 \mathrm{~kJ} \cdot \mathrm{mol}^{-1}\right)$, and C-C $\left(336 \mathrm{~kJ} \cdot \mathrm{mol}^{-1}\right)$ single bonds ${ }^{[1,92]}$. Thus, the photocatalytic conversion of $\mathrm{CO}_{2}$ to hydrocarbons requires high energy input to activate the $\mathrm{C}=\mathrm{O}$ double bonds and convert them into $\mathrm{C}-\mathrm{H}$ single bonds. Photogenerated e with an appropriate reduction potential can supply a driving force for the reduction of $\mathrm{CO}_{2}$. Photocatalytic $\mathrm{CO}_{2}$ conversion takes place through a multi-step reaction pathway with the participation of $2,6,8,12,14$ or $18 \mathrm{e}^{-}$and $\mathrm{H}^{+}$[Figure 12] ${ }^{[93,94]}$. Various products, including $\mathrm{C}_{1}$ compounds (e.g., $\mathrm{CO}, \mathrm{CH}_{4}, \mathrm{HCOOH}, \mathrm{CH}_{3} \mathrm{OH}$ and $\mathrm{HCHO}$ ) and $\mathrm{C}_{2}$ molecules (e.g., $\mathrm{CH}_{2} \mathrm{CH}_{2}$, $\mathrm{C}_{2} \mathrm{H}_{5} \mathrm{OH}$ and $\left.\mathrm{CH}_{3} \mathrm{COOH}\right)^{[95]}$, can be generated. Some reactions related to photocatalytic $\mathrm{CO}_{2}$ conversion and the relevant reduction potentials $\left(E^{0}\right)$ are listed in Table $1^{[96,97]}$.

As shown in Table 1, a reduction potential of $-1.85 \mathrm{~V}$ is required for direct single-electron $\mathrm{CO}_{2}$ reduction ${ }^{[98]}$. So far, almost no photocatalysts have displayed sufficient ability to drive this single-electron transfer process. On the contrary, $\mathrm{H}^{+}$-assisted multi-electron $/ \mathrm{H}^{+}$reduction represents an alternative and more advantageous method.

\section{Recent advances in photocatalytic $\mathrm{CO}_{2}$ conversion}

Photocatalytic $\mathrm{CO}_{2}$ conversion with $\mathrm{H}_{2} \mathrm{O}$

The utilization of $\mathrm{H}_{2} \mathrm{O}$ as a reducing agent to photocatalytically convert $\mathrm{CO}_{2}$ is an intriguing process ${ }^{[99]}$ that involves multi-electron reactions [Table 1] ${ }^{[100,101]}$. As a result, various products, such as $\mathrm{CO}^{[102,103]}, \mathrm{CH}_{4}$ and $\mathrm{CH}_{3} \mathrm{OH}$, can be obtained. Taking $\mathrm{CO}$ production as an example, the photogenerated $h^{+}$oxidize $\mathrm{H}_{2} \mathrm{O}$ into $\mathrm{O}_{2}$ with the generation of $\mathrm{H}^{+}$(Equation 5), while the photogenerated e- reduce $\mathrm{CO}_{2}$ to $\mathrm{CH}_{4}$ via a two-electron reaction with two protons (Equation 6):

$$
\begin{aligned}
& \mathrm{H}_{2} \mathrm{O}+2 \mathrm{~h}^{+} \rightarrow 1 / 2 \mathrm{O}_{2}+2 \mathrm{H}^{+}(5) \\
& \mathrm{CO}_{2}+2 \mathrm{H}^{+}+2 \mathrm{e}^{-} \rightarrow \mathrm{CO}+\mathrm{H}_{2} \mathrm{O}(6)
\end{aligned}
$$

At present, photocatalytic $\mathrm{CO}_{2}$ conversion with $\mathrm{H}_{2} \mathrm{O}$ mainly involves two reaction systems ${ }^{[8]]}$. One is a liquid phase system, in which the $\mathrm{CO}_{2}$ conversion efficiency is largely limited due to the low solubility of $\mathrm{CO}_{2}$ ( $0.03 \mathrm{M}$ under ambient conditions) with the occurrence of competitive $\mathrm{H}_{2}$ production from $\mathrm{H}_{2} \mathrm{O}$. Thus, many efforts have been made to enhance the pressure of $\mathrm{CO}_{2}$ and increase the solubility of $\mathrm{CO}_{2}$ in alkaline 
Table 1. Electrochemical reactions involved in aqueous $\mathrm{CO}_{2}$ and proton reduction with their corresponding reduction potentials $E^{0}$ (V vs. NHE at pH 7)

\begin{tabular}{llll}
\hline Entry & Equation & Product & $E^{0}(\mathbf{V})$ \\
\hline 1 & $\mathrm{CO}_{2}+\mathrm{e}^{-} \rightarrow \mathrm{CO}_{2}^{-}$ & Carbonate anion radical & -1.85 \\
2 & $\mathrm{CO}_{2}+2 \mathrm{H}^{+}+2 \mathrm{e}^{-} \rightarrow \mathrm{HCOOH}$ & Formic acid & -0.61 \\
3 & $\mathrm{CO}_{2}+2 \mathrm{H}^{+}+2 \mathrm{e}^{-} \rightarrow \mathrm{CO}+\mathrm{H}_{2} \mathrm{O}$ & Carbon monoxide & -0.53 \\
4 & $\mathrm{CO}_{2}+4 \mathrm{H}^{+}+4 \mathrm{e}^{-} \rightarrow \mathrm{HCHO}+\mathrm{H}_{2} \mathrm{O}$ & Formaldehyde & -0.48 \\
5 & $\mathrm{CO}_{2}+4 \mathrm{H}^{+}+4 \mathrm{e}^{-} \rightarrow \mathrm{C}+2 \mathrm{H}_{2} \mathrm{O}$ & Carbon & -0.20 \\
6 & $\mathrm{CO}_{2}+6 \mathrm{H}^{+}+6 \mathrm{e}^{-} \rightarrow \mathrm{CH}_{3} \mathrm{OH}+\mathrm{H}_{2} \mathrm{O}$ & Methanol & -0.38 \\
7 & $\mathrm{CO}_{2}+8 \mathrm{H}^{+}+8 \mathrm{e}^{-} \rightarrow \mathrm{CH}_{4}+2 \mathrm{H}_{2} \mathrm{O}$ & Methane & -0.24 \\
8 & $2 \mathrm{CO}_{2}+12 \mathrm{H}^{+}+12 \mathrm{e}^{-} \rightarrow \mathrm{C}_{2} \mathrm{H}_{4}+4 \mathrm{H}_{2} \mathrm{O}$ & Ethylene & -0.34 \\
9 & $2 \mathrm{CO}_{2}+12 \mathrm{H}^{+}+12 \mathrm{e}^{-} \rightarrow \mathrm{C}_{2} \mathrm{H}_{5} \mathrm{OH}+3 \mathrm{H}_{2} \mathrm{O}$ & Ethanol & -0.33 \\
10 & $2 \mathrm{CO}_{2}+14 \mathrm{H}^{+}+14 \mathrm{e}^{-} \rightarrow \mathrm{C}_{2} \mathrm{H}_{6}+4 \mathrm{H}_{2} \mathrm{O}$ & Ethane & -0.27 \\
11 & $3 \mathrm{CO}_{2}+18 \mathrm{H}^{+}+18 \mathrm{e}^{-} \rightarrow \mathrm{C}_{3} \mathrm{H}_{7} \mathrm{OH}+5 \mathrm{H}_{2} \mathrm{O}$ & Propanol & -0.32 \\
12 & $2 \mathrm{H}^{+}+2 \mathrm{e}^{-} \rightarrow \mathrm{H}_{2}$ & Hydrogen & -0.42 \\
\hline
\end{tabular}

Reproduced from Ref. ${ }^{[96]}$ with permission from Wiley.

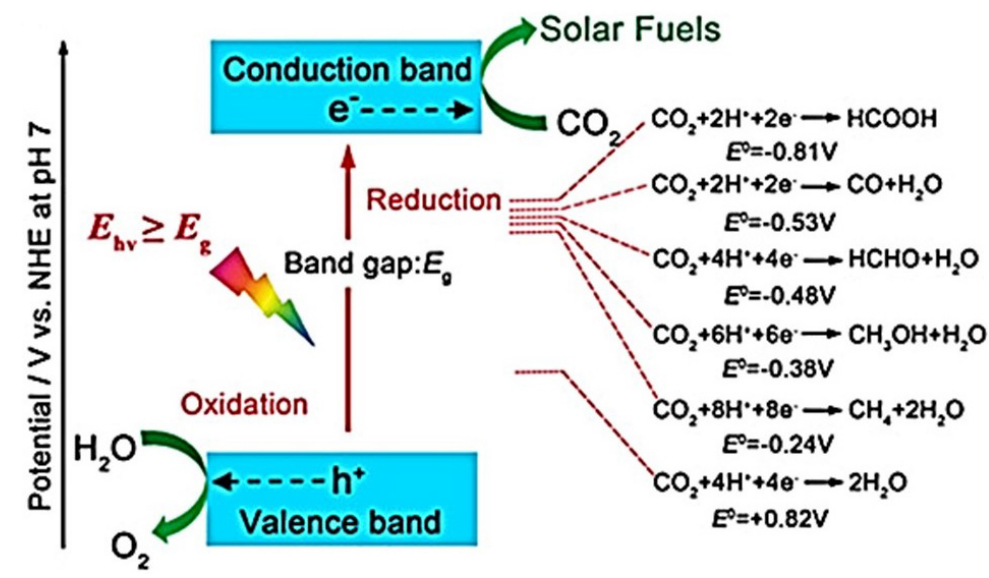

Figure 12. Schematic energy diagram for $\mathrm{CO}_{2}$ reduction and $\mathrm{H}_{2} \mathrm{O}$ oxidation on a semiconductor. Reproduced from Refs. ${ }^{[93,94]}$ with permission from Wiley.

systems ${ }^{[104]}$. The other is a gas-phase system that uses $\mathrm{CO}_{2}$ and $\mathrm{H}_{2} \mathrm{O}$ vapor and realizes a higher selectivity for $\mathrm{CO}_{2}$ reduction ${ }^{[105]}$. Multifarious photocatalysts have been explored for $\mathrm{CO}_{2}$ conversion using $\mathrm{H}_{2} \mathrm{O}$.

I. Metal oxide-based photocatalysts

Sorcar et al. ${ }^{[106]}$ reported bimetallic $\mathrm{Cu}-\mathrm{Pt}$ nanoparticle-sensitized blue titania $\left(\mathrm{TiO}_{2}\right)$ that generated large amounts of $\mathrm{CH}_{4}$ and $\mathrm{CH}_{3} \mathrm{CH}_{3}$ during artificial-sunlight-driven $\mathrm{CO}_{2}$ reduction with $\mathrm{H}_{2} \mathrm{O}$. Within $6 \mathrm{~h}$ of the reaction, $3.0 \mathrm{mmol} \cdot \mathrm{g}^{-1}$ of $\mathrm{CH}_{4}$ and $0.15 \mathrm{mmol} \cdot \mathrm{g}^{-1}$ of $\mathrm{CH}_{3} \mathrm{CH}_{3}$ were produced.

Li et al ${ }^{[107]}$ reported a cake-like porous $\mathrm{TiO}_{2}$ photocatalyst with the surface-localized doping of copper and cobalt. The doped $\mathrm{TiO}_{2}$ photocatalyst boosted the photoreduction of $\mathrm{CO}_{2}$ with water vapor. $1 \% \mathrm{Cu}$-doped $\mathrm{TiO}_{2}$ promoted the breaking of $\mathrm{C}=\mathrm{O}$ bonds. The production rates of $\mathrm{CO}$ and $\mathrm{CH}_{4}$ reached 45.31 and $42.35 \mu \mathrm{mol} \cdot \mathrm{h}^{-1}$, respectively, under simulated sunlight irradiation. This activity was further enhanced by incorporating trace cobalt. In addition to the enhanced performance in terms of the production of $\mathrm{CO}$ and $\mathrm{CH}_{4}$, the selectivity was also increased for the production of hydrocarbons $\left(\mathrm{C}_{2+}\right)$. The production rates of 
$\mathrm{C}_{2} \mathrm{H}_{6}$ and $\mathrm{C}_{3} \mathrm{H}_{8}$ reached 89.20 and $3.36 \mu \mathrm{mol} \cdot \mathrm{h}^{-1}$, respectively, over $0.02 \% \mathrm{Co}-1 \% \mathrm{Cu} / \mathrm{TiO}_{2}$. The incorporation of copper and cobalt ions realized efficient charge separation in the catalyst, resulting in the generation and enrichment of methyl radicals upon cobalt ions, which induced the production of $\mathrm{C}_{2+}$.

Atomically dispersed $\mathrm{Cu}$-supported mesoporous $\mathrm{TiO}_{2}\left(\mathrm{mTiO}_{2}\right)$ was used for the light-driven reduction of $\mathrm{CO}_{2}$ with $\mathrm{H}_{2} \mathrm{O}$ by Yuan et al. ${ }^{[108]}$. The authors revealed that the atom-dispersed $\mathrm{Cu}(\mathrm{II})$ underwent reduction to $\mathrm{Cu}(\mathrm{I})$ and finally to $\mathrm{Cu}(0)$, with the mixture of $\mathrm{Cu}(\mathrm{I})$ and $\mathrm{Cu}(0)$ proving effective for the production of $\mathrm{CH}_{4}$.

La- and Rh-doped $\mathrm{SrTiO}_{3}\left(\mathrm{SrTiO}_{3}: \mathrm{La}, \mathrm{Rh}\right)$ and Mo-doped $\mathrm{BiVO}_{4}\left(\mathrm{BiVO}_{4}: \mathrm{Mo}\right)$ light absorbers were integrated into a photocatalyst by Wang et al. ${ }^{[109]}$. This photocatalyst converted $\mathrm{CO}_{2}$ and $\mathrm{H}_{2} \mathrm{O}$ into formate ( $\left.\mathrm{HCOO}^{-}\right)$ and $\mathrm{O}_{2}$ and achieved a solar-to-HCOO conversion efficiency of $0.08 \%$ and a selectivity of $97 \%$.

Z-scheme type photocatalysts composed of $\mathrm{g}-\mathrm{C}_{3} \mathrm{~N}_{4}$ and $\mathrm{Au}$-loaded anatase $\mathrm{TiO}_{2}\left(\mathrm{~A}-\mathrm{TiO}_{2}\right)$ were fabricated by Wang et al. ${ }^{[110]}$. The surface heterojunction between the coexposed $\{001\}$ and $\{101\}$ facets in $\mathrm{A}-\mathrm{TiO}_{2}$ improved the separation efficiency of the photogenerated $\mathrm{e}^{-}-\mathrm{h}^{+}$pairs. The loaded Au gathered and transferred the stimulated electrons originating from $\mathrm{A}-\mathrm{TiO}_{2}$ to $g-\mathrm{C}_{3} \mathrm{~N}_{4}$. The g- $\mathrm{C}_{3} \mathrm{~N}_{4}$ component trapped the photogenerated $\mathrm{e}^{-}$and improved the adsorption ability of $\mathrm{CO}_{2}$. This catalyst exhibited high photoactivity of $\mathrm{CO}_{2}$ conversion under the illumination of visible light, with $\mathrm{CH}_{4}$ and $\mathrm{CO}$ formation rates of 37.4 and $21.7 \mu \mathrm{mol} \cdot \mathrm{g}^{-1} \cdot \mathrm{h}^{-1}$, respectively.

Wang et al. ${ }^{[11]}$ loaded $\mathrm{Ag}$ and Co dual cocatalysts on $\mathrm{Al}$-doped $\mathrm{SrTiO}_{3}$ [Figure 13], which brought about an enhanced CO production rate and a corresponding selectivity of $99.8 \%$ at $\lambda=300 \mathrm{~nm}$. The CO production rate of $52.7 \mu \mathrm{mol} \cdot \mathrm{h}^{-1}$ was 12 times that of the catalyst without Co cocatalysts $\left(4.7 \mu \mathrm{mol} \cdot \mathrm{h}^{-1}\right)$. The AQE for CO production was $\sim 0.03 \%$ at $\lambda=365 \mathrm{~nm}$, with a selectivity of $98.6 \%$ for CO production. The Ag and Co cocatalysts acted as reduction and oxidation sites to promote the production of $\mathrm{CO}$ and $\mathrm{O}_{2}$, respectively.

A $\mathrm{CuO}_{\mathrm{x}} @ \mathrm{p}-\mathrm{ZnO}$ photocatalyst with $\mathrm{CuO}_{\mathrm{x}}$ uniformly dispersed on polycrystalline $\mathrm{ZnO}$ was fabricated by Wang et al. ${ }^{[12]}$. This catalyst reduced $\mathrm{CO}_{2}$ to $\mathrm{C}_{2} \mathrm{H}_{4}$ with a selectivity of $32.9 \%$ and the production rate was $2.7 \mu \mathrm{mol} \cdot \mathrm{g}^{-1} \cdot \mathrm{h}^{-1}$ with $\mathrm{H}_{2} \mathrm{O}$ as a hole scavenger under illumination. During the reduction reaction, a unique $\mathrm{Cu}^{+}$site was formed on the surface of the $\mathrm{CuO}$ matrix and this surface $\mathrm{Cu}^{+}$site can anchor the generated $\mathrm{CO}$ and further stabilize the intermediate ${ }^{*} \mathrm{OC}-\mathrm{COH}$ of $\mathrm{C}$ - $\mathrm{C}$ coupling, which thus promoted the production of $\mathrm{C}_{2} \mathrm{H}_{4}$.

II. MOF- and COF-based photocatalysts

Lu et al. ${ }^{[113]}$ synthesized crystalline porphyrin tetrathiafulvalene COFs for $\mathrm{CO}_{2}$ conversion with $\mathrm{H}_{2} \mathrm{O}$ without the addition of photosensitizers, sacrificial agents or noble metal cocatalysts. The photogenerated e- were effectively transferred from tetrathiafulvalene to porphyrin, which led to the separation of $\mathrm{e}^{-}-\mathrm{h}^{+}$pairs for $\mathrm{CO}_{2}$ reduction and $\mathrm{H}_{2} \mathrm{O}$ oxidation. As a result, a photocatalytic $\mathrm{CO}$ production rate of $123.3 \mu \mathrm{mol} \cdot \mathrm{g}^{-1}$ with a selectivity of $100 \%$ was achieved, along with $\mathrm{H}_{2} \mathrm{O}$ oxidation to $\mathrm{O}_{2}$ under the illumination of visible light after $60 \mathrm{~h}$.

Fang et al. ${ }^{[114]}$ reported a pyrazolyl porphyrinic Ni-MOF (PCN-601) that integrated a light photosensitizer, active sites and large surface areas as an excellent and durable photocatalyst for visible-light-driven $\mathrm{CO}_{2}$ conversion with $\mathrm{H}_{2} \mathrm{O}$ vapor. The production rate of $\mathrm{CH}_{4}$ was much higher than that of similar MOFs based on carboxylate porphyrin. 
A

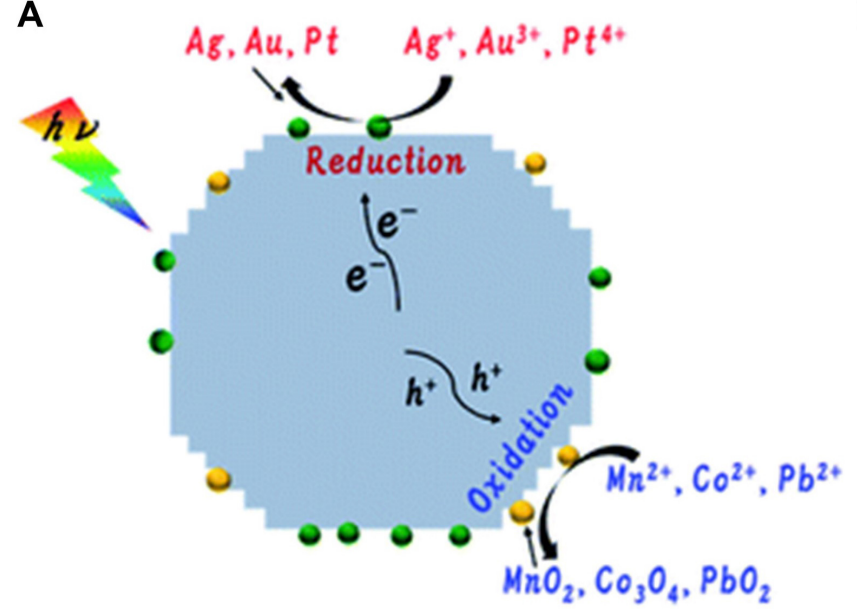

B

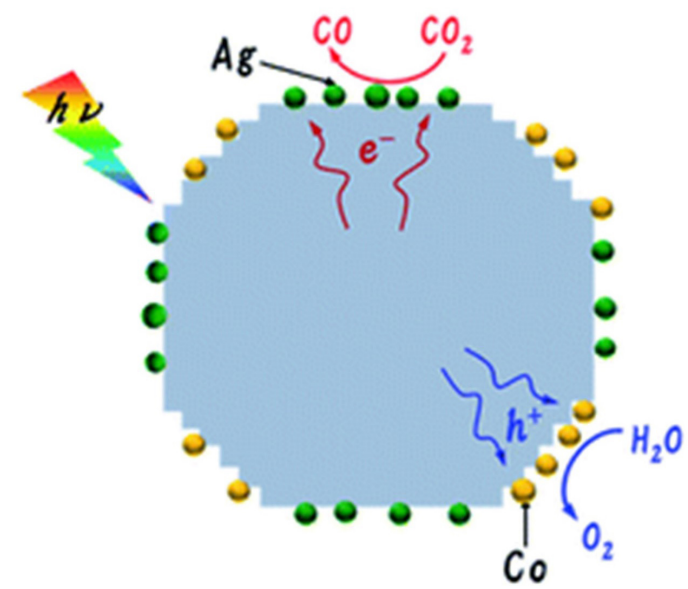

Figure 13. (A) Cocatalyst loading by the photodeposition method. (B) Photocatalytic $\mathrm{CO}_{2}$ conversion into $\mathrm{CO}$ over $\mathrm{Al}_{-} \mathrm{SrTiO}_{3}$ modified with $\mathrm{Ag}$ and $\mathrm{Co}$ using water as the reductant. Reproduced from Ref. ${ }^{[111]}$ with permission from the Royal Society of Chemistry.

Heterometallic $\mathrm{Fe}_{2} \mathrm{M}$ cluster-based MOF (NNU-31-M, M = Co, Ni and Zn) photocatalysts were fabricated by Dong et al. ${ }^{[115]}$. The overall conversion of $\mathrm{CO}_{2}$ and $\mathrm{H}_{2} \mathrm{O}$ into $\mathrm{HCOOH}$ and $\mathrm{O}_{2}$ was achieved in the absence of any sacrificial agent and photosensitizer when using these MOFs. Under visible-light irradiation, the heterometallic clusters and photosensitive ligands can generate separated $\mathrm{e}^{-} \mathrm{h}^{+}$pairs. The metal $\mathrm{M}$ accepts $\mathrm{e}^{-}$ to reduce $\mathrm{CO}_{2}$ and the metal $\mathrm{Fe}$ uses $\mathrm{h}^{+}$to oxidize $\mathrm{H}_{2} \mathrm{O}$. NNU-31-Zn showed the highest $\mathrm{HCOOH}$ production of $26.3 \mu \mathrm{mol} \cdot \mathrm{g}^{-1} \cdot \mathrm{h}^{-1}$ and a selectivity of $100 \%$.

Feng et al. ${ }^{[116]}$ synthesized a Zr-based mixed-linker MOF (mPT-MOF), consisting of Zr clusters and 4,4'(1,10-phenanthroline-3,8-diyl)dibenzoic acid and 2"-nitro-[1,1':4',1":4",1"'-quaterphenyl]-4,4"'-dicarboxylic acid linkers. $\mathrm{Cu}^{\mathrm{I}}$ photosensitizers (Cu-PSs) and molecular Re catalysts were incorporated in the MOF to form $\mathrm{mPT}-\mathrm{Cu} / \mathrm{Re}$ for photocatalytic $\mathrm{CO}_{2}$ reduction with water. Installation of the $\mathrm{Cu}-\mathrm{PSs}$ and molecular $\mathrm{Re}$ catalysts in the MOF promoted the transfer of multi-electrons to drive $\mathrm{CO}_{2}$ reduction under visible-light irradiation. A turnover number of 1328 was obtained, which was a 95 -fold improvement over the homogeneous counterparts.

Jiang et al. ${ }^{[117]}$ created "molecular compartments" inside MOF crystals by growing $\mathrm{TiO}_{2}$ inside different pores of a chromium (Cr) terephthalate-based MOF (MIL-101) and its derivatives. This allows for the synergy between the light-absorbing/electron-generating $\mathrm{TiO}_{2}$ units and the catalytic metal Cr clusters in the MOFs, thus facilitating the photoreduction of $\mathrm{CO}_{2}$ to $\mathrm{CO}$ and $\mathrm{CH}_{4}$ with the production of $\mathrm{O}_{2}$ from $\mathrm{H}_{2} \mathrm{O}$. An AQE of $11.3 \%$ for $\mathrm{CO}_{2}$ reduction at $\lambda=350 \mathrm{~nm}$ was obtained over $42 \%-\mathrm{TiO}_{2}$-in-MIL-101-Cr- $\mathrm{NO}_{2}(42 \%$ of $\mathrm{TiO}_{2}$ in a MIL-101 derivative).

Very recently, $\mathrm{Yu}$ et al. ${ }^{[118]}$ integrated $\mathrm{MoS}_{2}$ NSs into defective MOFs (d-UiO-66) to form Mo-O-Zr bimetallic sites between $\mathrm{UiO}-66$ and $\mathrm{MoS}_{2}$. The active interfaces were beneficial for the transfer of photogenerated charge carriers, resulting in enhanced activity. The d-UiO-66/MoS 2 composite facilitated visible-light-driven $\mathrm{CO}_{2}$ conversion with $\mathrm{H}_{2} \mathrm{O}$ to $\mathrm{CH}_{3} \mathrm{COOH}$. The production rate of $\mathrm{CH}_{3} \mathrm{COOH}$ was $39.0 \mu \mathrm{mol} \cdot \mathrm{g}^{-1} \cdot \mathrm{h}^{-1}$ and the selectivity was $94 \%$.

Wu et al.$^{[119]}$ reported Cu-based $\mathrm{MOF}, \mathrm{Cu}_{3}(\mathrm{BTC})_{2}\left(\mathrm{BTC}=1,3,5\right.$-benzene tricarboxylate), encapsulated $\mathrm{Cu}_{2} \mathrm{O}$ nanowires for the photoreduction of $\mathrm{CO}_{2}$ to $\mathrm{CH}_{4}$ with water vapor. Such a MOF not only inhibits the water 
vapor-induced corrosion of $\mathrm{Cu}_{2} \mathrm{O}$ but also facilitates $\mathrm{CO}_{2}$ uptake and charge separation [direct transfer of photogenerated electrons from the $\mathrm{CB}$ of $\mathrm{Cu}_{2} \mathrm{O}$ to the $\mathrm{LUMO}$ level of non-excited $\left.\mathrm{Cu}_{3}(\mathrm{BTC})_{2}\right]$, thus leading to a 1.9-fold higher photoactivity of $\mathrm{CO}_{2}$ reduction into $\mathrm{CH}_{4}$, compared to that of pure $\mathrm{Cu}_{2} \mathrm{O}$.

III. Nitride-based photocatalysts

Li et al. ${ }^{[120]}$ incorporated the heteroatom B-Co dimer into a porous $\mathrm{C}_{2} \mathrm{~N}$ to form B-Co@ $\mathrm{C}_{2} \mathrm{~N}$, which was used for the photoreduction of $\mathrm{CO}_{2}$ to $\mathrm{C}_{2} \mathrm{H}_{6}$. The combination of $\mathrm{B}$ and Co regulated the $3 \mathrm{~d}$ orbital of the Co atoms to a lower energy level, which impairs the $\mathrm{CO}$ adsorption strength in comparison with Co-Co@ $\mathrm{C}_{2} \mathrm{~N}$ and results in a low energy barrier of $\sim 0.61 \mathrm{eV}$ for $\mathrm{C}-\mathrm{C}$ coupling. The $\mathrm{H}_{2}$ production reaction was inhibited owing to the strong adsorption of the ${ }^{*} \mathrm{CO}_{2} /{ }^{*} \mathrm{COOH}$ intermediates. Furthermore, the light absorbance of BCo@ $\mathrm{C}_{2} \mathrm{~N}$ in the visible and infrared light regions was improved in comparison with that on pure $\mathrm{C}_{2} \mathrm{~N}$.

$\mathrm{A} \mathrm{Au} / \mathrm{p}-\mathrm{GaN}$ photocatalyst with a plasmonic heterostructure realized the photoreduction of gas-phase $\mathrm{CO}_{2}$ to $\mathrm{CO}$ with water oxidation under solar illumination ${ }^{[121]}$. This heterostructure photocatalyst was composed of metal/insulator/semiconductor components with an $\mathrm{Al}_{2} \mathrm{O}_{3}$ layer between the metal nanoparticles and p$\mathrm{GaN}$, which contributed to the promotion of $\mathrm{CO}$ production.

IV. Other photocatalysts

Wang et al. ${ }^{[122]}$ fabricated a marigold-like SiC@ $\mathrm{MoS}_{2}$ photocatalyst with a unique Z-scheme structure to realize visible-light-driven $\mathrm{CO}_{2}$ conversion with water. The production rates of $\mathrm{CH}_{4}$ and $\mathrm{O}_{2}$ were 323 and $621 \mu \mathrm{L} \cdot \mathrm{g}^{-1} \cdot \mathrm{h}^{-1}$, respectively, with stability over five cycles of $40 \mathrm{~h}$.

Layered bismuth oxyhalides ( $\mathrm{BiOX}$, where $\mathrm{X}=\mathrm{F}, \mathrm{CI}, \mathrm{Br}$ and I) were used for the conversion of $\mathrm{CO}_{2}$ with $\mathrm{H}_{2} \mathrm{O}$ without adding photosensitizers or sacrificial agents ${ }^{[123]}$. The optimal $\mathrm{BiOBr}$ photocatalyst displayed $\mathrm{CO}$ and $\mathrm{CH}_{4}$ production rates of 21.6 and $1.2 \mu \mathrm{mol} \cdot \mathrm{g}^{-1} \cdot \mathrm{h}^{-1}$, respectively, under simulated sunlight irradiation.

SnS-SnS 2 heterostructured NS frameworks were grown on FTO substrates for the photoconversion of $\mathrm{CO}_{2}$ with $\mathrm{H}_{2} \mathrm{O}$ to $\mathrm{C}_{2}$ (acetaldehyde) and $\mathrm{C}_{3}$ (acetone) hydrocarbons ${ }^{[124]}$. The photoactivity of SnS-SnS ${ }_{2}$ was improved by increasing the fraction of $\mathrm{SnS}$ in the composite through the partial transformation of $\mathrm{SnS}_{2}$ to $\mathrm{SnS}$. SnS provides $\mathrm{CO}_{2}$ adsorption sites with lower activation energy, which is the rate-determining step for $\mathrm{CO}_{2}$ reduction. The Z-scheme charge transfer dynamic in the $\mathrm{SnS}-\mathrm{SnS}{ }_{2}$ catalyst drives the water oxidation on $\mathrm{SnS}_{2}$ and $\mathrm{CO}_{2}$ reduction on $\mathrm{SnS}$.

Photocatalytic $\mathrm{CO}_{2}$ conversion with $\mathrm{H}_{2}$

Photocatalytic $\mathrm{CO}_{2}$ conversion with $\mathrm{H}_{2}$ is a prospective method for $\mathrm{CO}_{2}$ reduction ${ }^{[125]}$. Light illumination can achieve a favorable rate and yield in eight-electron $\mathrm{CO}_{2}$ reduction with $\mathrm{H}_{2}^{[125,126]}$. The photogenerated $\mathrm{h}^{+}$in the active VB of the photocatalysts can react with $\mathrm{H}_{2}$ to produce $\mathrm{H}^{+}$. The produced $\mathrm{H}^{+}$and photogenerated $\mathrm{e}^{-}$can then convert $\mathrm{CO}_{2}$ into $\mathrm{CO}, \mathrm{CH}_{3} \mathrm{OH}$ and hydrocarbons (e.g., $\mathrm{CH}_{4}, \mathrm{C}_{2} \mathrm{H}_{4}, \mathrm{C}_{2} \mathrm{H}_{6}, \mathrm{C}_{3} \mathrm{H}_{6}$ and $\mathrm{C}_{3} \mathrm{H}_{8}$ ). Generally, $\mathrm{CH}_{4}$ or $\mathrm{CO}$ products are produced during photocatalytic $\mathrm{CO}_{2}$ conversion with $\mathrm{H}_{2}$ (Equations 7 and 8$)^{[89]}$.

$\mathrm{CO}_{2}+4 \mathrm{H}_{2} \rightarrow \mathrm{CH}_{4}+2 \mathrm{H}_{2} \mathrm{O}(7)$

$\mathrm{CO}_{2}+\mathrm{H}_{2} \rightarrow \mathrm{CO}+\mathrm{H}_{2} \mathrm{O}(8)$ 
In 2018, Jelle et al. ${ }^{[127]}$ fabricated highly dispersed nanostructured $\mathrm{RuO}_{2}$ catalysts loaded on 3D silicon photonic crystal supports for photocatalytic conversion of $\mathrm{CO}_{2}$ with $\mathrm{H}_{2}$ to $\mathrm{CH}_{4}$. A conversion rate of $4.4 \mathrm{mmol} \cdot \mathrm{g}_{\text {cat }}{ }^{-1} \cdot \mathrm{h}^{-1}$ was obtained under simulated solar irradiation. Silicon photonic crystals have unique light-harvesting characteristics in the entire spectrum of sunlight, coupled with its large surface area, resulting in the high $\mathrm{CH}_{4}$ production rate. In the same year, Wang et al. ${ }^{[128]}$ reported a defect-rich indium oxide $\left[\mathrm{In}_{2} \mathrm{O}_{3-\mathrm{x}}(\mathrm{OH})_{\mathrm{y}}\right]$ catalyst for the light-driven reduction of $\mathrm{CO}_{2}$ to $\mathrm{CH}_{3} \mathrm{OH}$. The $\mathrm{CH}_{3} \mathrm{OH}$ production rate and selectivity were $0.06 \mathrm{mmol} \cdot \mathrm{g}_{\text {cat }}{ }^{-1} \cdot \mathrm{h}^{-1}$ and $50 \%$, respectively, under simulated solar irradiation. Furthermore, in 2019, Yan et al..$^{[129]}$ used the rhombohedral polymorph of an indium sesquioxide photocatalyst for the photocatalytic reduction of $\mathrm{CO}_{2}$ to $\mathrm{CH}_{3} \mathrm{OH}$ and $\mathrm{CO}$. Notably, the rhombohedral polymorph exhibited higher photoactivity, superior stability and improved selectivity toward $\mathrm{CH}_{3} \mathrm{OH}$ over CO. In 2020, Yan et al. ${ }^{[130]}$ reported the isomorphic replacement of Lewis acid sites ( $\mathrm{In}^{3+}$ ions) in $\mathrm{In}_{2} \mathrm{O}_{3}$ with single-site $\mathrm{Bi}^{3+}$ ions to activate $\mathrm{CO}_{2}$ molecules. The as-formed $\mathrm{Bi}_{x} \mathrm{In}_{2-\mathrm{x}} \mathrm{O}_{3}$ photocatalyst showed a three orders of magnitude higher photoactivity than $\mathrm{In}_{2} \mathrm{O}_{3}$ itself and also exhibited significant photoactivity for $\mathrm{CH}_{3} \mathrm{OH}$ production. The enhanced photoactivity was attributed to the increased solar energy utilization rate and rapid separation and transfer of photogenerated charges.

Photocatalytic $\mathrm{CO}_{2}$ conversion with methane reforming

Methane $\left(\mathrm{CH}_{4}\right)$ is the second most common greenhouse gas ${ }^{[8]}$. The photocatalytic conversion of $\mathrm{CO}_{2}$ into syngas $\left(\mathrm{H}_{2}\right.$ and $\mathrm{CO}$ ) with $\mathrm{CH}_{4}$ reforming (Equation 9) is considered an effective method to decrease the environmental concentration of these two greenhouse gases. Generally, metal catalysts are highly effective for this reaction.

$\mathrm{CO}_{2}+\mathrm{CH}_{4} \rightarrow 2 \mathrm{H}_{2}+2 \mathrm{CO}(9)$

Huang et al. ${ }^{[131]}$ reported the conversion of $\mathrm{CO}_{2}$ by $\mathrm{CH}_{4}$ upon a Ni nanocrystal modified with silica clusters, which exhibited excellent durability for methane reforming ( $>700 \mathrm{~h}$ ). It achieved high $\mathrm{H}_{2}$ and $\mathrm{CO}$ production rates of 17.1 and $19.9 \mathrm{mmol} \cdot \mathrm{g}^{-1} \cdot \mathrm{min}^{-1}$, respectively, and excellent solar fuel efficiency of $12.5 \%$ under solar light irradiation. Even under IR irradiation $(\lambda>830 \mathrm{~nm})$, the solar-to-fuel efficiency remained at $3.1 \%$.

Zhou et al. ${ }^{[132]}$ loaded single-atom Ru sites on a Cu nanoparticle surface for photocatalytic $\mathrm{CO}_{2}$ conversion with $\mathrm{CH}_{4}$ reforming. A stability of $50 \mathrm{~h}$ and a selectivity of $>99 \%$ were achieved. Photoexcited hot carriers and single-atom Ru active sites led to the observed photoactivity.

Shoji et al. ${ }^{[133]}$ reported a $\mathrm{SrTiO}_{3}$-supported $\mathrm{Rh}$ catalyst for $\mathrm{UV}$-light-driven $\mathrm{CO}_{2}$ reduction with $\mathrm{CH}_{4}$ reforming, which cannot be realized by traditional thermal catalysis. The photogenerated $\mathrm{h}^{+}$and $\mathrm{e}^{-}$were employed for the oxidation of $\mathrm{CH}_{4}$ over $\mathrm{SrTiO}_{3}$ and the reduction of $\mathrm{CO}_{2}$ over Rh, respectively.

The photoassisted steam reforming and dry $\mathrm{CO}_{2}$ reforming of $\mathrm{CH}_{4}$ at room temperature with high selectivity of syngas were realized in gas-phase catalysis by Zhao et al ${ }^{[134]}$ for the first time. Bimetallic Rh-V oxide cluster anions $\left(\mathrm{Rh}_{2} \mathrm{VO}_{1-3}{ }^{-}\right)$were used as catalysts and both the oxidation of $\mathrm{CH}_{4}$ and the reduction of $\mathrm{H}_{2} \mathrm{O} / \mathrm{CO}_{2}$ were achieved effectively without light irradiation. The key step in controlling the syngas ( $\mathrm{CO}$ and $\mathrm{H}_{2}$ ) selectivity in this system was to photoinduce the reaction intermediates $\left(\mathrm{Rh}_{2} \mathrm{VO}_{2,3} \mathrm{CH}_{2}^{-}\right)$into electronically excited states [Figure 14] $]^{[134]}$. 


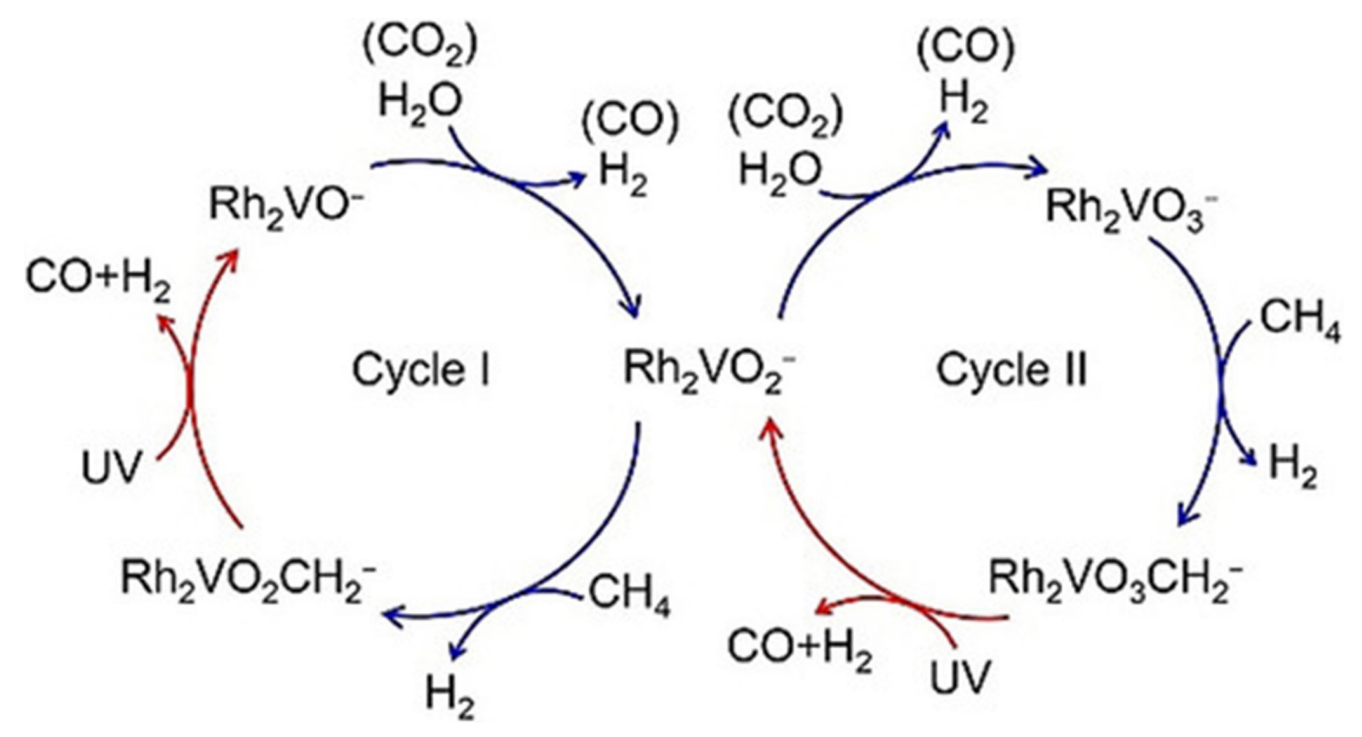

Figure 14. Two consecutive catalytic cycles of photoassisted steam reforming or dry $\mathrm{CO}_{2}$ reforming of methane to syngas mediated by $\mathrm{Rh}_{2} \mathrm{VO}_{1-3}$ " clusters. "UV" represents ultraviolet light $\left(\lambda=355 \mathrm{~nm}\right.$ photon). Reproduced from Ref. ${ }^{[134]}$ with permission from Wiley.

Photocatalytic $\mathrm{CO}_{2}$ conversion with other electron donors

TEOA, TEA, triisopropanolamine (TIPA) and sodium sulfite $\left(\mathrm{Na}_{2} \mathrm{SO}_{3}\right)$ have been reported as efficient electron donors for quenching the photogenerated $\mathrm{h}^{+}$during photocatalytic $\mathrm{CO}_{2}$ conversion.

I. TEOA as an electron donor

The growth and assembly of highly dispersed $\mathrm{UiO}-66-\mathrm{NH}_{2}$ nanocrystals upon graphene to form an active photocatalyst for $\mathrm{CO}_{2}$ conversion was reported by Wang et al. ${ }^{[135]}$. The as-synthesized UiO-66- $\mathrm{NH}_{2}$ /graphene photocatalyst displayed both high activity and selectivity for the visible-light-driven conversion of $\mathrm{CO}_{2}$ to $\mathrm{HCOOH}$ in the presence of TEOA. The photoreduction efficiency of UiO-66- $\mathrm{NH}_{2}$ /graphene for $\mathrm{CO}_{2}$ was $\sim 11$ times greater than that of UiO-66- $\mathrm{NH}_{2}$. The strong interaction between $\mathrm{UiO}-66-\mathrm{NH}_{2}$ and graphene effectively boosted the transfer of photogenerated $\mathrm{e}^{-}$and inhibited the separation of $\mathrm{UiO}-66-\mathrm{NH}_{2}$ from graphene, resulting in its high photoactivity and good cyclability.

Wang et al. ${ }^{[136]}$ confined highly dispersed nickel cobalt oxyphosphide nanoparticles (NiCoOP NPs) in multichannel hollow carbon fibers (MHCFs) to form a NiCoOP-NP@MHCF catalyst for photocatalytic $\mathrm{CO}_{2}$ reduction. The photoactivity was investigated in a tandem system, with $\left[\mathrm{Ru}(\mathrm{bpy})_{3}\right] \mathrm{Cl}_{2} \cdot 6 \mathrm{H}_{2} \mathrm{O}\left(\mathrm{bpy}=2^{\prime} 2-\right.$ bipyridine) used as a photosensitizer in the presence of TEOA. The as-formed catalyst exhibited considerable activity, offering a CO production rate of $166 \mu \mathrm{mol} \cdot \mathrm{mg}_{\text {cat }}{ }^{-1} \cdot \mathrm{h}^{-1}$.

Wang et al. ${ }^{[137]}$ decorated single-atom $\mathrm{Cu}$ sites upon $\mathrm{UiO}-66-\mathrm{NH}_{2}\left(\mathrm{Cu} \mathrm{SAs} / \mathrm{UiO}-66-\mathrm{NH}_{2}\right)$ to promote the photoreduction of $\mathrm{CO}_{2}$ to liquid fuels, with TEOA used as an electron donor. The decoration of single-atom $\mathrm{Cu}$ sites on $\mathrm{UiO}-66-\mathrm{NH}_{2}$ facilitated the conversion of $\mathrm{CO}_{2}$ to $\mathrm{CHO}^{*}$ and $\mathrm{CO}^{*}$ intermediates, resulting in good selectivity for $\mathrm{CH}_{3} \mathrm{OH}$ and $\mathrm{CH}_{3} \mathrm{CHOH}$. This photocatalyst realized $\mathrm{CH}_{3} \mathrm{OH}$ and $\mathrm{CH}_{3} \mathrm{CH}_{2} \mathrm{OH}$ production rates of 5.33 and $4.22 \mu \mathrm{mol} \cdot \mathrm{g}^{-1} \cdot \mathrm{h}^{-1}$, respectively, which were much higher compared to those of pure UiO-66- $\mathrm{NH}_{2}$ and $\mathrm{Cu} \mathrm{NP}-$ loaded UiO-66- $\mathrm{NH}_{2}$.

Yang et al ${ }^{[138]}$ demonstrated that a Ni-based metal-organic layer (MOL) exposing rich (100) crystal facets (Ni-MOL-100) showed much higher $\mathrm{CO}_{2}$-to-CO photoactivity than with rich (010) crystal facets exposed 
(Ni-MOL-010) and bulky Ni-MOF. Under Xe lamp irradiation (300 $\mathrm{mW}, \lambda>420 \mathrm{~nm}$ ), the catalytic activity in a $\left[\mathrm{Ru}(\mathrm{phen})_{3}\right]\left(\mathrm{PF}_{6}\right)_{2}, \mathrm{TEOA}, \mathrm{CH}_{3} \mathrm{CN}$ and $\mathrm{H}_{2} \mathrm{O}$ system reached 2.5- and 4.6-fold higher than those of NiMOL-010 and bulky Ni-MOF, respectively.

Li et al ${ }^{[139]}$ presented a bioinspired MOF with flexible $\mathrm{Cu}$ and $\mathrm{Ni}$ dual-metal-site pairs (DMSPs) that exhibited self-adaptive behavior to fit mutative $\mathrm{C} 1$ intermediates, realizing visible-light-driven $\mathrm{CO}_{2}$ reduction to $\mathrm{CH}_{4}$. The $\mathrm{Cu}$ and Ni DMSPs were incorporated into MOF-808 to form MOF-808-CuNi, leading to a production rate of $158.7 \mu \mathrm{mol} \cdot \mathrm{g}^{-1} \cdot \mathrm{h}^{-1}$ and a promoted $\mathrm{CH}_{4}$ selectivity of $97.5 \%$. Various $\mathrm{C} 1$ intermediates were stabilized by the flexible self-adaptive DMSPs in multistep reactions, resulting in the high selectivity of $\mathrm{CH}_{4}$.

II. TEA as an electron donor

Qi et al. ${ }^{[140]}$ proposed a single molecular cage of Ir(III) complex-decorated Zr-based metal-organic cages $\left(\mathrm{Ir}^{\mathrm{III}}-\mathrm{MOC}-\mathrm{NH}_{2}\right.$ ) for visible-light-driven $\mathrm{CO}_{2}$ reduction. The $\mathrm{Ir}^{\mathrm{III}}-\mathrm{MOC}-\mathrm{NH}_{2}$ catalyst had high photoactivity and selectivity for $\mathrm{CO}_{2}$-to-CO conversion in the presence of TEA. The selectivity was $99.5 \%$ and the turnover frequency reached $\sim 120 \mathrm{~h}^{-1}$, which was 3.4 times that of bulk $\mathrm{Ir}^{\mathrm{III}}-\mathrm{MOC}-\mathrm{NH}_{2}$. The AQE was $6.71 \%$.

III. TIPA as an electron donor

Liu et al. ${ }^{[141]}$ reported three functionalized polyoxo-titanium cluster-based photocatalysts for $\mathrm{CO}_{2}$ reduction, namely, $\mathrm{Ti}_{6}$ functionalized with phenylphosphonic acid and $\mathrm{Ti}_{8}$ and $\mathrm{Ti}_{6}$ functionalized with 1,1 -ferrocene dicarboxylic acid (Fcdc). The light absorption range of $\mathrm{Ti}_{8}-\mathrm{Fcdc}$ and $\mathrm{Ti}_{6}-\mathrm{Fcdc}$ was expanded to the visible light region. The introduction of Fcdc ligands in the photocatalysts boosted the transfer of electrons from the Fcdc ligands to the Ti-oxo nucleus. In particular, both $\mathrm{Ti}_{8}-\mathrm{Fcdc}$ and $\mathrm{Ti}_{6}-\mathrm{Fcdc}$ achieved the photocatalytic reduction of $\mathrm{CO}_{2}$ to $\mathrm{HCOO}^{-}$with high selectivity $(96.2 \%$ and $97.5 \%$, respectively) and photoactivity (170.30 and $350.00 \mu \mathrm{mol} \cdot \mathrm{g}^{-1} \cdot \mathrm{h}^{-1}$, respectively) under visible-light irradiation in the presence of TIPA.

IV. Sodium sulfite $\left(\mathrm{Na}_{2} \mathrm{SO}_{3}\right)$ as an electron donor

Zhu et al. ${ }^{[142]}$ prepared a $\mathrm{Cu} / \mathrm{Cu}^{+}$-modified $\mathrm{Ti}^{3+} / \mathrm{TiO}_{2}\left(\mathrm{Cu} / \mathrm{Cu}^{+} @ \mathrm{TiO}_{2}\right)$ photocatalyst for photocatalytic $\mathrm{CO}_{2}$ conversion under Xe lamp irradiation with $\mathrm{Na}_{2} \mathrm{SO}_{3}$ as an electron donor. The $\mathrm{Cu}^{+}-\mathrm{O}$ valences inside the $\mathrm{TiO}_{2}$ lattice promoted the transfer of carriers and the $\mathrm{Cu}$ on the surface of the catalyst as active sites promoted the reduction of $\mathrm{CO}_{2}$. The synergistic effect between $\mathrm{Cu}$ and $\mathrm{Cu}^{+}$ions increased the charge carrier density. All the photogenerated $\mathrm{e}^{-}$in the photocatalyst (100\%) were used for $\mathrm{CO}_{2}$ reduction.

\section{Photocatalytic $\mathrm{H}_{2} \mathrm{O}_{2}$ production}

Basic principles of photocatalytic $\mathrm{H}_{2} \mathrm{O}_{2}$ production

Since $\mathrm{H}_{2} \mathrm{O}_{2}$ was first synthesized in $1818^{[143]}$, it has captured more and more attention and has even been listed as one of the 100 most important chemicals ${ }^{[144]}$. As a green oxidant, $\mathrm{H}_{2} \mathrm{O}_{2}$ contains a $47.1 \%(\mathrm{w} / \mathrm{w})$ active oxygen content. Apart from $\mathrm{H}_{2} \mathrm{O}$ and $\mathrm{O}_{2}$, no other byproducts are generated during its reactions. As a result, $\mathrm{H}_{2} \mathrm{O}_{2}$ has been widely used in organic synthesis ${ }^{[145]}$, wastewater treatment and disinfection ${ }^{[146]}$ and the pulp and paper industry ${ }^{[147]}$. Moreover, $\mathrm{H}_{2} \mathrm{O}_{2}$ has also been employed in energy research as a onecompartment fuel cell ${ }^{[148]}$. The theoretical maximum output potential of $1.09 \mathrm{~V}$ in $\mathrm{H}_{2} \mathrm{O}_{2}$ fuel cells is comparable to that in conventional $\mathrm{H}_{2}$ fuel cells (1.23 V). However, unlike $\mathrm{H}_{2}, \mathrm{H}_{2} \mathrm{O}_{2}$ is completely soluble in water and easy to transport, which paves the way for it to become a desirable alternative energy carrier. These wide applications result in a huge demand for $\mathrm{H}_{2} \mathrm{O}_{2}$, with the global annual demand at $\sim 2.2 \mathrm{Mt}^{[149]}$.

At present, anthraquinone oxidation is the primary technology for industrial $\mathrm{H}_{2} \mathrm{O}_{2}$ production ${ }^{[143]}$. However, its industrial synthetic route is complicated, with high energy consumption and toxic byproducts. 
Alternative approaches are in development, such as the direct production of $\mathrm{H}_{2} \mathrm{O}_{2}$ from $\mathrm{O}_{2}$ and $\mathrm{H}_{2}$, but this method has a high cost, high energy intensity and a risk of explosions. Compared with these two methods, photocatalytic $\mathrm{H}_{2} \mathrm{O}_{2}$ production requires only earth-abundant $\mathrm{H}_{2} \mathrm{O}$ or other sacrificial agents and $\mathrm{O}_{2}$ as raw materials instead of dangerous $\mathrm{H}_{2} / \mathrm{O}_{2}$ mixtures and can be operated using semiconductors as catalysts under sunlight irradiation ${ }^{[150-153]}$. Moreover, no pollutants are produced during this process.

A detailed illustration of photocatalytic $\mathrm{H}_{2} \mathrm{O}_{2}$ production is presented in Figure $15^{[0]}$. The photogenerated $\mathrm{h}^{+}$ in the VB oxidizes $\mathrm{H}_{2} \mathrm{O}$ (or other sacrificial agents) to generate $\mathrm{O}_{2}$ (or other oxidation products) and protons $\left(\mathrm{H}^{+}\right.$, Equation 10), while the photogenerated $\mathrm{e}^{-}$in the $\mathrm{CB}$ reacts with the adsorbed $\mathrm{O}_{2}$ to generate $\mathrm{H}_{2} \mathrm{O}_{2}$. Specifically, $\mathrm{H}_{2} \mathrm{O}_{2}$ can be produced through either an indirect sequential two-step one-electron reduction route (Equations 11 and 12) or a direct one-step two-electron reduction route (Equation 13). In the indirect two-step one-electron reduction process, the one-electron reduction of $\mathrm{O}_{2}$ produces a superoxide radical $\left(\mathrm{O}_{2}^{-}\right.$, Equation 11), which then reacts with two $\mathrm{H}^{+}$ions and another electron to produce $\mathrm{H}_{2} \mathrm{O}_{2}$ (Equation 12). In the direct one-step two-electron reduction of $\mathrm{O}_{2}$ to $\mathrm{H}_{2} \mathrm{O}_{2}, \mathrm{O}_{2}$ reacts directly with two $\mathrm{H}^{+}$ions to form $\mathrm{H}_{2} \mathrm{O}_{2}$ via a two-electron reduction process (Equation 13). These two processes can both be described by the overall reaction in Equation 14.

$$
\begin{aligned}
& 2 \mathrm{H}_{2} \mathrm{O}+4 \mathrm{~h}^{+} \rightarrow \mathrm{O}_{2}+4 \mathrm{H}^{+}(10) \\
& \mathrm{O}_{2}+\mathrm{e}^{-} \rightarrow \mathrm{O}_{2}^{-}-(11) \\
& \mathrm{O}_{2}^{--}+2 \mathrm{H}^{+} \rightarrow \mathrm{H}_{2} \mathrm{O}_{2}(12) \\
& \mathrm{O}_{2}+2 \mathrm{H}^{+}+2 \mathrm{e}^{-} \rightarrow \mathrm{H}_{2} \mathrm{O}_{2}(13) \\
& 2 \mathrm{H}_{2} \mathrm{O}+\mathrm{O}_{2} \rightarrow 2 \mathrm{H}_{2} \mathrm{O}_{2}(14)
\end{aligned}
$$

Recent advances in photocatalytic $\mathrm{H}_{2} \mathrm{O}_{2}$ production

$\mathrm{H}_{2} \mathrm{O}_{2}$ production from $\mathrm{O}_{2}$ reduction

I. $\mathrm{C}_{3} \mathrm{~N}_{4}$-based photocatalysts

An interfacial Schottky junction consisting of $\mathrm{Ti}_{3} \mathrm{C}_{2}$ and porous $\mathrm{g}_{-} \mathrm{C}_{3} \mathrm{~N}_{4} \mathrm{NSs}$ was designed by Yang et al. ${ }^{[154]}$ for visible-light-driven $\mathrm{H}_{2} \mathrm{O}_{2}$ production. It displayed an $\mathrm{H}_{2} \mathrm{O}_{2}$ production rate of $2.20 \mu \mathrm{mol} \cdot \mathrm{L}^{-1} \cdot \mathrm{min}^{-1}$, which was $\sim 2.1$ times that of pure $\mathrm{g}-\mathrm{C}_{3} \mathrm{~N}_{4}$. The improved photoactivity was ascribed to the formed interfacial Schottky junction and built-in electric field, which boosted the spatial separation of photogenerated charges.

Wu et al. ${ }^{[155]}$ introduced alkali metal dopants and $\mathrm{N}$ vacancies in $\mathrm{C}_{3} \mathrm{~N}_{4}$. This extended the light absorption region, shortened the band gap from 2.85 to $2.63 \mathrm{eV}$ and suppressed the recombination of photogenerated charges. The synergistic effect of the dopants and defects brought about a photocatalytic $\mathrm{H}_{2} \mathrm{O}_{2}$ production rate of $10.2 \mathrm{mmol} \cdot \mathrm{g}^{-1} \cdot \mathrm{h}^{-1}$ using isopropanol as an electron donor, which was 89.5 times that of pure $\mathrm{C}_{3} \mathrm{~N}_{4}$. Similarly, Xie et al ${ }^{[156]}$ introduced two types of cooperative $\mathrm{N}$ vacancies, that is, $\mathrm{NH}_{x}$ and $\mathrm{N}_{2} \mathrm{C}$ vacancies, into polymeric carbon nitride. It delivered a 15 -fold improvement in $\mathrm{H}_{2} \mathrm{O}_{2}$ production with excellent stability using ethanol as a sacrificial hole scavenger. The AQE reached $26.78 \%$ and $11.86 \%$ at 340 and $420 \mathrm{~nm}$, respectively. The $\mathrm{NH}_{x}$ and $\mathrm{N}_{2} \mathrm{C}$ vacancies accelerated the photoexcited charge separation and assisted in activating $\mathrm{O}_{2}$ in the two-electron pathway, respectively. 


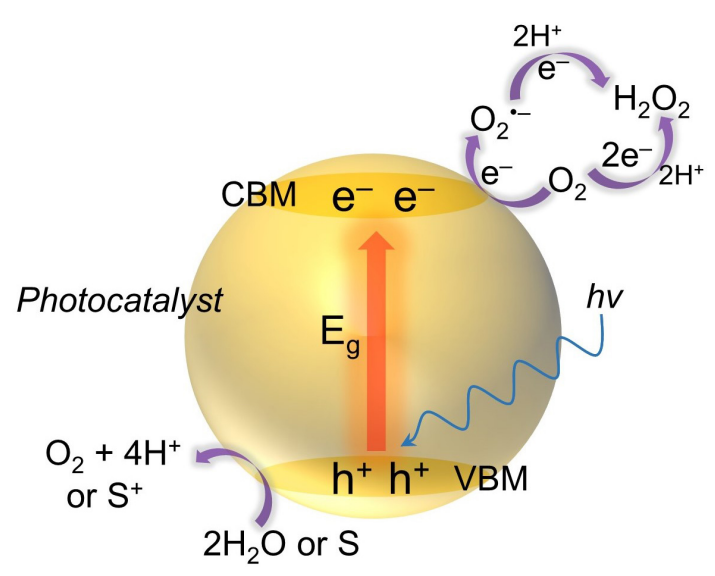

Figure 15. Illustration of photocatalytic $\mathrm{H}_{2} \mathrm{O}_{2}$ production. S represents the sacrificial agents. CBM: Conduction band minimum; VBM: valence band maximum.

Zhang et al. ${ }^{[157]}$ prepared an alkali and sulfur codoped polymeric carbon nitride and used it as a photocatalyst for $\mathrm{H}_{2} \mathrm{O}_{2}$ production from the $\mathrm{O}_{2}$ reduction reaction. The photocatalyst realized a $\mathrm{H}_{2} \mathrm{O}_{2}$ production rate on the millimolar level under the irradiation of visible light with an AQE of $100 \%$ and a selectivity of $96 \%$. Alkali and sulfur dopants in the photocatalyst boosted the separation of interlayer charges and the polarization of trapped electrons for the capture and reduction of $\mathrm{O}_{2}$, respectively.

Zhou et al. ${ }^{[158]}$ synthesized surface $\cdot \mathrm{OH}$ group-functionalized $\mathrm{g}-\mathrm{C}_{3} \mathrm{~N}_{4}$ nanotubes. The nanotube structures provided a high surface area and promoted mass transfer. The $\cdot \mathrm{OH}$ groups captured the photogenerated $\mathrm{h}^{+}$ to facilitate the separation of photogenerated charges and were also beneficial in suppressing the selfdecomposition of $\mathrm{H}_{2} \mathrm{O}_{2}$. Consequently, a $\mathrm{H}_{2} \mathrm{O}_{2}$ production rate of $240.36 \mu \mathrm{mol} \cdot \mathrm{g}^{-1} \cdot \mathrm{h}^{-1}$ was obtained.

Chen et al. ${ }^{[159]}$ prepared a $\mathrm{Na}^{+}$-doped cyano-rich g- $\mathrm{C}_{3} \mathrm{~N}_{4}$ photocatalyst. The porous $\mathrm{g}-\mathrm{C}_{3} \mathrm{~N}_{4}$ with $\mathrm{Na}^{+}$dopants and cyano groups simultaneously optimized the photoactivity and selectivity, showing $\mathrm{H}_{2} \mathrm{O}_{2}$ production rates of $7.01 \mathrm{mmol} \cdot \mathrm{h}^{-1}$ under visible light irradiation $(\lambda \geq 420 \mathrm{~nm})$ and $16.05 \mathrm{mmol} \cdot \mathrm{h}^{-1}$ under simulated sun conditions, respectively, and a selectivity of $93 \%$ from two-electron $\mathrm{O}_{2}$ reduction.

II. MOF- and COF-based photocatalysts

In 2018, Isaka et al. ${ }^{[160]}$ reported the visible-light-driven $\mathrm{H}_{2} \mathrm{O}_{2}$ production via two-electron $\mathrm{O}_{2}$ reduction using a MIL-125- $\mathrm{NH}_{2}$ photocatalyst with TEOA or benzyl alcohols as electron donors. Depositing NiO nanoparticles upon MIL-125- $\mathrm{NH}_{2}$ drastically improved its photoactivity. Furthermore, in 2021, Chen et al ${ }^{[161]}$ introduced a photosensitizer, 4,4,4', $4^{\prime \prime}$-(pyrene-1,3,6,8-tetrayl)tetrabenzoic acid (L2), into MIL-125 to form L2-functionalized MOFs (MIL-125-L2), which showed a $\mathrm{H}_{2} \mathrm{O}_{2}$ production rate of $1654 \mu \mathrm{mol} \cdot \mathrm{L}^{-1} \cdot \mathrm{h}^{-1}$ under the illumination of visible light $(\lambda>400 \mathrm{~nm})$ with TEOA as a sacrificial hole scavenger. This high photoactivity was ascribed to the visible light absorption of L2, which originated from the $\pi$-electron system in L2, making MIL-125-L2 a catalyst for visible light response.

In 2020, Krishnaraj et al. ${ }^{[162]}$ reported two new 2D COFs, in which the (diarylamino)benzene linkers formed a Kagome lattice and showed strong visible light absorption. The high crystallinity and large surface area of these COFs allowed for effective charge transfer and diffusion. The diarylamine (donor) unit in these COFs efficiently promoted the reduction of $\mathrm{O}_{2}$ to $\mathrm{H}_{2} \mathrm{O}_{2}$ using alcohols as sacrificial hole scavengers. 
$\mathrm{H}_{2} \mathrm{O}_{2}$ production from $\mathrm{O}_{2}$ reduction coupled with value-added organic chemical synthesis from organic matter oxidation

The production of $\mathrm{H}_{2} \mathrm{O}_{2}$ from $\mathrm{O}_{2}$ reduction coupled with the synthesis of value-added organic chemicals is attractive. On this basis, photogenerated carriers can be fully utilized during the process of photocatalytic renewable energy production, enhancing the processes of solar-to-chemical conversion efficiency.

I. Reduction of $\mathrm{O}_{2}$ coupled with oxidation of benzyl alcohol

Benzaldehyde is the simplest and most important aromatic aldehyde in industry. It has a wide range of applications in medicine, dyes, perfumes, resins and other industries ${ }^{[163]}$. The photocatalytic production of benzaldehyde from the oxidation of benzyl alcohol is a green process (Equation 15).

$\mathrm{O}_{2}+\mathrm{Ph}-\mathrm{CH}_{2} \mathrm{OH} \rightarrow \mathrm{H}_{2} \mathrm{O}_{2}+\mathrm{Ph}-\mathrm{CHO}(15)$

In 2019, Isaka et al. ${ }^{[164]}$ reported hydrophobic linker-alkylated MOFs, MIL-125-Rn ( $n=4$ and 7$)$, for the photocatalytic production of $\mathrm{H}_{2} \mathrm{O}_{2}$ in a two-phase system (water/benzyl alcohol) [Figure 16A and B]. The hydrophobization of MIL-125- $\mathrm{NH}_{2}$ separated it from the aqueous phase into the benzyl alcohol phase. In this two-phase system, $\mathrm{H}_{2} \mathrm{O}_{2}$ was produced in the water phase, while the MOF structure was more stable in the benzyl alcohol phase. This resulted in improved photoactivity [Figure 16C]. The as-prepared hydrophobic MOF also showed its feasible application in $\mathrm{H}_{2} \mathrm{O}_{2}$ production in various aqueous solutions, including extremely low $\mathrm{pH}$ and $\mathrm{NaCl}$ solutions [Figure 16D]. Furthermore, Kawase et al. ${ }^{[165]}$ reported another hydrophobic cluster-alkylated MIL-125- $\mathrm{NH}_{2}\left(\mathrm{OPA} / \mathrm{MIL}-125-\mathrm{NH}_{2}\right)$. Its Ti clusters were alkylated by octadecylphosphonic acid (OPA). The activity for $\mathrm{H}_{2} \mathrm{O}_{2}$ production was higher than that of the reported MIL-125-Rn in the abovementioned two-phase system $^{[164]}$. OPA modified the outermost surface of the MOFs while preserving the inner pores, which resulted in enhanced activity. In 2020, Chen et al. ${ }^{[166]}$ further synthesized a hydrophobic OPA/ $\mathrm{Zr}_{100-\mathrm{x}} \mathrm{Ti}_{\mathrm{x}}-\mathrm{MOF}(\mathrm{x}=$ 0, 5, 7.5 and 10), in which $\mathrm{Zr}$ clusters were alkylated with OPA, and applied it for $\mathrm{H}_{2} \mathrm{O}_{2}$ production in the above-mentioned two-phase system. The optimal OPA $/ \mathrm{Zr}_{92.5} \mathrm{Ti}_{7.5}$-MOF photocatalyst displayed a $\mathrm{H}_{2} \mathrm{O}_{2}$ production rate of $9.7 \mathrm{mmol} \cdot \mathrm{L}^{-1} \cdot \mathrm{h}^{-1}$ under the illumination of visible light $(\lambda>420 \mathrm{~nm})$, which was $\sim 4.5$ times that of the $\mathrm{Zr}_{100}-\mathrm{MOF} . \mathrm{H}_{2} \mathrm{O}_{2}$ production cycling tests indicated that it showed good stability.

II. Reduction of $\mathrm{O}_{2}$ coupled with oxidation of benzylamine

The synthesis of nitriles from the selective oxidation of amines plays a key role in both laboratory and industrial synthetic processes because nitrile is an important intermediate product for the synthesis of several fine chemicals, pharmaceuticals and agrochemicals ${ }^{[167-173]}$. The photocatalytic oxidation of amines to nitriles is an effective approach for the synthesis of nitriles under mild conditions (Equation 16).

$2 \mathrm{O}_{2}+\mathrm{Ph}-\mathrm{CH}_{2} \mathrm{NH}_{2} \rightarrow 2 \mathrm{H}_{2} \mathrm{O}_{2}+\mathrm{Ph}-\mathrm{CN}(16)$

In 2021, Tian et al. ${ }^{[174]}$ reported that benzylamine oxidation could be used as a half-reaction to couple with $\mathrm{H}_{2} \mathrm{O}_{2}$ production from $\mathrm{O}_{2}$ reduction (Equation 13) using defective $\mathrm{ZrS}_{3}$ nanobelts with disulfide $\left(\mathrm{S}_{2}{ }^{2-}\right)$ and sulfide anion $\left(\mathrm{S}^{2-}\right)$ vacancies [Figure 17A-F]. The defective $\mathrm{ZrS}_{3}$ nanobelts exhibited good photoactivity for $\mathrm{H}_{2} \mathrm{O}_{2}$ production and high selectivity (>99\%) for benzonitrile production from benzylamine oxidation [Figure $17 \mathrm{G}$ and $\mathrm{H}$ ]. The $\mathrm{S}_{2}{ }^{2-}$ vacancies facilitated the separation of $\mathrm{e}^{-}-\mathrm{h}^{+}$pairs and the $\mathrm{S}^{2-}$ vacancies improved the $\mathrm{e}^{-}$conduction, $\mathrm{h}^{+}$extraction and benzylamine oxidation kinetics. As a result, the photocatalyst displayed a $\mathrm{H}_{2} \mathrm{O}_{2}$ production rate of $78.1 \pm 1.5$ and a benzonitrile production rate $32.0 \pm 1.2 \mu \mathrm{mol} \cdot \mathrm{h}^{-1}$ under simulated sunlight irradiation. 
A
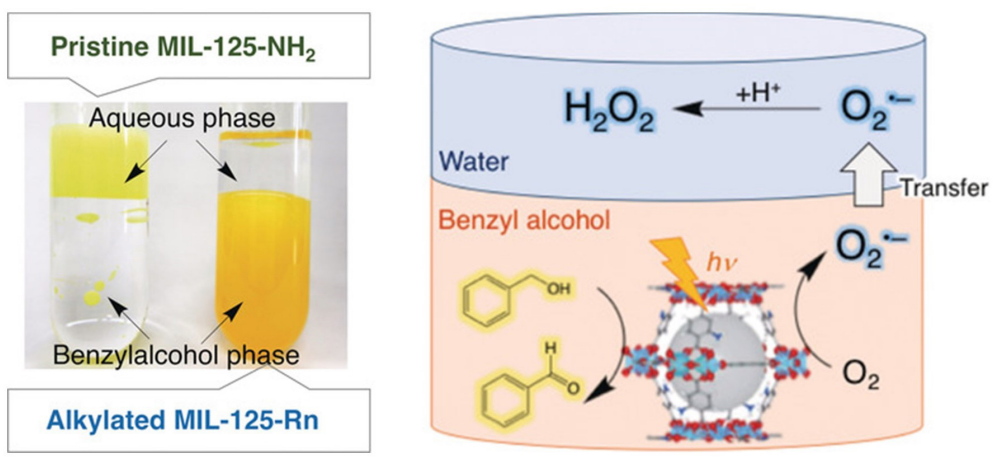

\section{B}<smiles>Nc1cc(C(=O)O)ccc1C(=O)O</smiles>

MIL-125- $\mathrm{NH}_{2}$<smiles>CC(C)Nc1cc(C(=O)[O-])ccc1C(=O)O</smiles>

MIL-125-R1<smiles>CCCCC(=O)Nc1cc(C(=O)[O-])ccc1C(=O)O</smiles>

MIL-125-R4

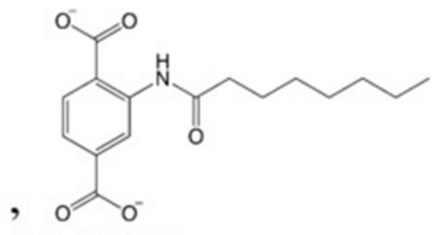

MIL-125-R7

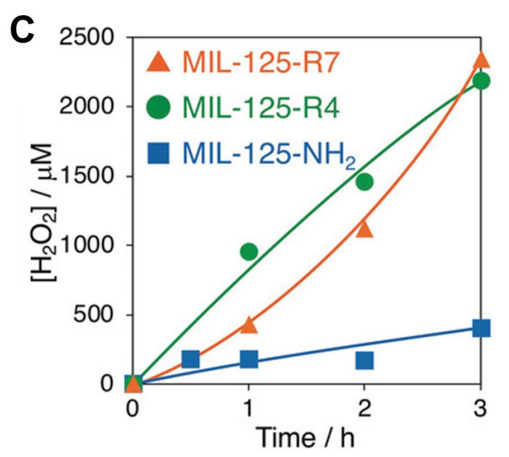

D

Benzylalcohol phase

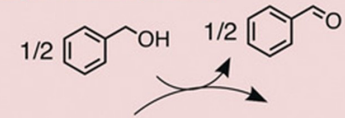

$\mathrm{Ti}_{8} \mathrm{O}_{8}(\mathrm{OH})_{4}{ }^{--}$-Linker+ $\mathrm{Ti}_{8} \mathrm{O}_{8}(\mathrm{OH})_{4}{ }^{--}$-Linker

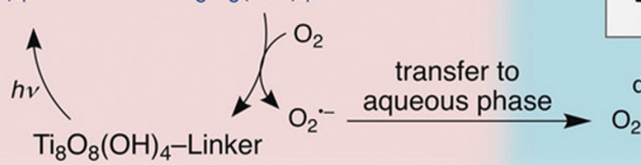

Aqueous phase

Accelerated by

$\left\{H^{+}\right.$(low pH)

$\left\{\mathrm{Na}^{+}(\mathrm{NaCl})\right.$

disproportionation

$\mathrm{O}_{2}^{*-}$

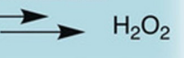

Figure 16. (A) Two-phase system (water/benzyl alcohol) for photocatalytic $\mathrm{H}_{2} \mathrm{O}_{2}$ production. (B) Alkylation reaction of linkers of MIL125- $\mathrm{NH}_{2}$ to form MIL-125-Rn ( $n=1,4$ or 7). (C) Photocatalytic activity and (D) related mechanism of $\mathrm{H}_{2} \mathrm{O}_{2}$ production in the two-phase system under photoirradiation $\left(\lambda>420 \mathrm{~nm}\right.$ ). Reproduced from Ref. ${ }^{[164]}$ with permission from Wiley.

$\mathrm{H}_{2} \mathrm{O}_{2}$ production from $\mathrm{O}_{2}$ and $\mathrm{H}_{2} \mathrm{O}$

To improve the eco-friendliness and sustainability of $\mathrm{H}_{2} \mathrm{O}_{2}$ production, earth-abundant water should be used instead of alcohols or other sacrificial agents (e.g., TEOA and TEA). The oxidation of $\mathrm{H}_{2} \mathrm{O}$ by h${ }^{+}$ produces $\mathrm{O}_{2}$ and $\mathrm{H}^{+}$, while the reduction of $\mathrm{O}_{2}$ by e $\mathrm{e}^{-}$produces $\mathrm{H}_{2} \mathrm{O}_{2}{ }^{[175]}$. On this basis, $\mathrm{H}_{2} \mathrm{O}_{2}$ can be synthesized from $\mathrm{H}_{2} \mathrm{O}$ and $\mathrm{O}_{2}$ with $100 \%$ efficiency.

Ma et al. ${ }^{[176]}$ fabricated a protonated $\mathrm{TiO}_{2}$ nanotube with carbon dots for $\mathrm{H}_{2} \mathrm{O}_{2}$ production under visible-light irradiation $(\lambda>420 \mathrm{~nm})$. It showed a $\mathrm{H}_{2} \mathrm{O}_{2}$ production rate of $3.42 \mathrm{mmol} \cdot \mathrm{g}_{\text {cat }}{ }^{-1} \cdot \mathrm{h}^{-1}$ in water, exceeding the values obtained on $\mathrm{TiO}_{2}$ catalysts with noble metals. The protons on the catalyst play a key role in $\mathrm{H}_{2} \mathrm{O}_{2}$ production by promoting the reduction of $\mathrm{O}_{2}$ to $\mathrm{H}_{2} \mathrm{O}_{2}$ and inhibiting $\mathrm{H}_{2} \mathrm{O}_{2}$ decomposition. This catalyst displayed a solar-to- $\mathrm{H}_{2} \mathrm{O}_{2}$ apparent energy conversion efficiency of $5.2 \%$.

Zeng et al. ${ }^{[177]}$ reported a $\mathrm{C}_{3} \mathrm{~N}_{4}$-grafted cationic polyethylenimine (PEI) molecule for the photocatalytic $\mathrm{H}_{2} \mathrm{O}_{2}$ production from $\mathrm{H}_{2} \mathrm{O}$ and $\mathrm{O}_{2}$. The $\mathrm{PEI} / \mathrm{C}_{3} \mathrm{~N}_{4}$ photocatalyst exhibited a $\mathrm{H}_{2} \mathrm{O}_{2}$ production rate of $208.1 \mu \mathrm{mol} \cdot \mathrm{g}^{-1} \cdot \mathrm{h}^{-1}$, which was 25 times that of the pure $\mathrm{C}_{3} \mathrm{~N}_{4}$. This was ascribed to the simultaneous improvement in charge separation and two-electron $\mathrm{O}_{2}$ reduction selectivity. 

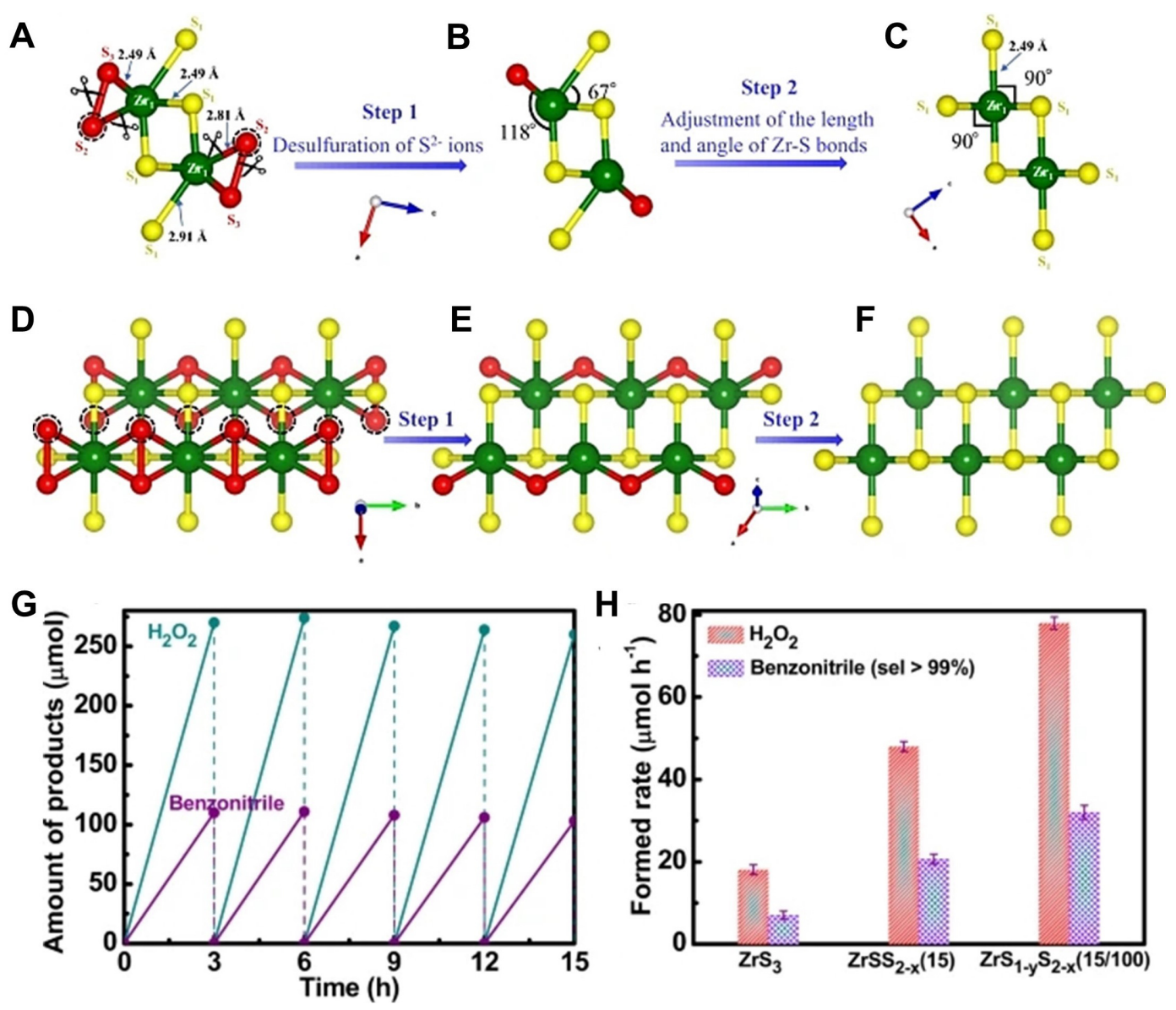

Figure 17. Transformation process of monoclinic $\mathrm{ZrS}_{3}$ into hexagonal $\mathrm{ZrS}_{2}$ from the [010] (A-C) and [001] (D-F) views. (A, D) Crystal structure of monolayer $\mathrm{ZrS}_{3}$ with a boundary of $1 \times 3 \times 1$. (B, E) Crystal structure of monolayer $\mathrm{ZrS}_{3}$ after desulfuration of $\mathrm{S}_{2}^{2-}$ ions. (C, F) Crystal structure of monolayer $\mathrm{ZrS}_{2}$ with a boundary of $1 \times 3 \times 1$. (G) Activity of $\mathrm{H}_{2} \mathrm{O}_{2}$ and benzonitrile production for a repeated photoreaction sequence with $\mathrm{ZrS}_{1-y} \mathrm{~S}_{2-x}(15 / 100)$ under simulated sunlight irradiation $\left[\mathrm{ZrSS}_{2-\mathrm{x}}\right.$ annealed for $\mathrm{X}$ time was denoted as $\mathrm{ZrSS}_{2-x}(X)$, and $\mathrm{ZrS}_{1-y} \mathrm{~S}_{2-x}$ annealed for $\mathrm{X}$ min and treated with $\mathrm{Y} \mathrm{mg} \mathrm{Li}$ was denoted as $\left.\mathrm{ZrS}_{1-y} \mathrm{~S}_{2-x}(\mathrm{X} / \mathrm{Y})\right]$. $(\mathrm{H}) \mathrm{H}_{2} \mathrm{O}_{2}$ and benzonitrile production rates. Reproduced from Ref. ${ }^{[174]}$ with permission from Springer Nature.

In 2020, Zhao et al. ${ }^{[178]}$ demonstrated a ZIF-8/ $\mathrm{C}_{3} \mathrm{~N}_{4}$ composite for visible-light-driven $\mathrm{H}_{2} \mathrm{O}_{2}$ production from $\mathrm{H}_{2} \mathrm{O}$ and $\mathrm{O}_{2}$. It displayed a $\mathrm{H}_{2} \mathrm{O}_{2}$ production rate of $2641 \mu \mathrm{mol} \cdot \mathrm{g}^{-1} \cdot \mathrm{h}^{-1}$ and an $\mathrm{AQE}$ of $19.57 \%$. In 2021 , Zhao et al. ${ }^{[179]}$ constructed a $\mathrm{C}_{3} \mathrm{~N}_{4}$-assisted $\mathrm{Ni}_{3}(\mathrm{HHTP})_{2}$ (Ni-CAT) photocatalyst that could catalyze the production of $\mathrm{H}_{2} \mathrm{O}_{2}$ from $\mathrm{H}_{2} \mathrm{O}$ and $\mathrm{O}_{2}$ under visible-light illumination. In this case, the Ni-CAT photocatalyst was the main active component for the reduction of $\mathrm{O}_{2}$, while $\mathrm{C}_{3} \mathrm{~N}_{4}$-assisted $\mathrm{Ni}$-CAT suppressed the recombination of photogeneration charge carriers by providing electrons. Furthermore, Wu et al ${ }^{[180]}$ fabricated a metal-free photocatalyst composed of carbon dots, organic dye molecules, procyanidins and 4-methoxybenzaldehyde for direct $\mathrm{H}_{2} \mathrm{O}_{2}$ production from seawater. This catalyst exhibited a visible-light-driven $\mathrm{H}_{2} \mathrm{O}_{2}$ production rate of $1776 \mu \mathrm{mol} \cdot \mathrm{g}^{-1} \cdot \mathrm{h}^{-1}$, which is $\sim 4.8$ times that of the pristine polymer.

In 2021, Teng et al. ${ }^{[181]}$ fabricated a Sb-single-atom-loaded $\mathrm{C}_{3} \mathrm{~N}_{4}$ photocatalyst for the production of $\mathrm{H}_{2} \mathrm{O}_{2}$ from water and $\mathrm{O}_{2}$ at $\lambda=420 \mathrm{~nm}$. An AQE of $17.6 \%$ and a conversion efficiency of solar energy to chemical energy of $0.61 \%$ for $\mathrm{H}_{2} \mathrm{O}_{2}$ production were achieved. The formed $\mu$-peroxide at the $\mathrm{Sb}$ sites promoted the two-electron $\mathrm{O}_{2}$ reduction reaction and highly concentrated photogenerated $\mathrm{h}^{+}$at its neighboring $\mathrm{N}$ atoms promoted water oxidation reaction, resulting in the excellent photocatalytic activity. Importantly, in the 
same year, Ye et al. ${ }^{[182]}$ reported a zinc polyphthalocyanine (ZnPPc)-decorated and B-doped carbon nitride (NBCN) hybrid (ZnPPc-NBCN) photocatalyst with a Z-scheme heterostructure. The high redox potential of the photocatalyst was stable during the reaction and the photocatalytic $\mathrm{H}_{2} \mathrm{O}_{2}$ production rate from pure water and open air reached $114 \mu \mathrm{mol} \cdot \mathrm{g}^{-1} \cdot \mathrm{h}^{-1}$.

\section{CONCLUSIONS AND OUTLOOK}

This review summarizes recent significant achievements in photocatalytic renewable energy production based on semiconductor and semiconductor-like driven photocatalysis, particularly for $\mathrm{H}_{2}$ production, $\mathrm{CO}_{2}$ reduction and $\mathrm{H}_{2} \mathrm{O}_{2}$ generation. To improve the photocatalytic performance, these research works have mainly focused on solving two scientific issues with photocatalysis, namely, light absorption and photogenerated charge separation. To improve the light utilization rate and/or boost the photogenerated charge separation, various strategies based on the design of photocatalysts have been employed: (1) doping of heteroelements/modification with single atoms; (2) creation of defects; (3) loading of dual cocatalysts; (4) construction of heterostructures (e.g., type II and Z-scheme); (5) fabrication of isotropic facets; and (6) generation of synergistic effects using multicomponents. Meanwhile, the improvement on the following reactions has also been considered: (1) for $\mathrm{H}_{2}$ production from overall water splitting: effective water oxidation half-reaction and separation of the $\mathrm{H}_{2}$ and $\mathrm{O}_{2}$ products; (2) for $\mathrm{CO}_{2}$ conversion: solubility and competitive $\mathrm{H}_{2}$ production in the liquid phase, activation of $\mathrm{CO}_{2}$ molecules and product selectivity; and (3) for $\mathrm{H}_{2} \mathrm{O}_{2}$ production from $\mathrm{O}_{2}$ (and water): the selectivity of two-electron $\mathrm{O}_{2}$ reduction, effective water oxidation half-reaction and self-decomposition of the formed $\mathrm{H}_{2} \mathrm{O}_{2}$.

The current semiconductor-based nanocomposite systems mainly consist of single inorganic semiconductor components or organic semiconductor-like polymers, such as MOFs and COFs. Although significant advances in photocatalytic renewable energy production have been achieved, these systems still exhibit some shortcomings, including the photocorrosion of sulfides and the instability of MOF and COF structures. For practical applications, it is necessary to bestow these traditional systems with new features or functionality in future research.

(1) Semiconductor-based bioinspired photocatalysis is a promising avenue for new photocatalysts with enhanced efficiency and stability, inspired by the abovementioned bioinspired HER-WOR-MOF photocatalyst ${ }^{[79]}$. Such a system can be constructed by the effective integration of the superiorities from traditional photocatalysis and biological components, that is, the combination of traditional inorganic semiconductors and highly selective bioenzymes.

(2) Photoelectrocatalysis that can efficiently combine photo- and electric energies represents an important direction, inspired by the aforementioned hydrogen farm project ${ }^{[83]}$. Such strategies can efficiently enhance the catalytic efficiency and easily separate the catalysts and products.

(3) Photothermal catalysis is another exciting direction. For example, the conversion of $\mathrm{CO}_{2}$ with $\mathrm{H}_{2}$ or $\mathrm{CH}_{4}$ via thermal catalysis requires high temperatures. Introducing photocatalysis can lower the temperature. Thus, the combination of photocatalysis and thermal catalysis is of great significance for future research.

\section{DECLARATIONS}

\section{Authors' contributions}

Wrote the manuscript: Chen X, Zhao J 
Reviewed the manuscript: Zhang D, Li G, Li H

\section{Availability of data and materials}

Not applicable.

\section{Financial support and sponsorship}

This work was supported by the National Key Research and Development Program of China (2020YFA0211004), and National Natural Science Foundation of China (22022608, 21876112, 21876113 , 92034301), "111" Innovation and Talent Recruitment Base on Photochemical and Energy Materials (No. D18020), Ministry of Education, and Shanghai Key Laboratory of Rare Earth Functional Materials, Shanghai Engineering Research Center of Green Energy Chemical Engineering (No. 18DZ2254200), Shanghai Frontiers Science Research Base of Biomimetic Catalysis and Shanghai government (18SG41).

\section{Conflicts of interest}

All authors declared that there are no conflicts of interest.

\section{Ethical approval and consent to participate}

Not applicable.

\section{Consent for publication}

Not applicable.

\section{Copyright}

(c) The Author(s) 2022.

\section{REFERENCES}

1. Martins F, Felgueiras C, Smitkova M, Caetano N. Analysis of fossil fuel energy consumption and environmental impacts in European countries. Energies 2019;12:964. DOI

2. Hisatomi T, Kubota J, Domen K. Recent advances in semiconductors for photocatalytic and photoelectrochemical water splitting. Chem Soc Rev 2014;43:7520-35. DOI PubMed

3. Wen M, Mori K, Kuwahara Y, An T, Yamashita H. Design and architecture of metal organic frameworks for visible light enhanced hydrogen production. Appl Catal B-Environ 2017;218:555-69. DOI

4. Cheng H, Wen M, Ma X, et al. Hydrogen doped metal oxide semiconductors with exceptional and tunable localized surface plasmon resonances. J Am Chem Soc 2016;138:9316-24. DOI PubMed

5. Bhatkhande DS, Pangarkar VG, Beenackers AA. Photocatalytic degradation for environmental applications - a review. $J$ Chem Technol Biotechnol 2002;77:102-16. DOI

6. Fuku K, Hayashi R, Takakura S, Kamegawa T, Mori K, Yamashita H. The synthesis of size- and color-controlled silver nanoparticles by using microwave heating and their enhanced catalytic activity by localized surface plasmon resonance. Angew Chem Int Ed Engl 2013;52:7446-50. DOI PubMed

7. Cheng H, Qian X, Kuwahara Y, Mori K, Yamashita H. A plasmonic molybdenum oxide hybrid with reversible tunability for visiblelight-enhanced catalytic reactions. Adv Mater 2015;27:4616-21. DOI PubMed

8. Kamegawa T, Shimizu Y, Yamashita H. Superhydrophobic surfaces with photocatalytic self-cleaning properties by nanocomposite coating of TiO(2) and polytetrafluoroethylene. Adv Mater 2012;24:3697-700. DOI PubMed

9. Hou H, Zeng X, Zhang X. Production of hydrogen peroxide by photocatalytic processes. Angew Chem Int Ed Engl 2020;59:1735676. DOI PubMed

10. Low J, Yu J, Jaroniec M, Wageh S, Al-Ghamdi AA. Heterojunction photocatalysts. Adv Mater 2017;29:1601694. DOI PubMed

11. Wang F, Li Q, Xu D. Recent progress in semiconductor-based nanocomposite photocatalysts for solar-to-chemical energy conversion. Adv Energy Mater 2017;7:1700529. DOI

12. Zhao W, Chen Z, Yang X, et al. Recent advances in photocatalytic hydrogen evolution with high-performance catalysts without precious metals. Renew Sustain Energy Rev 2020;132:110040. DOI

13. Wang Z, Li C, Domen K. Recent developments in heterogeneous photocatalysts for solar-driven overall water splitting. Chem Soc Rev 2019;48:2109-25. DOI PubMed

14. Ou M, Li J, Chen Y, et al. Formation of noble-metal-free 2D/2D Zn $\mathrm{Zn}_{\mathrm{m}} \mathrm{In}_{2} \mathrm{~S}_{\mathrm{m}+3}(\mathrm{~m}=1,2,3) / \mathrm{MX}$ ene Schottky heterojunction as an efficient photocatalyst for hydrogen evolution. Chem Eng $J$ 2021;424:130170. DOI

15. Ou M, Li J, Geng M, Wang J, Wan S, Zhong Q. Construction of Z-scheme photocatalyst containing $\mathrm{ZnIn}_{2} \mathrm{~S}_{4}, \mathrm{Co}_{3} \mathrm{O}_{4}$-photodeposited 
$\mathrm{BiVO}_{4}(110)$ facets and rGO electron mediator for overall water splitting into $\mathrm{H}_{2}$ and $\mathrm{O}_{2}$. Catal Lett 2021;151:2570-82. DOI

16. Wang L, Zhang J, Zhang Y, Yu H, Qu Y, Yu J. Inorganic metal-oxide photocatalyst for $\mathrm{H}_{2} \mathrm{O}_{2}$ production. Small 2021. DOI

17. Hejazi S, Mohajernia S, Osuagwu B, et al. On the controlled loading of single platinum atoms as a Co-catalyst on $\mathrm{TiO}_{2}$ anatase for optimized photocatalytic $\mathrm{H}_{2}$ generation. Adv Mater 2020;32:e1908505. DOI PubMed

18. Cho Y, Park B, Padhi DK, et al. Disordered-layer-mediated reverse metal-oxide interactions for enhanced photocatalytic water splitting. Nano Lett 2021;21:5247-53. DOI PubMed

19. Méndez-Medrano MG, Kowalska E, Ohtani B, et al. Heterojunction of $\mathrm{CuO}$ nanoclusters with $\mathrm{TiO}_{2}$ for photo-oxidation of organic compounds and for hydrogen production. J Chem Phys 2020;153:034705. DOI PubMed

20. Osuagwu B, Raza W, Tesler AB, Schmuki P. A drastic improvement in photocatalytic $\mathrm{H}_{2}$ production by $\mathrm{TiO}_{2}$ nanosheets grown directly on $\mathrm{Ta}_{2} \mathrm{O}_{5}$ substrates. Nanoscale 2021;13:12750-6. DOI PubMed

21. Sun L, Zhuang Y, Yuan Y, et al. Nitrogen-Doped carbon-coated CuO- $\mathrm{In}_{2} \mathrm{O}_{3}$ p-n heterojunction for remarkable photocatalytic hydrogen evolution. Adv Energy Mater 2019;9:1902839. DOI

22. Han L, Jing F, zhang J, et al. Environment friendly and remarkably efficient photocatalytic hydrogen evolution based on metal organic framework derived hexagonal/cubic In2O3 phase-junction. Appl Catal B-Environ 2021;282:119602. DOI

23. Guo L, Yang Z, Marcus K, et al. $\mathrm{MoS}_{2} / \mathrm{TiO}_{2}$ heterostructures as nonmetal plasmonic photocatalysts for highly efficient hydrogen evolution. Energy Environ Sci 2018;11:106-14. DOI

24. Wang W, Zhu S, Cao Y, et al. Edge-enriched ultrathin $\mathrm{MoS}_{2}$ embedded yolk-shell $\mathrm{TiO}_{2}$ with boosted charge transfer for superior photocatalytic $\mathrm{H}_{2}$ evolution. Adv Funct Mater 2019;29:1901958. DOI

25. Lai G, Lyu L, Huang Y, et al. Few-layer $\mathrm{WS}_{2}-\mathrm{MoS}_{2}$ in-plane heterostructures for efficient photocatalytic hydrogen evolution. Nano Energy 2021;81:105608. DOI

26. Xiao S, Dai W, Liu X, et al. Microwave-induced metal dissolution synthesis of core-shell copper nanowires/ZnS for visible light photocatalytic $\mathrm{H}_{2}$ evolution. Adv Energy Mater 2019;9:1900775. DOI

27. Wang S, Zhu B, Liu M, Zhang L, Yu J, Zhou M. Direct Z-scheme ZnO/CdS hierarchical photocatalyst for enhanced photocatalytic H2-production activity. Appl Catal B-Environ 2019;243:19-26. DOI

28. Dai B, Fang J, Yu Y, et al. Construction of infrared-light-responsive photoinduced carriers driver for enhanced photocatalytic hydrogen evolution. Adv Mater 2020;32:e1906361. DOI PubMed

29. Zhang P, Luan D, Lou XWD. Fabrication of CdS frame-in-cage particles for efficient photocatalytic hydrogen generation under visible-light irradiation. Adv Mater 2020;32:e2004561. DOI PubMed

30. Ong WJ, Tan LL, Ng YH, Yong ST, Chai SP. Graphitic carbon nitride (g-C3N4)-based photocatalysts for artificial photosynthesis and environmental remediation: are we a step closer to achieving sustainability? Chem Rev 2016;116:7159-329. DOI PubMed

31. Ismael M. A review on graphitic carbon nitride ( $\mathrm{g}-\mathrm{C} 3 \mathrm{~N} 4)$ based nanocomposites: Synthesis, categories, and their application in photocatalysis. $J$ Alloys Compd 2020;846:156446. DOI

32. Gong Y, Li M, Wang Y. Carbon nitride in energy conversion and storage: recent advances and future prospects. ChemSusChem 2015;8:931-46. DOI PubMed

33. Wang X, Blechert S, Antonietti M. Polymeric graphitic carbon nitride for heterogeneous photocatalysis. ACS Catal 2012;2:1596-606. DOI

34. Zheng Y, Liu J, Liang J, Jaroniec M, Qiao SZ. Graphitic carbon nitride materials: controllable synthesis and applications in fuel cells and photocatalysis. Energy Environ Sci 2012;5:6717. DOI

35. Mo Z, Xu H, Chen Z, et al. Construction of $\mathrm{MnO}_{2} /$ Monolayer $\mathrm{g}-\mathrm{C}_{3} \mathrm{~N}_{4}$ with $\mathrm{Mn}$ vacancies for Z-scheme overall water splitting. Appl Catal B-Environ 2019;241:452-60. DOI

36. Wang $\mathrm{Y}, \mathrm{Xu} \mathrm{W}$, Zhang $\mathrm{Y}$, et al. Introducing spin polarization into atomically thin $2 \mathrm{D}$ carbon nitride sheets for greatly extended visible-light photocatalytic water splitting. Nano Energy 2021;83:105783. DOI

37. Xu Y, Fan M, Yang W, et al. Homogeneous carbon/potassium-incorporation strategy for synthesizing red polymeric carbon nitride capable of near-infrared photocatalytic $\mathrm{H}_{2}$ production. Adv Mater 2021;33:e2101455. DOI PubMed

38. Yamashita H, Mori K, Kuwahara Y, et al. Single-site and nano-confined photocatalysts designed in porous materials for environmental uses and solar fuels. Chem Soc Rev 2018;47:8072-96. DOI PubMed

39. Chen X, Xiao S, Wang H, et al. MOFs Conferred with transient metal centers for enhanced photocatalytic activity. Angew Chem Int Ed Engl 2020;59:17182-6. DOI PubMed

40. Chen X, Cai Y, Liang R, et al. NH2-UiO-66(Zr) with fast electron transfer routes for breaking down nitric oxide via photocatalysis. Appl Catal B-Environ 2020;267:118687. DOI

41. Wen M, Li G, Liu H, Chen J, An T, Yamashita H. Metal-organic framework-based nanomaterials for adsorption and photocatalytic degradation of gaseous pollutants: recent progress and challenges. Environ Sci : Nano 2019;6:1006-25. DOI

42. Wen M, Mori K, Kuwahara Y, Yamashita H. Plasmonic Au@Pd nanoparticles supported on a basic metal-organic framework: synergic boosting of $\mathrm{H}_{2}$ production from formic acid. ACS Energy Lett 2017;2:1-7. DOI

43. Xiao JD, Han L, Luo J, Yu SH, Jiang HL. Integration of plasmonic effects and Schottky junctions into metal-organic framework composites: steering charge flow for enhanced visible-light photocatalysis. Angew Chem Int Ed Engl 2018;57:1103-7. DOI PubMed

44. Dong D, Yan C, Huang J, et al. An electron-donating strategy to guide the construction of MOF photocatalysts toward co-catalystfree highly efficient photocatalytic $\mathrm{H}_{2}$ evolution. J Mater Chem A 2019;7:24180-5. DOI

45. Sun K, Liu M, Pei J, et al. Incorporating transition-metal phosphides into metal-organic frameworks for enhanced photocatalysis. Angew Chem Int Ed Engl 2020;59:22749-55. DOI PubMed

46. Meng X, Sheng J, Tang H, Sun X, Dong H, Zhang F. Metal-organic framework as nanoreactors to co-incorporate carbon nanodots 
and CdS quantum dots into the pores for improved $\mathrm{H} 2$ evolution without noble-metal cocatalyst. Appl Catal B-Environ 2019;244:340-6. DOI

47. Lin C, Han C, Zhang $\mathrm{H}$, et al. Porphyrin-based metal-organic frameworks for efficient photocatalytic $\mathrm{H}_{2}$ production under visiblelight irradiation. Inorg Chem 2021;60:3988-95. DOI PubMed

48. Lyle SJ, Waller PJ, Yaghi OM. Covalent organic frameworks: organic chemistry extended into two and three dimensions. Trends Chem 2019;1:172-84. DOI

49. Geng K, He T, Liu R, et al. Covalent organic frameworks: design, synthesis, and functions. Chem Rev 2020;120:8814-933. DOI PubMed

50. Segura JL, Mancheño MJ, Zamora F. Covalent organic frameworks based on Schiff-base chemistry: synthesis, properties and potential applications. Chem Soc Rev 2016;45:5635-71. DOI PubMed

51. Gao C, Li J, Yin S, et al. Isostructural three-dimensional covalent organic frameworks. Angew Chem Int Ed Engl 2019;58:9770-5. DOI PubMed

52. Jiang L, Tian Y, Sun T, et al. A Crystalline polyimide porous organic framework for selective adsorption of acetylene over ethylene. J Am Chem Soc 2018;140:15724-30. DOI PubMed

53. Li LH, Feng XL, Cui XH, Ma YX, Ding SY, Wang W. Salen-based covalent organic framework. J Am Chem Soc 2017;139:6042-5. DOI PubMed

54. Yan S, Guan X, Li H, et al. Three-dimensional Salphen-based covalent-organic frameworks as catalytic antioxidants. J Am Chem Soc 2019;141:2920-4. DOI PubMed

55. Lin G, Ding H, Yuan D, Wang B, Wang C. A pyrene-based, fluorescent three-dimensional covalent organic framework. J Am Chem Soc 2016;138:3302-5. DOI PubMed

56. Wang P, Zhou F, Zhang C, et al. Ultrathin two-dimensional covalent organic framework nanoprobe for interference-resistant twophoton fluorescence bioimaging. Chem Sci 2018;9:8402-8. DOI PubMed PMC

57. Das G, Biswal BP, Kandambeth S, et al. Chemical sensing in two dimensional porous covalent organic nanosheets. Chem Sci 2015;6:3931-9. DOI PubMed PMC

58. Ding H, Li J, Xie G, et al. An AIEgen-based 3D covalent organic framework for white light-emitting diodes. Nat Commun 2018;9:5234. DOI PubMed PMC

59. Bessinger D, Ascherl L, Auras F, Bein T. Spectrally switchable photodetection with near-infrared-absorbing covalent organic frameworks. J Am Chem Soc 2017;139:12035-42. DOI PubMed PMC

60. Wang S, Wang Q, Shao P, et al. Exfoliation of covalent organic frameworks into few-layer redox-active nanosheets as cathode materials for lithium-ion batteries. J Am Chem Soc 2017;139:4258-61. DOI PubMed

61. Du Y, Yang H, Whiteley JM, et al. Ionic covalent organic frameworks with spiroborate linkage. Angew Chem Int Ed Engl 2016;55:1737-41. DOI PubMed

62. Mulzer CR, Shen L, Bisbey RP, et al. Superior charge storage and power density of a conducting polymer-modified covalent organic framework. ACS Cent Sci 2016;2:667-73. DOI PubMed PMC

63. Xie J, Shevlin SA, Ruan Q, et al. Efficient visible light-driven water oxidation and proton reduction by an ordered covalent triazinebased framework. Energy Environ Sci 2018;11:1617-24. DOI

64. Chen R, Wang Y, Ma Y, et al. Rational design of isostructural 2D porphyrin-based covalent organic frameworks for tunable photocatalytic hydrogen evolution. Nat Commun 2021;12:1354. DOI PubMed PMC

65. Zhou T, Wang L, Huang X, et al. PEG-stabilized coaxial stacking of two-dimensional covalent organic frameworks for enhanced photocatalytic hydrogen evolution. Nat Commun 2021;12:3934. DOI PubMed PMC

66. Yang J, Acharjya A, Ye MY, et al. Protonated imine-linked covalent organic frameworks for photocatalytic hydrogen evolution. Angew Chem Int Ed Engl 2021;60:19797-803. DOI PubMed PMC

67. Cheng Z, Qi W, Pang CH, et al. Recent advances in transition metal nitride-based materials for photocatalytic applications. Adv Funct Materials 2021;31:2100553. DOI

68. Xiao J, Vequizo JJM, Hisatomi T, et al. Simultaneously tuning the defects and surface properties of $\mathrm{Ta}_{3} \mathrm{~N}_{5}$ nanoparticles by Mg-Zr codoping for significantly accelerated photocatalytic $\mathrm{H}_{2}$ evolution. J Am Chem Soc 2021;143:10059-64. DOI PubMed

69. Wang Z, Luo Y, Hisatomi T, et al. Sequential cocatalyst decoration on $\mathrm{BaTaO}_{2} \mathrm{~N}$ towards highly-active Z-scheme water splitting. Nat Commun 2021;12:1005. DOI PubMed PMC

70. Wang Y, Zhao J, Chen Z, et al. Construction of Z-scheme $\mathrm{MoSe}_{2} / \mathrm{CdSe}$ hollow nanostructure with enhanced full spectrum photocatalytic activity. Appl Catal B-Environ 2019;244:76-86. DOI

71. Zhang G, Wang X. Oxysulfide semiconductors for photocatalytic overall water splitting with visible light. Angew Chem Int Ed Engl 2019;58:15580-2. DOI PubMed

72. Pan R, Hu M, Liu J, et al. Two-dimensional all-in-one sulfide monolayers driving photocatalytic overall water splitting. Nano Lett 2021;21:6228-36. DOI PubMed

73. Chen X, Shi R, Chen Q, et al. Three-dimensional porous $\mathrm{g}_{-} \mathrm{C}_{3} \mathrm{~N}_{4}$ for highly efficient photocatalytic overall water splitting. Nano Energy 2019;59:644-50. DOI

74. Lin Y, Su W, Wang X, Fu X, Wang X. LaOCl-coupled polymeric carbon nitride for overall water splitting through a one-photon excitation pathway. Angew Chem Int Ed Engl 2020;59:20919-23. DOI PubMed

75. Chen X, Wang J, Chai Y, Zhang Z, Zhu Y. Efficient photocatalytic overall water splitting induced by the giant internal electric field of a g- $\mathrm{C}_{3} \mathrm{~N}_{4} / \mathrm{rGO} / \mathrm{PDIP} Z$-scheme heterojunction. Adv Mater 2021;33:e2007479. DOI

76. Wu C, Xue S, Qin Z, et al. Making g- $\mathrm{C}_{3} \mathrm{~N}_{4}$ ultra-thin nanosheets active for photocatalytic overall water splitting. Appl Catal B- 
Environ 2021;282:119557. DOI

77. Zhao D, Wang Y, Dong C, et al. Boron-doped nitrogen-deficient carbon nitride-based Z-scheme heterostructures for photocatalytic overall water splitting. Nat Energy 2021;6:388-97. DOI

78. Zhang J, Bai T, Huang H, et al. Metal-organic-framework-based photocatalysts optimized by spatially separated cocatalysts for overall water splitting. Adv Mater 2020;32:e2004747. DOI PubMed

79. $\mathrm{Hu} \mathrm{H}$, Wang Z, Cao L, et al. Metal-organic frameworks embedded in a liposome facilitate overall photocatalytic water splitting. Nat Chem 2021;13:358-66. DOI PubMed

80. Wang Y, Wu Y, Sun K, Mi Z. A quadruple-band metal-nitride nanowire artificial photosynthesis system for high efficiency photocatalytic overall solar water splitting. Mater Horiz 2019;6:1454-62. DOI

81. Pan Z, Zhang G, Wang X. Polymeric carbon nitride/reduced graphene oxide/ $\mathrm{Fe}_{2} \mathrm{O}_{3}$ : all-solid-state Z-scheme system for photocatalytic overall water splitting. Angew Chem Int Ed Engl 2019;58:7102-6. DOI

82. Oshima T, Nishioka S, Kikuchi Y, et al. An artificial Z-scheme constructed from dye-sensitized metal oxide nanosheets for visible light-driven overall water splitting. J Am Chem Soc 2020;142:8412-20. DOI PubMed

83. Zhao Y, Ding C, Zhu J, et al. A hydrogen farm strategy for scalable solar hydrogen production with particulate photocatalysts. Angew Chem Int Ed Engl 2020;59:9653-8. DOI PubMed

84. Takata T, Jiang J, Sakata Y, et al. Photocatalytic water splitting with a quantum efficiency of almost unity. Nature 2020;581:411-4. DOI PubMed

85. Zhang Z, Liu Y, Fang Y, et al. Near-infrared-plasmonic energy upconversion in a nonmetallic heterostructure for efficient $\mathrm{H}_{2}$ evolution from ammonia borane. Adv Sci (Weinh) 2018;5:1800748. DOI PubMed PMC

86. Zhang MY, Li JK, Wang R, Zhao SN, Zang SQ, Mak TCW. Construction of core-shell MOF@COF hybrids with controllable morphology adjustment of COF shell as a novel platform for photocatalytic cascade reactions. Adv Sci (Weinh) 2021;8:e2101884. DOI PubMed PMC

87. Cao S, Chen Y, Wang H, et al. Ultrasmall CoP nanoparticles as efficient cocatalysts for photocatalytic formic acid dehydrogenation. Joule 2018;2:549-57. DOI

88. Zhang S, Li M, Zhao J, et al. Plasmonic AuPd-based Mott-Schottky photocatalyst for synergistically enhanced hydrogen evolution from formic acid and aldehyde. Appl Catal B-Environ 2019;252:24-32. DOI

89. Wang C, Sun Z, Zheng Y, Hu YH. Recent progress in visible light photocatalytic conversion of carbon dioxide. J Mater Chem A 2019;7:865-87. DOI

90. Hu Y. Advances in $\mathrm{CO}_{2}$ conversion and utilization. Washington: American Chemical Society; 2010.

91. Mao J, Li K, Peng T. Recent advances in the photocatalytic $\mathrm{CO}_{2}$ reduction over semiconductors. Catal Sci Technol 2013;3:2481. DOI

92. Shi R, Waterhouse GI, Zhang T. Recent progress in photocatalytic $\mathrm{CO}_{2}$ reduction over perovskite oxides. Sol RRL 2017;1:1700126. DOI

93. Duan X, Xu J, Wei Z, et al. Metal-free carbon materials for $\mathrm{CO}_{2}$ electrochemical reduction. Adv Mater 2017;29:1701784. DOI PubMed

94. Leitner W. The coordination chemistry of carbon dioxide and its relevance for catalysis: a critical survey. Coord Chem Rev 1996;153:257-84. DOI

95. Zhang L, Zhao ZJ, Gong J. Nanostructured materials for heterogeneous electrocatalytic $\mathrm{CO}_{2}$ reduction and their related reaction mechanisms. Angew Chem Int Ed Engl 2017;56:11326-53. DOI PubMed

96. Shen H, Peppel T, Strunk J, Sun Z. Photocatalytic reduction of $\mathrm{CO}_{2}$ by metal-free-based materials: recent advances and future perspective. Sol RRL 2020;4:1900546. DOI

97. Sun Z, Talreja N, Tao H, et al. Catalysis of carbon dioxide photoreduction on nanosheets: fundamentals and challenges. Angew Chem Int Ed Engl 2018;57:7610-27. DOI PubMed

98. Habisreutinger SN, Schmidt-Mende L, Stolarczyk JK. Photocatalytic reduction of $\mathrm{CO}_{2}$ on $\mathrm{TiO}_{2}$ and other semiconductors. Angew Chem Int Ed Engl 2013;52:7372-408. DOI PubMed

99. Inoue T, Fujishima A, Konishi S, Honda K. Photoelectrocatalytic reduction of carbon dioxide in aqueous suspensions of semiconductor powders. Nature 1979;277:637-8. DOI

100. Morris AJ, Meyer GJ, Fujita E. Molecular approaches to the photocatalytic reduction of carbon dioxide for solar fuels. Acc Chem Res 2009;42:1983-94. DOI PubMed

101. Angamuthu R, Byers P, Lutz M, Spek AL, Bouwman E. Electrocatalytic $\mathrm{CO}_{2}$ conversion to oxalate by a copper complex. Science 2010;327:313-5. DOI PubMed

102. Li J, Shao W, Geng M, Wan S, Ou M, Chen Y. Combined Schottky junction and doping effect in $\mathrm{Cd}_{\mathrm{x}} \mathrm{Zn}_{1-\mathrm{x}} \mathrm{S} @ \mathrm{Au} / \mathrm{BiVO}_{4} \mathrm{Z}-\mathrm{Scheme}$ photocatalyst with boosted carriers charge separation for $\mathrm{CO}_{2}$ reduction by $\mathrm{H}_{2} \mathrm{O}$. J Colloid Interface Sci 2022;606:1469-76. DOI PubMed

103. Ou M, Tu W, Yin S, et al. Amino-assisted anchoring of $\mathrm{CsPbBr}_{3}$ perovskite quantum dots on porous g- $\mathrm{C}_{3} \mathrm{~N}_{4}$ for enhanced photocatalytic $\mathrm{CO}_{2}$ reduction. Angew Chem Int Ed Engl 2018;57:13570-4. DOI PubMed

104. Zhang Q, Han W, Hong Y, Yu J. Photocatalytic reduction of $\mathrm{CO}_{2}$ with $\mathrm{H}_{2} \mathrm{O}$ on Pt-loaded $\mathrm{TiO}_{2}$ catalyst. Catalysis Today 2009;148:335-40. DOI

105. Xie S, Wang Y, Zhang Q, Deng W, Wang Y. MgO- and Pt-promoted $\mathrm{TiO}_{2}$ as an efficient photocatalyst for the preferential reduction of carbon dioxide in the presence of water. ACS Catal 2014;4:3644-53. DOI

106. Sorcar S, Hwang Y, Lee J, et al. $\mathrm{CO}_{2}$, water, and sunlight to hydrocarbon fuels: a sustained sunlight to fuel (Joule-to-Joule) 
photoconversion efficiency of 1\%. Energy Environ Sci 2019;12:2685-96. DOI

107. Li N, Wang B, Si Y, et al. Toward high-value hydrocarbon generation by photocatalytic reduction of $\mathrm{CO}_{2}$ in water vapor. ACS Catal 2019;9:5590-602. DOI

108. Yuan L, Hung S, Tang Z, Chen HM, Xiong Y, Xu Y. Dynamic evolution of atomically dispersed $\mathrm{Cu}$ species for $\mathrm{CO}_{2}$ photoreduction to solar fuels. ACS Catal 2019;9:4824-33. DOI

109. Wang Q, Warnan J, Rodríguez-jiménez S, et al. Molecularly engineered photocatalyst sheet for scalable solar formate production from carbon dioxide and water. Nat Energy 2020;5:703-10. DOI

110. Wang $\mathrm{C}$, Zhao Y, Xu H, et al. Efficient Z-scheme photocatalysts of ultrathin g- $\mathrm{C}_{3} \mathrm{~N}_{4}$-wrapped $\mathrm{Au} / \mathrm{TiO}_{2}$-nanocrystals for enhanced visible-light-driven conversion of $\mathrm{CO}_{2}$ with $\mathrm{H}_{2} \mathrm{O}$. Appl Catal B-Environ 2020;263:118314. DOI

111. Wang $\mathrm{S}$, Teramura $\mathrm{K}$, Hisatomi $\mathrm{T}$, et al. Dual Ag/Co cocatalyst synergism for the highly effective photocatalytic conversion of $\mathrm{CO}_{2}$ by $\mathrm{H}_{2} \mathrm{O}$ over Al-SrTiO ${ }_{3}$. Chem Sci 2021;12:4940-8. DOI PubMed PMC

112. Wang W, Deng C, Xie S, et al. Photocatalytic C-C coupling from carbon dioxide reduction on copper oxide with mixed-valence copper(I)/copper(II). J Am Chem Soc 2021;143:2984-93. DOI PubMed

113. Lu M, Liu J, Li Q, et al. Rational design of crystalline covalent organic frameworks for efficient $\mathrm{CO}_{2}$ photoreduction with $\mathrm{H}_{2} \mathrm{O}$. Angew Chem Int Ed Engl 2019;58:12392-7. DOI PubMed

114. Fang ZB, Liu TT, Liu J, et al. Boosting interfacial charge-transfer kinetics for efficient overall $\mathrm{CO}_{2}$ photoreduction via rational design of coordination spheres on metal-organic frameworks. J Am Chem Soc 2020;142:12515-23. DOI PubMed

115. Dong LZ, Zhang L, Liu J, et al. Stable heterometallic cluster-based organic framework catalysts for artificial photosynthesis. Angew Chem Int Ed Engl 2020;59:2659-63. DOI PubMed

116. Feng X, Pi Y, Song Y, et al. Metal-organic frameworks significantly enhance photocatalytic hydrogen evolution and $\mathrm{CO}_{2}$ reduction with earth-abundant copper photosensitizers. J Am Chem Soc 2020;142:690-5. DOI PubMed

117. Jiang Z, Xu X, Ma Y, et al. Filling metal-organic framework mesopores with $\mathrm{TiO}_{2}$ for $\mathrm{CO}_{2}$ photoreduction. Nature 2020;586:549-54. DOI PubMed

118. Yu F, Jing X, Wang Y, Sun M, Duan C. Hierarchically porous metal-organic framework/MoS $\mathrm{S}_{2}$ interface for selective photocatalytic conversion of $\mathrm{CO}_{2}$ with $\mathrm{H}_{2} \mathrm{O}$ into $\mathrm{CH}_{3} \mathrm{COOH}$. Angew Chem Int Ed Engl 2021;60:24849-53. DOI

119. Wu H, Kong XY, Wen X, et al. Metal-organic framework decorated cuprous oxide nanowires for long-lived charges applied in selective photocatalytic $\mathrm{CO}_{2}$ reduction to $\mathrm{CH}_{4}$. Angew Chem Int Ed Engl 2021;60:8455-9. DOI PubMed

120. Li L, Guo H, Yao G, et al. Visible/infrared light-driven high-efficiency $\mathrm{CO}_{2}$ conversion into ethane based on a B-Co synergistic catalyst. J Mater Chem A 2020;8:22327-34. DOI

121. Li R, Cheng W, Richter MH, et al. Unassisted highly selective gas-phase $\mathrm{CO}_{2}$ reduction with a plasmonic Au/p-GaN photocatalyst using $\mathrm{H}_{2} \mathrm{O}$ as an electron donor. ACS Energy Lett 2021;6:1849-56. DOI

122. Wang $\mathrm{Y}$, Zhang $\mathrm{Z}$, Zhang L, et al. Visible-light driven overall conversion of $\mathrm{CO}_{2}$ and $\mathrm{H}_{2} \mathrm{O}$ to $\mathrm{CH}_{4}$ and $\mathrm{O}_{2}$ on 3D-SiC@2D-MoS heterostructure. J Am Chem Soc 2018;140:14595-8. DOI PubMed

123. Ren X, Gao M, Zhang Y, et al. Photocatalytic reduction of $\mathrm{CO}_{2}$ on BiOX: effect of halogen element type and surface oxygen vacancy mediated mechanism. Appl Catal B-Environ 2020;274:119063. DOI

124. Wu CY, Lee CJ, Yu YH, et al. Efficacious $\mathrm{CO}_{2}$ photoconversion to $\mathrm{C}_{2}$ and $\mathrm{C}_{3}$ hydrocarbons on upright SnS-SnS $\mathrm{S}_{2}$ heterojunction nanosheet frameworks. ACS Appl Mater Interfaces 2021;13:4984-92. DOI PubMed

125. Thampi KR, Kiwi J, Grätzel M. Methanation and photo-methanation of carbon dioxide at room temperature and atmospheric pressure. Nature 1987;327:506-8. DOI

126. Ahmed N, Shibata Y, Taniguchi T, Izumi Y. Photocatalytic conversion of carbon dioxide into methanol using zinc-copper-M(III) (M=aluminum, gallium) layered double hydroxides. $J$ Catal 2011;279:123-35. DOI

127. Jelle AA, Ghuman KK, O'brien PG, et al. Highly efficient ambient temperature $\mathrm{CO}_{2}$ photomethanation catalyzed by nanostructured $\mathrm{RuO}_{2}$ on silicon photonic crystal support. Adv Energy Mater 2018;8:1702277. DOI

128. Wang L, Ghoussoub M, Wang H, et al. Photocatalytic hydrogenation of carbon dioxide with high selectivity to methanol at atmospheric pressure. Joule 2018;2:1369-81. DOI

129. Yan T, Wang L, Liang Y, et al. Polymorph selection towards photocatalytic gaseous $\mathrm{CO}_{2}$ hydrogenation. Nat Commun 2019;10:2521. DOI PubMed PMC

130. Yan T, Li N, Wang L, et al. Bismuth atom tailoring of indium oxide surface frustrated Lewis pairs boosts heterogeneous $\mathrm{CO}_{2}$ photocatalytic hydrogenation. Nat Commun 2020;11:6095. DOI PubMed PMC

131. Huang $\mathrm{H}$, Mao $\mathrm{M}$, Zhang Q, et al. Solar-light-driven $\mathrm{CO}_{2}$ reduction by $\mathrm{CH}_{4}$ on silica-cluster-modified Ni nanocrystals with a high solar-to-fuel efficiency and excellent durability. Adv Energy Mater 2018;8:1702472. DOI

132. Zhou L, Martirez JMP, Finzel J, et al. Light-driven methane dry reforming with single atomic site antenna-reactor plasmonic photocatalysts. Nat Energy 2020;5:61-70. DOI

133. Shoji S, Peng X, Yamaguchi A, et al. Photocatalytic uphill conversion of natural gas beyond the limitation of thermal reaction systems. Nat Catal 2020;3:148-53. DOI

134. Zhao YX, Yang B, Li HF, et al. Photoassisted selective steam and dry reforming of methane to syngas catalyzed by rhodiumvanadium bimetallic oxide cluster anions at room temperature. Angew Chem Int Ed Engl 2020;59:21216-23. DOI PubMed

135. Wang X, Zhao X, Zhang D, Li G, Li H. Microwave irradiation induced UIO-66-NH2 anchored on graphene with high activity for photocatalytic reduction of $\mathrm{CO}_{2}$. Appl Catal B-Environ 2018;228:47-53. DOI

136. Wang Y, Wang S, Lou XWD. Dispersed nickel cobalt oxyphosphide nanoparticles confined in multichannel hollow carbon fibers for photocatalytic $\mathrm{CO}_{2}$ reduction. Angew Chem Int Ed Engl 2019;58:17236-40. DOI PubMed 
137. Wang G, He CT, Huang R, Mao J, Wang D, Li Y. Photoinduction of Cu single atoms decorated on UiO-66- $\mathrm{NH}_{2}$ for enhanced photocatalytic reduction of $\mathrm{CO}_{2}$ to Liquid fuels. J Am Chem Soc 2020;142:19339-45. DOI PubMed

138. Yang W, Wang HJ, Liu RR, et al. Tailoring crystal facets of metal-organic layers to enhance photocatalytic activity for $\mathrm{CO}_{2}$ reduction. Angew Chem Int Ed Engl 2021;60:409-14. DOI PubMed

139. Li J, Huang H, Xue W, et al. Self-adaptive dual-metal-site pairs in metal-organic frameworks for selective $\mathrm{CO}_{2}$ photoreduction to $\mathrm{CH}_{4}$. Nat Catal 2021;4:719-29. DOI

140. Qi X, Zhong R, Chen M, et al. Single Metal-organic cage decorated with an $\operatorname{Ir}(\mathrm{III})$ complex for $\mathrm{CO}_{2}$ photoreduction. ACS Catal 2021;11:7241-8. DOI

141. Liu J, Li N, Sun J, et al. Ferrocene-functionalized polyoxo-titanium cluster for $\mathrm{CO}_{2}$ photoreduction. ACS Catal 2021;11:4510-9. DOI

142. Zhu S, Chen X, Li Z, et al. Cooperation between inside and outside of $\mathrm{TiO}_{2}$ : Lattice $\mathrm{Cu}^{+}$accelerates carrier migration to the surface of metal copper for photocatalytic $\mathrm{CO}_{2}$ reduction. Appl Catal B-Environ 2020;264:118515. DOI

143. Campos-Martin JM, Blanco-Brieva G, Fierro JL. Hydrogen peroxide synthesis: an outlook beyond the anthraquinone process. Angew Chem Int Ed Engl 2006;45:6962-84. DOI PubMed

144. Sato K, Aoki M, Noyori R. A "Green" route to adipic acid: direct oxidation of cyclohexenes with 30 percent hydrogen peroxide. Science 1998;281:1646-7. DOI PubMed

145. Zhan W, Ji L, Ge Z, Wang X, Li R. A continuous-flow synthesis of primary amides from hydrolysis of nitriles using hydrogen peroxide as oxidant. Tetrahedron 2018;74:1527-32. DOI

146. Ksibi M. Chemical oxidation with hydrogen peroxide for domestic wastewater treatment. Chem Eng J 2006;119:161-5. DOI

147. Gurram RN, Al-Shannag M, Lecher NJ, Duncan SM, Singsaas EL, Alkasrawi M. Bioconversion of paper mill sludge to bioethanol in the presence of accelerants or hydrogen peroxide pretreatment. Bioresour Technol 2015;192:529-39. DOI PubMed

148. Yamazaki S, Siroma Z, Senoh H, Ioroi T, Fujiwara N, Yasuda K. A fuel cell with selective electrocatalysts using hydrogen peroxide as both an electron acceptor and a fuel. J Power Sources 2008;178:20-5. DOI

149. Chen X, Kondo Y, Kuwahara Y, Mori K, Louis C, Yamashita H. Metal-organic framework-based nanomaterials for photocatalytic hydrogen peroxide production. Phys Chem Chem Phys 2020;22:14404-14. DOI PubMed

150. Haider Z, Cho H, Moon G, Kim H. Minireview: Selective production of hydrogen peroxide as a clean oxidant over structurally tailored carbon nitride photocatalysts. Catalysis Today 2019;335:55-64. DOI

151. Su J, Vayssieres L. A place in the sun for artificial photosynthesis? ACS Energy Lett 2016;1:121-35. DOI

152. Lewis NS. Developing a scalable artificial photosynthesis technology through nanomaterials by design. Nat Nanotechnol 2016;11:1010-9. DOI PubMed

153. Faunce TA, Lubitz W, Rutherford AW, et al. Energy and environment policy case for a global project on artificial photosynthesis. Energy Environ Sci 2013;6:695. DOI

154. Yang Y, Zeng Z, Zeng G, et al. $\mathrm{Ti}_{3} \mathrm{C}_{2}$ Mxene/porous g- $\mathrm{C}_{3} \mathrm{~N}_{4}$ interfacial Schottky junction for boosting spatial charge separation in photocatalytic $\mathrm{H}_{2} \mathrm{O}_{2}$ production. Appl Catal B-Environ 2019;258:117956. DOI

155. Wu S, Yu H, Chen S, Quan X. Enhanced photocatalytic $\mathrm{H}_{2} \mathrm{O}_{2}$ production over carbon nitride by doping and defect engineering. ACS Catal 2020;10:14380-9. DOI

156. Xie Y, Li Y, Huang Z, et al. Two types of cooperative nitrogen vacancies in polymeric carbon nitride for efficient solar-driven $\mathrm{H}_{2} \mathrm{O}_{2}$ evolution. Appl Catal B-Environ 2020;265:118581. DOI

157. Zhang P, Tong Y, Liu Y, et al. Heteroatom dopants promote two-electron $\mathrm{O}_{2}$ reduction for photocatalytic production of $\mathrm{H}_{2} \mathrm{O}_{2}$ on polymeric carbon nitride. Angew Chem Int Ed Engl 2020;59:16209-17. DOI PubMed

158. Zhou L, Lei J, Wang F, et al. Carbon nitride nanotubes with in situ grafted hydroxyl groups for highly efficient spontaneous $\mathrm{H}_{2} \mathrm{O}_{2}$ production. Appl Catal B-Environ 2021;288:119993. DOI

159. Chen L, Chen C, Yang Z, Li S, Chu C, Chen B. Simultaneously tuning band structure and oxygen reduction pathway toward highefficient photocatalytic hydrogen peroxide production using cyano-rich graphitic carbon nitride. Adv Funct Mater 2021;31:2105731. DOI

160. Isaka Y, Kondo Y, Kawase Y, Kuwahara Y, Mori K, Yamashita H. Photocatalytic production of hydrogen peroxide through selective two-electron reduction of dioxygen utilizing amine-functionalized MIL-125 deposited with nickel oxide nanoparticles. Chem Commun (Camb) 2018;54:9270-3. DOI PubMed

161. Chen X, Kuwahara Y, Mori K, Louis C, Yamashita H. Introduction of a secondary ligand into titanium-based metal-organic frameworks for visible-light-driven photocatalytic hydrogen peroxide production from dioxygen reduction. $J$ Mater Chem A 2021;9:2815-21. DOI

162. Krishnaraj C, Sekhar Jena H, Bourda L, et al. Strongly Reducing (Diarylamino)benzene-based covalent organic framework for metalfree visible light photocatalytic $\mathrm{H}_{2} \mathrm{O}_{2}$ generation. J Am Chem Soc 2020;142:20107-16. DOI PubMed PMC

163. Mal DD, Khilari S, Pradhan D. Efficient and selective oxidation of toluene to benzaldehyde on manganese tungstate nanobars: a noble metal-free approach. Green Chem 2018;20:2279-89. DOI

164. Isaka Y, Kawase Y, Kuwahara Y, Mori K, Yamashita H. Two-phase system utilizing hydrophobic metal-organic frameworks (MOFs) for photocatalytic synthesis of hydrogen peroxide. Angew Chem Int Ed Engl 2019;58:5402-6. DOI PubMed

165. Kawase Y, Isaka Y, Kuwahara Y, Mori K, Yamashita H. Ti cluster-alkylated hydrophobic MOFs for photocatalytic production of hydrogen peroxide in two-phase systems. Chem Commun (Camb) 2019;55:6743-6. DOI PubMed

166. Chen X, Kuwahara Y, Mori K, Louis C, Yamashita H. A hydrophobic titanium doped zirconium-based metal organic framework for photocatalytic hydrogen peroxide production in a two-phase system. J Mater Chem A 2020;8:1904-10. DOI

167. Huang Y, Chong X, Liu C, Liang Y, Zhang B. Boosting hydrogen production by anodic oxidation of primary amines over a nise 
nanorod electrode. Angew Chem Int Ed Engl 2018;57:13163-6. DOI PubMed

168. Martin A, Kalevaru VN. Heterogeneously catalyzed ammoxidation: a valuable tool for one-step synthesis of nitriles. ChemCatChem 2010;2:1504-22. DOI

169. Łuczak T. Electrochemical behaviour of benzylamine, 2-phenylethylamine and 4-hydroxyphenylethylamine at gold. A comparative study. J Appl Electrochem 2007;38:43-50. DOI

170. Fleming FF, Yao L, Ravikumar PC, Funk L, Shook BC. Nitrile-containing pharmaceuticals: efficacious roles of the nitrile pharmacophore. J Med Chem 2010;53:7902-17. DOI PubMed PMC

171. Wang T, Jiao N. Direct approaches to nitriles via highly efficient nitrogenation strategy through C-H or C-C bond cleavage. Acc Chem Res 2014;47:1137-45. DOI PubMed

172. Yan G, Zhang Y, Wang J. Recent advances in the synthesis of aryl nitrile compounds. Adv Synth Catal 2017;359:4068-105. DOI

173. Liu RY, Bae M, Buchwald SL. Mechanistic insight facilitates discovery of a mild and efficient copper-catalyzed dehydration of primary amides to nitriles using hydrosilanes. J Am Chem Soc 2018;140:1627-31. DOI PubMed PMC

174. Tian Z, Han C, Zhao Y, et al. Efficient photocatalytic hydrogen peroxide generation coupled with selective benzylamine oxidation over defective $\mathrm{ZrS}_{3}$ nanobelts. Nat Commun 2021;12:2039. DOI PubMed PMC

175. Shiraishi Y, Kanazawa S, Kofuji Y, et al. Sunlight-driven hydrogen peroxide production from water and molecular oxygen by metalfree photocatalysts. Angew Chem Int Ed Engl 2014;53:13454-9. DOI PubMed

176. Ma R, Wang L, Wang H, et al. Solid acids accelerate the photocatalytic hydrogen peroxide synthesis over a hybrid catalyst of titania nanotube with carbon dot. Appl Catal B-Environ 2019;244:594-603. DOI

177. Zeng X, Liu Y, Kang Y, et al. Simultaneously tuning charge separation and oxygen reduction pathway on graphitic carbon nitride by polyethylenimine for boosted photocatalytic hydrogen peroxide production. ACS Catal 2020;10:3697-706. DOI

178. Zhao Y, Liu Y, Cao J, et al. Efficient production of $\mathrm{H}_{2} \mathrm{O}_{2}$ via two-channel pathway over ZIF-8/C3N4 composite photocatalyst without any sacrificial agent. Appl Catal B-Environ 2020;278:119289. DOI

179. Zhao Y, Liu Y, Wang Z, et al. Carbon nitride assisted 2D conductive metal-organic frameworks composite photocatalyst for efficient visible light-driven $\mathrm{H}_{2} \mathrm{O}_{2}$ production. Appl Catal B-Environ 2021;289:120035. DOI

180. Wu Q, Cao J, Wang X, et al. A metal-free photocatalyst for highly efficient hydrogen peroxide photoproduction in real seawater. Nat Commun 2021;12:483. DOI PubMed PMC

181. Teng Z, Zhang Q, Yang H, et al. Atomically dispersed antimony on carbon nitride for the artificial photosynthesis of hydrogen peroxide. Nat Catal 2021;4:374-84. DOI

182. Ye YX, Pan J, Xie F, et al. Highly efficient photosynthesis of hydrogen peroxide in ambient conditions. Proc Natl Acad Sci U S A 2021;118:e2103964118. DOI PubMed PMC 